\title{
Alternate methods of changing nursing home staff attitudes toward sexual behavior in the aged
}

Anne Marie Cipoletti Aja

College of William \& Mary - School of Education

Follow this and additional works at: https://scholarworks.wm.edu/etd

Part of the Educational Psychology Commons

\section{Recommended Citation}

Aja, Anne Marie Cipoletti, "Alternate methods of changing nursing home staff attitudes toward sexual behavior in the aged" (1982). Dissertations, Theses, and Masters Projects. Paper 1539618404.

https://dx.doi.org/doi:10.25774/w4-0sfg-wr53

This Dissertation is brought to you for free and open access by the Theses, Dissertations, \& Master Projects at W\&M ScholarWorks. It has been accepted for inclusion in Dissertations, Theses, and Masters Projects by an authorized administrator of W\&M ScholarWorks. For more information, please contact scholarworks@wm.edu. 


\section{INFORMATION TO USERS}

This reproduction was made from a copy of a document sent to us for microfilming. While the most advanced technology has been used to photograph and reproduce this document, the quality of the reproduction is heavily dependent upon the quality of the material submitted.

The following explanation of techniques is provided to help clarify markings or notations which may appear on this reproduction.

1. The sign or "target" for pages apparently lacking from the document photographed is "Missing Page(s)". If it was possible to obtain the missing page(s) or section, they are spliced in to the film along with adjacent pages. This may have necessitated cutting through an image and duplicating adjacent pages to assure complete continuity.

2. When an image on the film is obliterated with a round black mark, it is an indication of either blurred copy because of movement during exposure, duplicate copy, or copyrighted materials that should not have been filmed. For blurred pages, a good image of the page can be found in the adjacent frame. If copyrighted materials were deleted, a target note will appear listing the pages in the adjacent frame.

3. When a map, drawing or chart, etc., is part of the material being photographed, a definite method of "sectioning" the material has been followed. It is customary to begin filming at the upper left hand comer of a large sheet and to continue from left to right in equal sections with small overlaps. If necessary, sectioning is continued again-beginning below the first row and continuing on until complete.

4. For illustrations that cannot be satisfactorily reproduced by xerographic means, photographic prints can be purchased at additional cost and inserted into your xerographic copy. These prints are available upon request from the Dissertations Customer Services Department.

5. Some pages in any document may have indistinct print. In all cases the best available copy has been filmed.

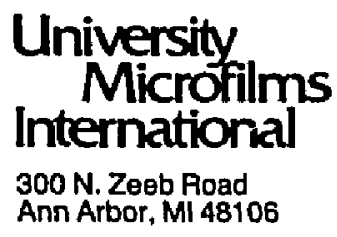


..

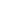


Aja, Anne Marie Cipoletti

ALTERNATE METHODS OF CHANGING NURSING HOME STAFF ATTITUDES TOWARD SEXUAL BEHAVIOR IN THE AGED

The College of William and Mary in Virginia

ED.D. 1982

\section{University} Microfilms

International 300N.Zeeb Road, Ann Arbor, Mi48106 

ALTERNATE METHODS OF CHANGING NURSING HOME STATF ATTITUDES TOWARD SEXUAL BEHAVIOR IN THE AGED

A Dissertation

Presented to

The Faculty of the School of Education

The College of William and Mary in Virginia

In Partial Fulfillment

Of the Requirements for the Degree

Doctor of Education

by

Anne Marie $\Lambda j a$

August 1982 
Alternative Methods of Changing Nursing Home Staff

Attitudes Toward Sexual Behavior in the Aged

by

Anne Marie Aja

Approved August 1982 by

Fork.adain

Fred L. Adair, Ph.D. (Chairman)
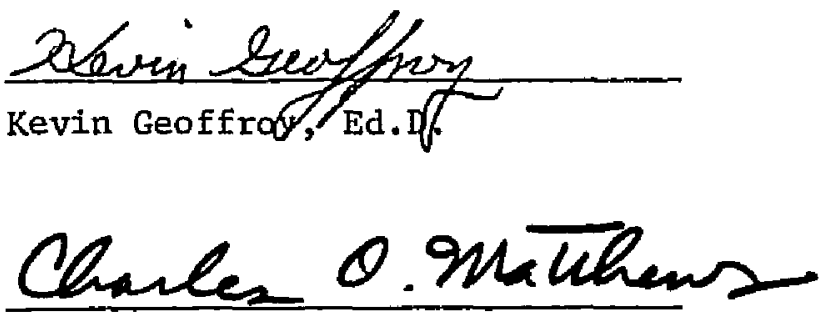

Charles O. Mathews, Ph.D. 
Acknowledgements

The author wishes to express her deepest appreciation to Dr. Fred L. Adair for his guidance, understanding and concern during the course of this thesis and throughout this student's graduate program. His continuous support and constructive criticisms were in large part responsible for the completion of this thesis. Appreciation is expressed to Dr. Kevin Geoffroy, Dr. Charles Mathews, Dr. Ronald Wheeler, and Dr. Ruth Mulliken, their concern, effort and insights proved extremely valuable in the development of the research model used in this study.

The author wishes to extend her gratitude to Mr. Gary Seay, Administrator of Lafayette Villa Nursing Home, Mrs. Elizabeth Chamberlain, R. N. and Mrs. Joan Kanter, R. N. for their cooperation throughout the data collection and treatment phases of the study.

Special thanks are extended to Dr. Al Craven, and Dr. Don Self, $\mathrm{Ph} . \mathrm{D}$. who participated as skillful group leaders and provided the extensive film materials required for this study. Appreciation is also given to Mrs. Stephanie Lloyd, R. N., B. S. N. and Mrs. Llew Roberts, R. N., B. S. N. who along with their vast experience as group leaders and sex educators, provided a dgree of special warmth and sensitivity to the project. Acknowledgements are also extended to David Reed for his help with the statistical analysis, and to the nursing home staff who volunteered for the study. Finally, I wish to thank my husband Jack, and children, Stephanie and Joaquin, for their support and understanding throughout my educational program. 
Table of Contents

Page

Acknowledgements . . . . . . . . . . . . . . 3

List of Tables . . . . . . . . . . . . . . 7

Chapter I: Introduction ................. 8

Statement of the Problem . . . . . . . . . . 8

Background and Need for the Study .......... 8

Theoretical Rationale . . . . . . . . . . . 14

Definition of Terms ............... 16

General Hypothesis ............... 18

Sample and Data Gathering Procedure . . . . . . . . 18

Limitations . . . . . . . . . . . . . 19

Summary ................ . . 20

Chapter II: Review of Related Literature . . . . . . . . . 22

Attitudes and Issues Related to Sexual Expression

in Nursing Home Staff ............... 22

Sumnary ....................... 29

Sexual Physiology in Later Life . . . . . . . . . 30

Summary ................. . . . 4 42

Outcome Studies of Programs Aimed at Changing

Sexual Attitudes ............... . . 43 43

Summary ..................... 51

Theory Related to the Concept of Dogmatism . . . . . . 52

Summary ................. . . 55

Chapter III: Procedures . . . . . . . . . . . . 56

Sample .................. 56 
Audio-Visual Materials . . . . . . . . . . . 58

The Independent Variable .............. 60

The Implicit Treatment: Group . . . . . . . . . . . 60

The Explicit Treatment Group . . . . . . . . . . . 67

The Observation Scheme ............... 71

Pre-experimental Workshop . . . . . . . . . . . 72

Measurement Techniques .............. 75

Hypotheses ................... 77

Statistical Methods ............... 78

Chapter IV: Results of Analysis . . . . . . . . . . . . 80

Hypothesis 1 . . . . . . . . . . . . . . 80

Hypothesis 2................... . . 84

Hypothesis 3 . . . . . . . . . . . . . . 87

Hypothesis 4 . . . . . . . . . . . . . . . 88

Hypothesis 5 . . . . . . . . . . . . . . 89

Hypothesis 6 . . . . . . . . . . . . . . . 89

Hypothesis 7 . . . . . . . . . . . . . . 90

Hypothesis 8 . . . . . . . . . . . . . . . . 95

Hypothesis 9 . . . . . . . . . . . . . . . 100

Sumnary ..................... . . 100

Chapter V: Summary, Conclusions, Implications and

Recommendations ................. 105

Summary ...................... 105

Conclusions ....................... 109

Implications . . . . . . . . . . . . . . . 122

Recommendations .................. 123 


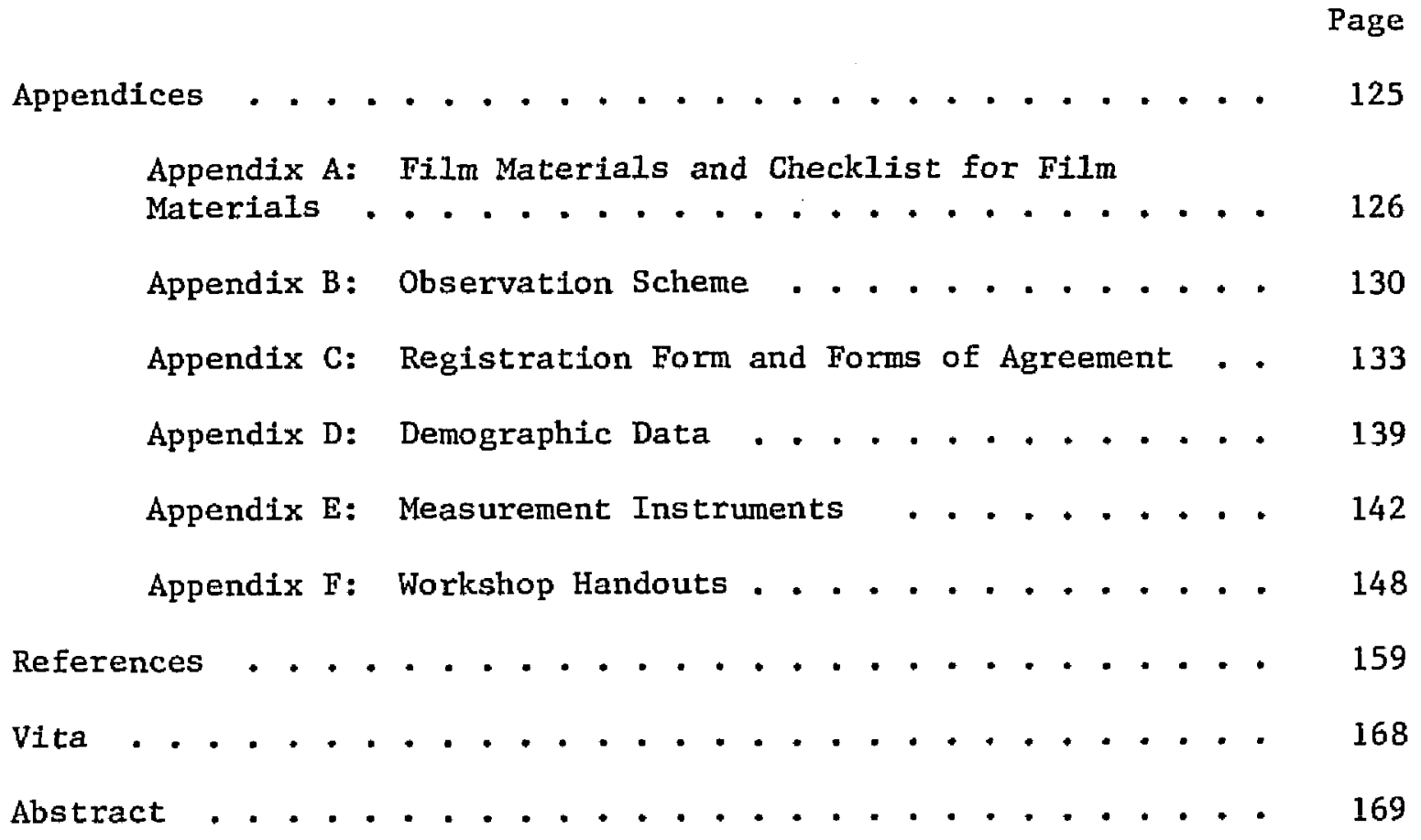


Table

Page

3:1 Summary of Means and Standard Deviations for the High Dogmatism and Low Dogmatism Groups on the Dogmatism

Scale .....................

4:1 Means and Standard Deviations on SKAT Sclaes for Experimental. and Control Groups . . . . . . . . .

4:2 Summary ANOVA for effects of treatment on SKAT Scales.

4:3 Post Hoc Comparison of Means on SKAT Scales . . . . .

4:4 SKAT Means for High and Low Dogmatism Implicit, Explici.t, and Control Groups: . . . . . . . . . .

4:5 Two-way Interaction Analysis of Main Effects (Treatment by Dogmatism) on Nursing Home Staff SKAT Scales . . .

4:6 Analysis of Variance for Effects of Treatment on LTK Attitude Rating Scale for Sexual Behavior 1 . . . . .

4:7 Analysis of Variance for Effects of Treatment on LTK Attitude Rating Scale for Sexual Behavior 2 . . . . .

4:8 Analysis of Variance for Effects of Treatment on LTK Attitude Rating Scale for Sexual Behavior 3.....

4:9 Cell Means for Effects of Age on Ratings of Sexual

Behavior Experimental and Control Groups . . . . . . .

4:10 Analysis of Variance for effects of Dogmatism on the LTK Attitude Rating Scale for Sexual Behavior 1 . .

4:11 Analysis of Variance for Effects of Dogmatism on the LTK Attitude Rating Scale for Sexual Behavior 2 . .

4:12 Analysis of Variance for Effects of Dogmatism on the LTK Attitude Rating Scale for Sexual Behavior 3 . .

4:13 Interaction Effects for LTK Attitude Rating Scale for Sexual Behavior 1... . . . . . . . . . .

4:14 Interaction Effects for LTK Attitude Rating Scale for Sexual Behavior 2.................

4:15 Interaction Effects for LTK Attitude Rating Scale for Sexual Behavior 3............... 


\section{Chapter I: Introduction}

\section{Statement of the Problem}

The purpose of this study was to determine whether or not nursing home staff differed in their perceptions, attitudes and knowledge as a result of exposture to either implicit or explicit sex-related materials. Background and Need for the Study

The regulation of sexual expression has occurred in all human societies. Strict sexual codes of conduct have served several important functions in society: first, they have provided a form of birth control and second, abstinence has served as a means to prevent venereal disease. Additionally, sexual strictures which applied only to women were a means by which male dominance was asserted within society (Brownmiller, 1976). However, the development of birth control measures, legal emancipation and the women's liberation movement have diminished the reasons for some of these strict codes of sexual conduct. Situation ethics have replaced these codes, producing a more liberal society which tolerates various forms of sexual expression by consenting adults-that is, for everyone but the aged (Fletcher, 1972). Older persons remain a section of the population for whom strict codes still apply.

The sexual needs of the elderly are usually misunderstood, stereotyped and ignored. Younger, healthier people tend to believe that sexual desire and activity normally cease with old age. In a study conducted by LaTorre and Kear (1977), the attitudes of college students 
and nursing home staff were measured as related to sex and the elderly. Both groups were presented with three stories: a neutral (problem solving story), a coital story, and a masturbatory story. For each story the age and gender of the main character were varied. Results Indicated that sexual behavior for the aged was less credible than sexual behavior for young people.

Attitudes regarding sexual expression in the elderly are generally negative. Gold and Kagan (1959) used a sentence completion test to assess attitudes regarding the importance of sex and the aged. One group of students received a sentence stem "Sex for most old people.. ." and another group received a stem "Sex for most people . . .." They found that 92.9 percent of the first group replied that sex for most old people was negligible or unimportant, while only 4.9 percent of respondents in the second group regarded sex as negligible or unimportant for most people.

Studies by Butler and Lewis (1976) reveal that the idea of people making love in their $70^{\prime} \mathrm{s}$ and $80^{\circ} \mathrm{s}$ is astounding to younger associates or relatives. Many of the general public are inclined to, or wish to, think that older people 1) do not have sexual desires, 2) could not if they wanted to, 3) are too fraglle and sex may hurt them, 4) are physically unattractive and therefore are assumed to be sexually undesirable, and finally, 5) the whole idea is shameful!

While much attention has been focused on younger populations, research on sexual behavior of older groups was not conducted until relatively recent times. The 1968 research at Duke University by 
Pfeiffer, Verwoerdt and Wong that investigated the sexual behavior of 254 men and women between the ages of 49 and 90 was the first study of its kind. Corroborating the findings of Kinsey (1948, 1953) and Masters and Johnson (1965), the Duke research showed that sexual expression continues to play an important role in the lives of many elderly. Research showed a gradual decline of the reported frequency in sexual intercourse with advancing age. The findings were that from 40 to 65 percent of the subjects between the ages of 60 and 71 still reported engaging in sexual intercourse with some frequency, while only 10 to 20 percent of the group 78 and over still reported sexual activity. A. rather surprising finding that emerged from the Duke study was that a significant portion, about 15 percent, showed increased patterns of sexual. activity as they grew older. Of the 63 men and 70 women who had stopped having sexual intercourse, the median age for stopping was 68 for men and 60 for the women. However, in assigning responsibility for the cessation of activity, both husbands and wives agreed that the husband was the determining factor.

The sexual needs of the aged are the same as those of younger people, but with variations in intensity of response, kind of need and others with whom to express more needs (Calderone, 1973). Sexuality may be expressed in the need for close, affectionate relationships, Intimacy, the need for some romance, and the need to feel feminine or masculine. Because of the various forces impinging on the behavior of the aged, many aged are restricted in their sexual expression. One force which impinges on sexual expression in the aged is the 
physiological change in the sexual response cycle due to aging. There is a natural slowing of the physical processes involved in sexual activity, just as there is a slowing of the rest of the body in aging. Unfortunately, this physical slowing is often misunderstood, and sexual activity may be forsaken completely, instead of being adjusted with the process (Masters and Johnson, 1970). Additional factors which inhibit sexual expression of the elderly are cultural. Kaas (1978) states that the cultural denial of sexual expression of the elderly may be one of the most important factors in the self-perception of sexIessness by the aged person. Society limits sexual expression of the aged by restrictive cues. These cues are often based on myths or stereotypes that lead to labeling those who are sexually expressive as "dirty old men" and "dirty old women."

The elderly have attitudes, opinions and beliefs about sex for themselves and for others, and those others have attitudes, opinions and bellefs about sex for the elderly. While such social attitudes may have an important effect on all old people, the power to enforce such beliefs is most apparent among those who are in positions of direct control over the institutionalized elderly. Negative attitudes from such caretakers would probably result in more inhibitory environments. Rosencrane (1969) reported the existence of more negative attitudes toward the aged from people who had clinical contacts with the aged. It also appears that the rest home environment is definitely one which inhibits sexuality.

LaTorre and Kear (1977) found nursing home staff more negative 
toward sex in general than were students, and stated in their discussion that "caretakers of the aged have negative attitudes toward sex which will be expressed toward the aged in their charge" (p, 212). Wasow and Loeb (1977) found conflicting results. Their study found a positive attitude among nursing home staff about freedom of sexual expression. However, 1ittle support for such activities was found within their own facility.

A specific effect that staff attitudes and administrative policies may have on the issue of sex among nursing home residents centers around privacy (Wassow, 1977). Not only do nursing homes and other Institutions not have PIaces where their married residents can have sex (Burnside, 1975), they often ignore or deny the sexual needs of their non-married residents. This is done most effectively by isolating the sexes and allowlng for little privacy. In most nursing homes female/male interaction is a llowed only in public lounge areas, and mixing of the sexes is done under supervision. Segregation of males and females by floor or unit is still common. However, this practice, as well as the separation of married couples is less frequent today (Kaas, 1978).

The expression of negative attitudes by staff members can do more than inhibi $\varepsilon$ sexual expression. The denial of sexual interest and activity can $b e$ a threat to the sexual identity of an elderly person, and have a damaging effect on the aged person's capacity to function sexually. In a discussion of mental health issues and the aged, Butlex and Lewis (1975) report that sex and self-esteem are closely related. The active Inhibition and discouragenent of sexuality should, therefore, 
lower one's self-esteem and might produce depressive, self-deprecatory beliefs.

The difficulty that health care practitioners have in discussing sexual matters with the aged is cited by Masters and Johnson (1970) and Lobsenz (1974). The myth that sick or older people should not, or do not have sexual desires makes it difficult for either the physician or patient to mention the subject (Ford and Orfirer, 1967). Since older individuals are often assumed not to be sexual, medications are sometimes prescribed without consideration of their effects on sexuality. Some tranquilizers, antidepressants, high blood pressure, and arthritis medications can have an inhibiting effect on sexual interest and arousal. These factors should be discussed with each person and adjustments made. It is also desirable for concerned parties to be thoroughly educated about the potential effects on sexuality of suggested surgeries, particularly those which involve the reproductive organs (Page, 1977). Stereotypes, prejudices and anxieties about sexual expression of the elderly have an impact on the attitudes of nursing home staff as well as society at large. However, it is the reponsibility of those charged with caring for the elderly to relate to their sexual concerns in health and illness (Kaas, 1978). To do this, the staff must be aware of the sexual needs of the elderly, as well as their own feelings about sexuality for themselves and for the aged.

The importance of sex education in the development of healthy sexual attitudes and fulfilling sexual relationships has been recognized by many psychologists and educators (Gordon, 1973; Kirkendal1, 1965; and 
Masters and Johnson, 1970). While a variety of sex education programs have been initiated across the country, few have addressed themselves to the specific topic of sexuality and the aged. Hinkley (1976) has developed a training program for nursing home staff related to this subject. However, the evaluation of this program was largely subjective. Group participants were encouraged to share their feelings about what they had gained from the experience and to make some statement about what activities were most and least valuable.

Monea (1975) devised an experiential approach to learning about sexuality and the aged. She designed a workshop in which participants used the medium of clay to express the feelings of an aged individual. Like the workshop designed by Hinkley, participants were asked to evaluate the workshop experience subjectively. Each student was asked to share what was meaningful to them about what they had learned. Although the merits of such an experience can be seen, it is clear that there are a number of difficulties in utilizing a design of this type. Plausible threats to inferences of program impact from this type of design axe those of maturation and history (Campbell and Stanley, 1966). Recognizing the problems inherent in the designs of the previous studies, a comparison between workshop participant changes with a group of randomly selected non-participants was conducted. In addition, a preworkshop measure of the participants' readiness to learn new information was incorporated in the design of the study. Theoretical Rationale

The term "sexuality" is used to refer to many different things. 
While it is often interpreted as referring to those sexual behaviors that result in orgasm, many contemporary writers suggest that this definition is too narrow. Burnside points out that sexuality is part of one's self-concept, body Image and self-esteem. She uses the word broadly to include" . . flirting, dating behavior, touching, man/man relationships, woman/woman relationships, and woman/man relationships" (1975, p . 10). Umland et al. (1980) suggest that sexuality is associated with a certain life force. The importance attributed to maintaining sexual functioning can be seen in the variety of remedies available to correct sexual dysfunction in all cultures. These include magic, potions, tissue implants and drugs. Loss of sexuality in primitive as well as advanced societies is equated with death. To many, becoming elderly means a loss of sexuality and consequently, a loss of womanliness or manliness.

Weg (1975) and Rubin (1965) deal with definitions of sexuality as it relates to the aging individual. Weg writes:

Being a sexual human being begins in utero; it's very much a part of being human. Yet we put sexuality in a very separate category and treat it very separately. While it is true we change with time physlologically and there is a slowing down, a decrement in function, it is also true there is much left to work with when the magic wand says, "you are sixty-five." The changes are not dramatic from sixty, even from fifty. Physiological changes are rather gradual and the body accomodates well to these small changes. The potential that sexual expression can continue to the day we die-- to eighty, ninety or a hundred is very great $(1975, \mathrm{p} .7)$.

Rubin (1965) emphasizes that sexuality is much more than intercourse. He is critical of a society which ignores the sexual needs and interests of the aged, and points to the potentlal harm of such an 
attitude.

sexuality does not necessarily express itself in the ability to have sexual intercourse; for many it expresses itself only in the need for continued closeness, affection, and intimacy, in a continued cultural and intellectual interest in eroticism, or in the need for some romance in life (1965, p. 231).

Each of these definitions deemphasizes the "performance ethic" as

it relates to sexual expression. Instead of focusing on frequency of intercourse, sexual relations are described to include non-coital behaviors as well. In a discussion of the timeless nature of sexual intimacy, Nass et al. (1980) suggest that sexual relations be considered In terms of genital and nongenital caressing, tender gestures, love talk, empathic kissing, and spontaneous skin to skin fun. If one accepts such a definition, no age barriers to sexual expression will exist. It was this broad definition of sexuality that provided the basis of the present research.

Definition of Terms

Aged. Individuals who are 60 years of age or older.

Attitudes. An organized predisposition to think, feel, perceive, and behave toward a referent or cognitive object. It is an enduring structure of beliefs that predisposes the individual to behave selectively toward attitude referents (Kerlinger, 1973).

Dogmatism. That concept which relates to an individual's openness or closedness to new information. The Dogmatism scale (D scale), developed by Rokeach (1954) will be used as a measure of this attribute. Nursing home staff. Individuals who are currently employed in a nursing home. 
Program evaluation. The systematic rating of program effectiveness. In the present study two measures of program effectiveness will be utilized: a Lykert type rating scale designed to measure attitude change related to sexual expression among the elderly; and the Sex Knowledge and Attitude Test designed to measure general changes in attitudes and information regarding sexual issues.

Sex education. Includes the study of the physiological, psychological and sociological aspects of human behaviors related to sex.

Sexless. Lacking the characteristics of sex; asexual. One who is apparently lacking in normal sexual passion or drive (Webster, 1977). Sexuality. The state or quality of being sexual. While the term is frequently interpreted as referring to those sexual behaviors that result in orgasm, it will be more broadly defined here. Rubin (1965) defines sexuality to include . . a need for continued closeness, affection, and intimacy, in a continued cultural and intellectual interest in eroticism, or in the need for some romance in life.

Sexual Attitude Reassessment Workshop (SAR). A SAR is an intensive program designed to sensitize individuals to the physiological, psychological and socfological aspects of sexuality. Workshop participants are encouraged to explore and reassess their personal attitudes towards human sexuality.

Sexual expression. The physical manifestation of sexual interest and desire, including genital and nongenital caressing, tender gestures, love talk, empathic kissing, and spontaneous skin to skin fun (Nass, 1980). 
Sexually explictt. Those films and slides which graphically depict sexual behaviors. The films and slides will include portions in which sexual behaviors are clearly presented such as, individuals engaged in masturbation, intercourse and homosexual activity.

Sexually implicit. Those films and slides which do not graphically depict sexual behaviors. The films and slides shown will not include scenes which are sexually explicit such as, individuals engaged in masturbation, intercourse, and homosexual activity. General Hypothesis

Exposure of nursing home staff to Sexual Attitude Reassessment (SAR) workshops will result in increased tolerance of sexual behavior in the aged when compared to the control group. Sample and Data Gathering Procedures

From a population of approximately 200 staff members at the Lafayette Villa Nursing Home, Norfolk, Virginia, 45 volunteers were recruited. Included in the sample were registered nurses, licensed practical nurses, nurse's aides, nursing home administrators, and nursing home activities directors.

The Dogmatism scale (Rokeach, 1960) was administered to the 45 workshop registrants prior to exposure to the experimental treatments. Depending on whether the registrant scored above or below the mean score on the Dogmatism scale, they were assigned to a high or a low dogmatism group. Staff members were then randomly assigned to one of three experimental groups: Experimental Group I, Experimental Group II, or the Control Group. 
Two instruments were used to measure between group differences in attitudes, knowledge and perceptions of sexual behavior in general, and sexual behavior in the aged. These included the Sex Knowledge and Attitude Test (SKAT) by Leif and Reed (1972), and the LTK Attitude Rating Scale by Aja (1982) (see Appendix E). To avoid contamination of groups these instruments were administered to the Control Group before the experimental workshops were begun. The two treatment groups were tested with the same instruments one week after their respective experimental workshops have been conducted.

\section{Limitations.}

While the present study attempts to measure between group differences in attitudes, it lacks a behavioral measure of program impact. It is plausible to suggest that the attitudes expressed on the SKAT and the LTK Attitude Rating Scale were more liberal than those which are manifested behaviorally. Results such as these were found in a study by Wasow and Loeb (1977). While positive attitudes were expressed by nursIng home staff about freedom of sexual expression of the aged, little support for such activitles was found within the facilities in which they worked.

Another concern of this researcher was the impact that certain materials may have on the audience. The use of audiovisual materials may have introduced elements that were difficult to assess. For example the films or slides themselves could have evoked positive or negative reactions depending on the quality of filming, the attractiveness of actors and actresses, and the degree of interpersonal warmth portrayed. 
As a means of accommodating this possibility, workshop leaders made an effort to caution participants to "look beyond" these elements of filming in their introductory statements. Instead, participants were encouraged to focus on their own reactions to the sexual behaviors presented in the films.

Summary

The problem of this study was to determine whether or not nursing home staff differed in their perceptions, attitudes and knowledge as a result of exposure to either implicit or explicit sex-related materials. Also discussed was the background and need for the study. It was pointed out that societal attitudes regarding sexual expression in the elderly are generally negative. Negative attitudes were also found to abound within the nursing home environment. The psychological effects of an environment which inhibits sexual expression and intimacy were discussed.

The findings of Butler and Lewis (1975) were cited to support the notion that negative attitudes of nursing home staff toward the expression of sexual behavior in the elderly can have damaging effects. The denial of sexual interest and activity poses the risk of threatening the sexual identity of an elderly person, damaging the aged person's capacity to function sexually, and leading to a lowered self-esteem. However, few programs have been directed at improving attitudes toward sexual expression in the aged, and increasing understanding of their sexual needs. The importance of sex education in the development of healthy sexual attitudes was discussed. It was also noted that while 
much attention has been directed at providing sex education to a variety of groups across the country, Iittle attention has been paid to the specific topic of sexuality and the aged.

Two training programs directed at improving nursing home staff attitudes toward sexual expression in the elderly were reviewed. Problems assoclated with their research methodology were discussed.

The theoretical rationale for the study was stated. Definitions for the following terms were given: aged, attitudes, dogmatism, nursing home staff, program evaluation, sex education, sexless, sexuality, Sexual Attitude Reassessment Workshop (SAR), sexual expression, sexually explicit, and sexually implicit.

A statement of the hypothesis was made which generally describes the dependent and independent variables. A brief description of the sample and data gathering procedures was included, as well. as a description of the Iimitations of the study. 
Chapter II. Review of Research

The related Iiterature clusters in four areas: (1) attitudes and issues related to sexual expression in nursing home residents; (2) sexual physiology in later life; (3) outcome studles of programs aimed at changing sexual attitudes; and (4) theory related to the concept of dogmatism.

Attitudes and Issues Related to Sexual Expression in Nursing Home Residents

In this age of liberation and expanding sexual understanding, sexual discrimination against the elderly still exists. Frequently, the sexual needs of elderly persons are minimized and the subject of jokes. Richman (1977) and Davis (1977) analyzed jokes aimed at the elderly and found that approximately two-thirds of them were negative. The content of the jokes focused on three major themes: sexual decline, physical decline, and loss of attractiveness.

Butler (1975a) describes these prejudiclal attitudes toward the elderly as "aglsm." AgIsm, he asserts, is just as damaging as other forms of discrimination such as sexism and racism. A number of stereotypes and prejudices are commonly held about the elderly. These Include: 1) most elderly are sick and live in rest homes; 2) the elderly move and think slower; 3) and that senility is a natural part of the aging process (Rodin, 1980). While studies show that only five percent of all people over 65 actually require custodial care (Berezin, 1972), the prevailing 
stereotype of the sick old person still exists.

Similarly, there are a number of myths and stereotypes associated with the sexual behavior of the elderly. Among these are: 1) that impotence is a function of aging; 2) that women lose interest in sex following menopause; 3) that the frequency of sexual Intercourse naturally declines with age (Sv1land, 1978); and 4) that old people are uninterested In sex, have no sexual feelings, and find sex unimportant (Golde and Kogan, 1959; LaTorre and Kear, 1977).

There are a number of reasons for the acceptance of these bellefs about sexual expression in the elderly. Part of the answer 1.s that American culture is still Influenced by the philosophy that equates sexuality exclusively with procreation. Since this prospect may be either unreallstic or nonexistent for older individuals, this viewpoint of fers few alternatives beyond self-dental (Crooks and Baur, 1980). Soctety also suppresses sexuality in its older members by disproportionately focusing on youth. Aging is unpopular In American culture, and sexual activity to thought to be the domain of only the young and beautiful (Falk and Falk, 1980).

Comfort (1980) speaks of the impact that this kind of prejudicial. thinking has on the elderly, He suggests that myths and folklore influence the behavior of the elderly and color the way In which they percetve themselves. He goes on to state that the stereotype of the old person being feeble, Ineducable, unintelligent and asexual forms the basis of a self-fulfilling prophecy. The elderly individual assumes these attitudes as a way of fulfilling soctetal expectations. An example 
of the internalization of society's negative values about sex and the aged is found in a study conducted by Kahana (1976). One hundred and twenty-four nursing home patients were surveyed as to their opinions about sex for individuals over 65 . Of these, 49 percent agreed with the statement that sex was ridiculous for the elderly.

While the belief that the aged are sexless is erroneous, there are advantages for those who choose to believe it. McCarthy (1979) reports that many of the elderly who hold this tenet may 1) have no sexual partner; 2) never have liked sex at any time in their lives; and 3) have partners who have lost their sexual capactty.

There are advantages to this belief for the younger generation as well. Lobsenz (1975) suggests that young people deny the Importance of sex in old age as a self-protective measure. Fearing loss of the1r own sexual capacity, they will instead deny the importance of sex in later years. If it is not important, then it doesn't matter whether they can function sexually or not.

Some suggest that younger people deny the sexualtty of their aged parents for personal reasons. Belleving that childhood Oedipal wishes and fears are never far from the surface, it is asserted that children (despite their age) have a great deal of difficulty belleving that their mothers and fathers are sexual betngs (Lobsenz, 1975).

In addition, there are practical considerations which may affect a son's or daughter's attitude about their parent's sexual behavior. When a single parent becomes involved in a sexual relationshlp, fear exists that it may lead to marriage and, potentially, the loss of financlal 
inheritance (Falk and Falk, 1980). Although this fear is frequently masked by moral disapproval, the impact remains the same.

Many of the elderly will reside in a nursing home. For these individuals, nursing home staff attitudes pertaining to their sexual expression become critically important. Research on nursing home staff attitudes toward sexual expresstion in the elderly has ylelded interesting results. Although positive responses toward this issue are often given, behavior supporting these attitudes is often lacking. Wasow and Loeb (1977) report that while the nursing home staff they studied responded positively to issues related to freedom of sexual expression in the elderly, little support for such activities was found within their facility.

LaTorre and Kear (1977) found nursing home staffs more negative toward sex than were students. While acknowledging that these negative attitudes might be a function of social factors, he clearly points to the potential consequences of negative staff attitudes. Drawing a relationship between sexual expression and self-esteem, La'Torre, et a1., state that the active inhibition of sexual expression in the aged may lead to depresston.

According to Wasow (1977) and Miller (1978), privacy is the primary Issue which impedes sexual expression within nursing homes. Beyond words, negative staff attitudes and administrative policies are expressed through curfews, the utilization of space and by segregating the sexes. Kaas (1978) adds that sexual expression is prevented in nursing homes in two other ways. First, it is condemned by society outside of nursing homes; 
and second, it is internalized by the aged themselves, since they feel they are no longer sexually attractive and that any sexual activity on their part stamps them as "dirty old man" and "dirty old woman." often, the sexual needs of married residents are Ignored. By the same token, few accommodations for sexual expression among unmarried residents are made within most institutions (Burnside, 1975). However, some experimentation in this regard is reported. One hospital introduced a "heterosexual living space" in which floors were integrated allowing both sexes to live in adjoining rooms. As a result, patients were observed to make better social adjustments and have an increased social 1ife. Improved grooming and a decrease in the use of profanity were also noted (Silverstone and Wynter, 1975).

Issues Related to Sexual Expression Among the Elderly

A number of benefits are associated with maintaining an active sex life in old age. Some authors emphasize the mental health aspects of maintaining sexual activity. Butler and Lewis (1976) cite the importance of emotional connectedness in old age. Love and sex are means by which the elderly can express affection as well as affirm their identity, maintain a sense of romance, reduce tension, and protect themselves from the negative stereotypes associated with aging.

Lovemaking may also produce positive physical effects for the elderly. As exercise, sexual intercourse stimulates the adrenal glands and sympathetic and parasympathetic nerves. Fitness is maintained by raising heart and breathing rates (Felstein, 1970). In both men and women, high levels of sexual activity make continued sexual responsiveness possible 
(Masters and Johnson, 1966). There is some evidence that sexual activity may even help arthritis. Wasow (1979) explains that the adrenal production of cortisone may have a pain relieving effect. Research shows that the sex act also helps reduce anxiety. Horn (1974) states that the sexual orgasm relieves anxiety as well as or better than tranquilizers.

While lovemaking among elderly individuals may decrease their anxiety, it is noted to cause increased anxiety among their family members. Dean (1966) reports that primary opposition to sexuality in the aged has been attributed to adult children. Normal parental urges for intimacy and romance are viewed as socially disgracing or signs of a slip into second childhood. Parents who are without a spouse are frequently told to take up a hobby as a means to combat loneliness. According to Sviland (1978) adult children frequently disapprove of their parents seeking new Intimate relationships. This disapproval is often expressed in subtle ways such as family coldness towards the elderly person's social companions. It has been suggested that the dread of family members of parental sexual acting out translates into policy at the institutional level. Despite the fact that free acceptance of sexuality in homes for the aged has been advocated as humanistic, most nursing home operators simply don't allow sexual relations between patients (Kassell, 1974)..

Besides the possible disapproval of bill paying family members, other potential problems may arise in attempting to accommodate the sexual needs of the elderly nursing home patient. Miller (1978) 
enumerates some of these. They include logistical problems such as rooms where patients can have assured privacy and beds which are large enough to accomodate two people. Federal and state regulations must also be taken into account. According to law, skilled nursing homes are prom hibited from having locks on doors and beds without siderails.

Some suggestions for dealing with these particular problems are offered. For example, a "Do not Disturb" sign could be used to alert staff of the patient's need for privacy. A spectal room could be available on a "sign up" basis for patients who want to entertain guests privately. Patients could also be encouraged to engage in off-premises sexual activity such as in a nearby motel (Miller, 1978).

Other problems are more complex. Since most individuals who reside in nursing homes are sick, it is important to assess whether the patient is physically and mentally able to engage in sexual activity. Frequent medical examinations and proper hygienic treatment would be very important.

Implications regarding sexual expression in nursing homes are far reaching and complex. Affected parties include the patients, their families, nursing home staff and board members, volunteers, visiting professionals and the community at large. Some solutions have been offered. These include staff education on sexuality and the aged and an examination of the medico-legal issues that administrators and physicians may face (Miller, 1978; Wasow, 1977). Others recommend training in sex education for the elderly (Sviland, 1978) and programs to inform patients of their legal rights to privacy and freedom of sexual expression (Lobsenz, 1974). 
Summary. A review of the research literature on attitudes and issues related to sexual expression in nursing home residents suggests strongly that sexual discrimination against the elderly still exists (Sviland, 1978; Golde and Kogan, 1959; LaTorre and Kear, 1977; Falk and Falk, 1980; Kahana, 1976; Lobsenz, 1975; Wasow and Loeb, 1977; Miller, 1978; and Kaas, 1978). The majority of these same studies suggest that sexual discrimination against the elderly can have damaging effects.

studies focusing on the impact that this kind of prejudicial thinking has on the elderly suggest thit myths and folklore about aging can have a negative influence on the behavior of the elderly (Comfort, 1980; Rodin, 1980; and Falk and Falk, 1980). Prevailing societal attitudes about aging are discussed, including the myth of sexlessness. Advantages to this myth are cited as they apply to the aged individual and his or her offspring.

For individuals who reside in nursing homes, staff attitudes regarding sexual expression are critically important. Some research shows nursing home staff attitudes toward sex were more negative than those held by students (LaTorre and Kear, 1977). Other research suggests that reported positive attitudes toward freedom of sexual expression by staff does not necessarily lead to behavioral demonstrations of these attitudes (Wasow and Loeb, 1977).

Logistical problems associated with sexual expression within nursing homes were discussed, as well as the legal ramifications. Also discussed was the disapproval exhibited by many adult children when parents engage in sexual activity. 
Recognizing the complexity of the issue, some solutions have been offered. These included staff education and examination of the medicolegal issues (Miller, 1978; Wasow, 1978), sex education programs for the elderly (Sviland, 1978), and workshops to inform patients of their legal rights (Lobsenz, 1974).

Sexual Physiology in Later Life

When one examines the fears and myths associated with sexuality and aging, it becomes apparent that many of these beliefs are founded on widespread ignorance concerning the facts about sexual functioning in old people. This section will examine the physiosexual changes and a1tered sexual responses that take place as part of the aging process. The impact of disease on sexual functioning will also be examined. Human sexual behavior, Iike all human behavior, is affected by a complex array of phystological, environmental and psychological influences. Extensive research has been conducted in the area of sexual behavior, and because of the important role that it plays in the lives of most people, it is felt to be particularly susceptible to these internal and external forces.

The sexual behaviors of older persons have only recently been objectively examined. The pioneers in the field, Kinsey (1948, 1953) and Masters and Johnson $(1966,1970)$ asserted that regular coitus may continue into the 7 th, 8 th and 9 th decades. Research conducted by Pfeiffer, Verwoerdt and Wong (1968) supports this contention, and reports that sexual expression continues to play an important role in the lives of many elderly. However, while the potential for erotic pleasure may be 
present from birth to death, Kaplan (1976) reporis that "Age shapes the biological component so that intensity and quality of response varies at different ages" (p. 104).

Changes in sexual response. Experts on aging appear to agree that there is a gradual decline of sexual activity for both males and females with advancing age (Masters and Johnson, 1970; Verwoerdt, Pfeiffer and Wong, 1968; and Rubin, 1966). This decline can be seen as a part of a normal aging process. However, this fact is in no way meant to imply that older men and women cannot enjoy an active and satisfying sex life throughout their later years (Kart, et al., 1978).

Differences in the sexual responses of older men and women have been studied by Masters and Johnson (1966, 1970). Their research popu1ation consisted of 61 women between the ages of 41 and 78 , and 39 men between the ages of 51 and 89 . While the sample was relatively small, important data resulted from their extensive inquiry.

Masters and Johnson (1966) have described a sexual response cycle consisting of four phases: excitement, plateau, orgasm and refractory period. While sexual activity is a continuous process, and is not marked by discreet stages (Katchadourian and Lunde, 1972), the division into phases facilitates observation and description. In this way, differences which occur between younger and older Individuals can be examined more closely.

Age differences in men. The slowing of response which is a characteristic feature of many processes of old age affects both the male and female's sexual response cycle. Among men, the excitement phase takes 
longer. During youth, many males are capable of attaining an erection in a few seconds. After 50, longer and more intense stimulation is required to achieve erection (Kaplan, 1974). While these changes in the rate of erectile response are a noxmal part of the aging process, they can cause alarm to the person who does not understand what is occurring to them physiologically. Some men interpret them as signs of loss of potency. If the emotional reaction to these physiologic changes is fear and anxiety, further interference to erectile capacity will result. The next phase, the plateau stage, also takes longer for older men. Older males do not typically experience as much myotonia during the plateau phase as when they were younger, and there is less drive for ejaculatory release (Zarit, 1980). These changes may enhance his sexual pleasure, however. Since there is greater ejaculatory control, the plateau phase can be maintained longer for his own pleasure as well as his partner's (Masters and Johnson, 1970).

For older males, the intensity of the orgasmic phase is reduced also. The distinction in phases apparent in younger men between the period of ejaculatory inevitability and the actual ejaculation are no longer as clear with older males. Although these changes may vary from individual to individual, research shows that the amount and force of the ejaculation for older men is diminished. In research conducted by Masters and Johnson (1966) it was found that young males were able to expel seminal fluid 12 to 24 inches from the urethral meatus, while the maximum distance for men over 60 was 6 to 12 inches. Despite these changes, most aging males continue to experience sensual pleasure, unless 
they misinterpret these physiologic changes as signs of dysfunction. There is, after age 50, a physiologically extended refractory period. After interviewing 212 men over age 50, and actually observing 33 of these men, Masters and Johnson (1966) found that they could not redevelop penile erection for a matter of 12 to 24 hours after ejaculation. Butler (1977) suggests that couples who are aware of this fact may want to delay ejaculation in order to prolong lovemaking.

While acknowledging the importance of these physiologic changes on sexual performance, Comfort (1980) suggests that age itself is never the cause of impotency. He identifies several factors which impair erectile functioning. First, men who misinterpret signs of aging as indications of oncoming impotency, may become anxious about their sexual performance. As with men of all ages, performance anxiety may result in the loss of erection. Second, Comfort suggests that age is a convenient excuse for some to stop functioning. Low interest in sex during youth, and possible guilt feelings associated with sexual desire may cause the older individual to terminate sexual activity. Research which supports these assertions was provided by Kinsey, Pomeroy and Martin (1948) and Pfeiffer and Davis (1972). Their data suggests that males who reported a high level of sexual activity in their youth, were more likely to report higher levels of functioning past age 50. Similarly, those males who reported low levels of sexual functioning in their younger years, were more likely to report no sexual activity in their later life. Other reasons for loss of sexual interest and impotency are cited. These include monotony of the sexual relationship. preoccupation with 
career and economic pursuits, overindulgence in food and drink, and physical infirmities of self or spouse (Masters and Johnson, 1966). Comfort (1980) describes two psychological problems which are often associated with erectile failure. These include depression, where impotency is either the precipitating factor, or the result of taking antidepressant medication. Second, Comfort speaks of a phenomenon known as the "widowers' syndrome." This occurs with men who have not engaged in sexual activity over a period of time. Often abstinence may result from prolonged illness of their spouse. Anxiety over sexual performance with a new partner, as well as atrophy brought about by disease, may inhibit sexual performance.

Effect of disease on the sexual behavior of men. There are a variety of physical illnesses which can induce impotence. Erectile impairment has been associated with diabetes and vascular insufficiencies (Zarit, 1980). A prolonged diabetic condition may reduce functioning of the peripheral and autonomic nervous systems (Umland, et al., 1981). Other diseases associated with aging are thought to interfere with sexual functioning. These include heart disease and prostate disease. A concern of people who are sick is that sexual activity will aggravate their illness and possibly cause death (Masters and Johnson, 1970). Recent evidence suggests that these fears are unjustified for most people. After reviewing the cases of men who had suffered a coronary, Friedman (1978) concluded that there was a major drop in sexual interest and activity in the year following their heart attack. Two reasons are cited for this decline: 1) the Iack of information that physicians supply 
regarding sexual activity and heart disease; and 2) fear of death during intercourse. While the number of post coronary patients who die during intercourse is as little as .3 to one percent (Butler and Lewis, 1973, 1976), this fear has a significant impact on the patient and his partner. Other causes of sexual problems in post coronary patients are cited. Among them are depression, misinterpretation of age changes in sexual response and medication (Friedman, 1978). Although cardiac patients can generally resume some level of sexual activity three months after myocardial infarction, medical attention is required if any of the following symptoms are present: angina, palpitations lasting for more than 15 minutes after intercourse, and extreme fatigue (Friedman, 1978). With increased life expectancy, the number of men who require prostate surgery has also increased. Many men who have undergone this surgery will experience some altered sensation during orgasm and ejaculation. However, unless a radical prostatectomy is performed, loss of potency should not occur (Comfort, 1980).

Age differences in women. Research suggests that except for fertility, the female's sexual capacity remains relatively stable throughout her Iffetime. Kinsey (1953) and Masters and Johnson (1966) report that a women's capacity to function sexually is not diminished by age. While there is no evidence that the capacity for orgasm declines with age, decreased intensity has been noted to occur in the sexual response cycle of the aged female.

Masters and Johnson (1966) have reported that the excitement phase takes longer in the post menopausal woman. In women under 40, vaginal 
lubrication occurs within 10 to 30 seconds following sexual stimulation. Older women require several minutes of sexual stimulation before vaginal lubrication will occur. While this latency generally increases with age, individual differences are to be noted. The Masters and Johnson group observed a few women over 60 who showed lubrication responses characteristic of women 30 years younger. It was explained that each of these subjects had maintained very regular sexual activfty throughout their adult years.

Other characteristic physiologic changes in the excitement phase, such as the sex flush and the expansion of the vagina, are often less pronounced in the aging female. However, clitoral sensitivity and nipple erection remain unchanged with age (Masters and Johnson, 1966). During the plateau stage, there is an expansion of the length and depth of the vagina. In a postmenopausal woman, the vaginal barrel. shortens in length and width and loses some of its elasticity (Masters and Johnson, 1966). There is also a thinning of the vaginal walls which may result in uncomfortable side effects following intercourse. The thick vaginal walls which are characteristic of younger women no longer provide the buffer from possible irritation. After sexual connection, some women experience vaginal burning and irritation on urination for a period of 24 to 36 hours (Silny, 1980). Irritation may also result from direct clitoral stimulation. Masters and Johnson (1970) have found that the pleasure a younger woman might feel with direct clitoral stimulation may cause pain in someone older.

As a women ages, some changes in the orgasmic phase of the sexual 
response cycle are also noted. While the capacity for orgasm remains undiminished following menopause, pelvic platform contractions are typically reduced in number and less intense. Following orgasm, the resolution or refractory stage occurs rapidly in older women. Labia color change, vaginal expansion, orgasmic platform formation, and clitoral. retraction return to their unstimulated state more quickly and uniformly than for younger women (Masters and Johnson, 1966).

However, the most dramatic change which occurs in the aging female is the drop in the circulating levels of estrogen and progesterone. After menopause, the ovary no longer has the ability to produce its principal steroid hormones (Silny, 1980). As a result, some women may experience certain uncomfortable physical symptoms in addition to the cessation of menstruation. These symptoms may include headaches, backaches, nervousness, coldness and crying (Stryker, 1977). In the past, sex steroid replacement therapy has been recommended for the alleviation of these problems. Today however, concern is being expressed about the potential risks involved with using estrogen to relieve the symptoms of menopause. Zarit (1980) reports that a link has been found between the use of estrogen in postmenopausal women and endometrial cancer.

While many women experience uncomfortable symptoms related to menopause, it has been suggested that the number has been exaggerated. Weg (1978) and Novack, et al. (1970) report that only about 25 percent of all women seek medical consultation due to difficulties related to menopause. Psychosocial factors are found to have an impact on the degree of menopausal symptoms which a woman may experience. Weg (1978) reports that 
women who work outside the home, or perceive themselves as having a purposeful role, express fewer symptoms of menopause than those who perceive themselves primarily as wives and mothers. Fewer physical symptoms of menopause are also found to be related to regularity of sexual intercourse. Masters and Johnson (1970) and Comfort (1980) report that women who maintain regular intercourse on a once or twice a week basis have fewer physical changes following menopause.

Few older women are able to maintain regular and frequent sexual intercourse, however. The primary reasons for this, according to Comfort (1980) are social convention and lack of a partner. There are now four unmarried women over 65 for each unmarried man in the same age range (Statistical Portrait of Women, 1976). Because of the greater longevity of women and the traditional pattern of marrying men who are older than themselves, many elderly women may have unmet sexual needs. Some have suggested alternatives to coitus for older women. In addition to masturbation, others suggestions have Included polygamous marriages (Berezin, 1969), non-marital cohabitation, and lesbian companionships (Cavin, 1973), marrying younger men (Sviland, 1975), and making sexual services available to the aged (Ullerstrom, 1966). While these suggestions may not be acceptable to most older women, it is important that a variety of options be explored.

In addition to those which have already been cited, others factors may influence a woman's sexual activity in her later years. According to KInsey (1948, 1953), women have less interest in sexual activity over the life cycle than men. In addition, age stereotypes related to sexual 
interest and activity provide a convenient excuse for avolding what some consider base and "dirty" (Comfort, 1980). Other determinants of sexual behavior among older women are how much pleasure they derived from sex in their younger years and their present orgasmic capacity. Religious, socio-economic and psychological factors are also found to have an Influence on the sexual behavior of older females (Corby and Solnick, 1980).

As is true of men, there are many disease related conditions which impact upon a woman's sexual functioning. Among them are hysterectomies and oophorectomies. In a hysterectomy the uterus is surglcally removed. The removal may be partial or total, depending on the extent of the disease. An oophorectomy is a surgical procedure in which one or both ovaries are removed. Hysterectomies and oophorectomies are being performed in rising numbers. Many of the women who undergo this surgery have a natural concern about its impact on their sexual behavior. Research suggests that a decline in sexual functioning frequently occurs. After surveying the literature, Corby and Solnick (1980) report that there is a decline of between 10 and 38 percent in the frequency of sexual intercourse. Dennerstein, Wood and Burrows (1977) studied 89 patients who had undergone hysterectomies and bilateral oophorectomies. In determining those factors which contributed most strongly to a diminished sexual relationship after surgery, it was found that "psychologic factors, particularly an expectation that the operation will adversely affect sexual relations, are responsible for the deterioration in sexual relations which rollow the operation" (p. 94). 
Similax fears are evident in women who have undergone mastectomies. However, some research suggests that the mastectomy is more stressful than any other type of surgery a woman may have. Polivy (1977) designed a study to evaluate the psychological effect of mastectomy stress on the woman and her spouse. It was found that for the woman mastectomy is psychologically more traumatic than any other operation. Unlike other types of surgery, the mastectomy involves organs to which strong emotions are attached. The breasts are the most external and conspicuous sign of a woman's sex-related organs. In our culture they represent both the maternal and the sensuous aspects of womanhood. As such, they are an important sign of femininity for most women. The loss of such a valued body part has serlous effects on a woman's self-esteem. However, these effects were not found immediately after surgery. Declines in body image and total self-image were evident during the months which followed surgery (Polivy, 1977).

A number of suggestions have been offered to facilitate adjustment. The three major recommendations are: presurgical counseling, involvement of the husband in the entire process, and the need for the surgeon to be sensitive to signs of depression in his patient (Corby and Solnick, 1980).

Recently, attention is being given to the psychological impact that mastectomy has on the patient's partner. Wellisch, et al. (1978) conducted a study to evaluate the effects of mastectomy from the male point of view. It was found that the primary determinant of a successful post mastectomy adjustment was strongly linked to the premorbid state of the 
marital relationship. In regard to the effect that mastectomy has on sexual relations, w1lisch reports: a) 14.3 percent rated it as bad; b) 21.4 percent as somewhat bad; c) 57.1 percent as having no influence; and d) 7.1 percent as having a somewhat positive influence.

Other common physical problems which are prevalent among older females are vaginitis, vulvitis and peritoneal pruritis. Ledger (1977) reports that elderly women are very prone toward these kinds of infections, and recommends a prompt and thorough gynecologic exam when symptoms first present themselves. Kent (1975) asserts that sexually active older women are more prone toward bacterial infections and urological problems because of age related physical and behavioral changes. He too suggests prompt gynecologic exams and appropriate treatment. Low grade inflammations of this type can cause discomfort and itching which may lead to decreased sexual pleasure and possible cessation of sexual activities. Prompt attention to and remediation of urologic problems among the elderly is especially important because of the tendency to solve the problem by avolding sexual relations. When a woman does this, it may in fact exacerbate the gynecologic problems as it will have the effect of reduced estrogen production.

Masters and Johnson (1966) have found a relationship between sexual activity and estrogen production. Women who maintain sexual functioning are less likely to experience as great a reduction in estrogen production as those who do not. The production of estrogen is important to the older woman for two primary reasons. First, it regulates the degree of aging which is to occur on both the internal and external genitalia. Second, 
estrogen is important for reducing many of the unpleasant symptoms associated with menopause (Crooks and Baur, 1980).

Summary. Human sexual behavior is normally life long. While a number of physical, social, cultural and psychological factors may interfere with the maintenance of an active sex Iife, age in itself does not present a barrier to sexual activity (Comfort, 1980). Research shows that sexual activity can continue into old age (Kinsey, 1948, 1953; Masters and Johnson, 1966, 1970; and Verwoerdt, Pfeiffer and Wang, 1968). Positive effects have been found to be associated with the maintenance of an active sex life (Masters and Johnson, 1966, 1970; Felstein, 1970; Butler, 1975a; and Butler and Lewis, 1976). Nevertheless, elderly individuals are very much victims of harsh attitudes and misinformation regarding sexuality. Geriatric sex is found to be not credible (LaTorre and Kear, 1977), unimportant (Golde and Kagan, 1959), and the subject of ridicule and jolses (Richman, 1977; Davis, 1977). Myths and misinformation about sexual physiology in old age inhibits sexual expression and may cause elderly individuals to terminate sexual activity prematurely. Many in the field of gerlatric medicine do not relate to the sexual concerns of the aged. In terms of medication, surgery and institutional living arrangements, the sexual needs of the elderly are frequently ignored.

Some gerontologists believe that it is important to change these negative attitudes. Comfort (1980), for example, believes that it is the role of the health care professional to "foster the sexual response as a supportive and enriching part of continued experience" (p. 891). Sexual 
counseling for the elderly and sex education programs for and about the aged have been advocated (Lobsenz, 1975; Wasow, 1979).

In emphasizing the right and ability of the aged individual to a full sexual life, a danger exists. That is, not all individuals may be interested in being sexually active. Personal values and conventional thinking may cause some elderly persons to be uncomfortable with the notion of sex after 65. Comfort (1980) suggests that health care professionals handle these issues gently. Respect for the values of the individual patient is critical.

Outcome Studies of Programs Designed to Change Sexual Attitudes Which Incorporate the Use of Erotic Films

Most of the experimental studies of effects of sexually explicit materials have used college students and middle class volunteers as subjects. One such study was conducted by Davis and Braucht (1971). One hundred and twenty-one male college students were studied to determine the impact of viewing sexually explicit films on their sexual arousal, fantasies and behavior. Subjects reported immediate and 24-hour postexposure effects. Statistically significant increases in sexual arousal, fantasies and desires were noted at both posttest intervals. However, no statistically different results occurred in the behavior of the respondents.

Other studies have attempted to determine if exposure to sexually explicit materials affects later behavior. The 1970 United States Commission on Obscenity and Pornography reviewed numerous studies of this kind and concluded that no significant long-lasting changes in behavior were 
evident in the research subjects.

Howard, Reifler and Liptzen (1971) studied the psychological and physiological effects of repeated exposure to erotic films on young adult males. Twenty-three experimental and nine control subjects participated in research designed to examine the hypothesis that repeated exposure to sexually explicit materials causes decreased interest in it, less response to it, and no lasting effects. As a pretest measure, subjects were required to complete a battery of tests and view a sexually explicit: film. Experimental subjects were then exposed to sexually explicit material for 90 minutes each day for 15 days. A posttest measure was then given to all subjects, along with the presentation of an erotic film. All physiologic measures, that is, measures of penile erection, acid phosphatase secretion and heart rate, indicated that exposure to sexually explicit material resulted in decreased subject responsiveness towards it. However, psychological testing indicated that repeated exposure to sexually explicit films resulted in increased "self-esteem." The investigators also noted that subjects expressed boredom with the sexually explicit materials as the project proceeded, and had fewer thoughts about sex than before the experiment began. Personal daily logs on which subjects recorded their moods, thoughts, and habits falled to reveal any significant behavioral changes over the course of the experiment.

Although no long-lasting changes in behavior were reported to result from exposure to erotic film materials, the Presidents Commission on Obscenity (1970) did conclude that some short-term effects may occur. Results indicated that during the 24 hours following the viewing of highly 
erotic material, there may be come sexual arousal and, in some cases, increased sexual activity. However, basic attitudes and sexual patterns were not found to change as a result of exposure to sexually explicit material. Much of the research summarized by the Commission on obscenity included experiments on the effects of pornographic material. It was found that younger people were more aroused by these materials than older. NInety percent of the 20 to 25 year olds reported arousal, as compared to 30 percent to 60 percent of those 40 to 50 years of age. Furthermore, the Commissions' report stated that

There are no recorded instances of sexual agression, homosexuality, lesbianism, exhibitionism, or sexual abuse of children attributable to reading or receiving erotic stimuIi among several hundred participants in the 12 experiments reviewed (p. 27).

Many of the sex education programs conducted with the past 15 years have incorporated erotic films as part of their program. It is claimed that the erotic films take participants through a process of demythologizing, desensitizing, and resensitizing to a greater awareness of and comfort with one's own sexuality and that of others (Rosenzweig and Pearsall, 1978).

While these programs have proliferated, research on their effectiveness in changlng sexual attitudes is relatively sparse. Program evaluations, when included, are typically subjective. Participants are asked to report their Impressions of the workshop and to state which features were most and least valuable (Gordon, 1973; Phillips, et al., 1975; Hinkley, 1976; Monea, 1978; Madison and Meadow, 1979; and Meston, 1980). Evaluations of this type are usually favorable, with the exception of those studies conducted by Crawley, et al. (1972) and Golden and 
Liston (1972). In general, participants report increased knowledge about sexual matters and more tolerant sexual attitudes (Voss, 1979). Recently, some attention has been given to changing the sexual attitudes of specific groups. Meston (1979) designed a sexual enrichment program to enhance the self-concept of homosexuals. A standard Sexual Attitude Reassessment process was utilized. This process, developed by the National Sex Forum, relies heavily on sexually explicit films, games and exercises to sensitize participants to sexual issues, and small group discussions (Rosenzweig and Pearsal1, 1978). Some modifications of this approach were made to reflect the purpose of the research. Instead of emphasizing heterosexually oriented films, Meston substituted films which were explicitly homosexual.

At the completion of the workshop, participants were required to fill out an evaluation form which asked for subjective reflection upon their experience. An overall improvement of self-concept was noted. Workshop participants expressed feelings of increased self-acceptance and a reaffirmation of self-worth.

Madison and Meadow (1980) conducted a one day Intensive workshop in female sexuality for women. Group members who participated in the workshop reported a variety of sexual concerns: not being able clearly to Identify or express sexual wants, lack of sexual interest, low levels of arousal, and most reaching orgasm consistently with self or partner. The workshop employed a number of educational tools. In addition to fllms, exercises and small group discussions, workshop leaders presented specific behavioral techniques for modifying behavior and improving 
communication skills. Anonymous evaluation forms were completed at the conclusion of the workshop. Participants were asked to critically review both the format of the workshop and the effectiveness of the faci1itators. No assessment of participant changes in attitudes or behavior were reported.

Problems related to assessing the effectiveness of a sex education workshop have been addressed. by Williams and Miller (1978). According to these authors, three types of course impact can be assessed: first, beneficfal/detrimental impact on the particlpants' sexual attitudes, on the quantity and quality of thelr factual knowledge, and impact on their behavior; second, both short-term and long-term effects; and third, the impact in reference to self and others, both personal and professional. In thelr article, Williams and Miller (1978) summarize nine paper and pencil instruments which are currently used to assess human sexuality programs. These tnclude: the Sexual Attitudes and Behavior Inventory, the Test for Assessing Sexual Knowledge and Attitudes, the Minnesota Sexual Attitude Scales, the Sexual Attitude and Behavior Survey, the Sex Knowledge and Attitude Test, the National Sex Forum Questionnafre, the Harvard Sex Questionnalre, the Physletans Workshop Questionnaire, and the Human Sexual Knowledge and Attitude Survey. Of these, the Sex Knowledge and Attitude Test (SKAT) has been the most widely used instrument for evaluation of educational experiences on human sexuallty (Lief, 1972). Garrard, et al. (1972) administered the SKAT in a pretest-posttest design to evaluate the effectiveness of a two-day seminar on human sexua11ty. Workshop participants included medfcal students, faculty members 
and Individuals from the communtty. Results showed a significant change in sexual attitudes tending toward increased liberalization. Improved scores in sexual knowledge were reported in all but the medical faculty group. These results contrast with those of Golden and Liston (1972), who found no changes on the SKAT following a course for second year medical students.

In an experimental study comparing two different seminar formats, VInes (1974) found signiflcant differences: on the Knowledge section, but not the Attitude section of the SKAT between workshop participants and non participants. In addition to a pre- and post-administration of the SKAT, Vines (1974) Included an assessment of behavior change following a human sexuality course. Subjects who partfcipanted in the training were matched with those in a control group. Each was then required to interview a "Simulated patient" (an actress) presenting with a sexual complaint. Videotape recordings of these interviews were made and clinictans "blindly" rated the subject's degree of comfort in conducting the Interview. Vines reported that students who had been In the course were rated as less anxious than controls.

Additional data obtained from this research suggests that the time element in human sexual training is critically important. Subjects who particlpated in training where films and small group discussion occurred within a short time frame (15 hours in two consecutive days) were reported to be more comfortable than those who particlpated in the same number of training hours spread out over a period of weeks (Vines, 1974). In recent years, other studies have attempted to go beyond subjective 
evaluations, and pre- and post-administrations of a pencil and paper test. Voss (1979) reviewed outcome research in the field of sex education. A number of flaws in sex education research are cited. These Include many of the elements which are essential to rigorous research: the implementations of adequate controls, random assignment of subjects, evaluation of treatment impact after a lapse of time, and a behavioral measure of treatment effects. An effort was made to incorporate some of these elements in her research. A Sex Questionnaire (Voss, 1979), covering sexual knowledge, attitudes and behaviors, was administered to a11 subjects at the time of registration. At this time, subjects were randomly assigned to two groups, treatment and control. A posttest administration of the Sex Questionnaire was administered one month after registration. Results showed a significant increase in attitude change regarding tolerance of one's own and other people's sexuality. Some behavioral changes were reported, but no significance changes were noted in regard to increased sexual knowledge.

Hong, et al. (1979) made a simllar effort in his research. Recognizing the importance of sex education for child psychiatrists, Hong formulated a program which emphasized the developmental nature of human sexuality. Thirteen seminars were conducted on a bi-weekly basis. Seminar leaders used films, lectures, live interviews, case presentations and group discussions to facilitate the sex education process. Program goals were clearly stated, and incorporated both cognitive and affective objectives. Topics covered included: childhood and adolescent psychosexual development, gender identity, assessment of sexual problems, normalcy and 
variation In adult sexuality, and disease and disability.

A number of techniques were utilized In evaluating this program. Immediate feedback was obtained from workshop participants by having them rate each session on a five point scale, 1 being "excellent" and 5 being "poor." Most ratings fell between the 2 and 3 range (between "very good" and "good"). Three paper-and-pencil tests were also administered before and after the course. Workshop particlpants were required to complete: (1) the Sexual Knowledge Test, (2) the Sexual Attitude and Behavior Survey, and (3) The Minnesota Sexual Attitude Scales. Although the returns on these measures were too small to analyze statistically (only eight of the participants completed them), some trends were apparent. All eight participants reported an increase in their comfort level and awareness in dealing with sex-related matters in a clinical setting. An improvement in knowledge of human sexuality was also noted.

Hong, et al. (1979) included a behavioral measure in the evaluative process. Since training was directed at improving clinical skilis, it was felt that program effects could best be seen by analyzing pre- and post-samples of clinical behavior. The research design used for this behavioral assessment was adapted from Vines (1974).

Each participant was asked to conduct a sex focused interview with a client (an actress with a sexual complaint). These ten-minute interviews were held before and after the training sequence. Independent raters later reviewed the tapes in terms of clinical effectiveness. Results from the behavioral assessment portion of the evaluation were difficult to assess. Administrative and logistical difficulties prevented the 
preclseness necessary to measure pre- and post-treatment changes. As it appeared, several participants were rated lower in the sequence following the training. This may have resulted from the fact that two different actresses were required for pre- and posttest taping: Nevertheless, the overall impact of the course was judged to be positive.

Summary. Available research on evaluation of programs designed to change sexual attitudes is sparse and of ten inadequate. While the use of pretests, immediate posttests and subjective reports gives some indication of changes which have occurred in sexual attitudes, one cannot be certain that these changes are not the result of variables other than workshop participation. The influence of variables such as maturation, history, and selection pose serious threats to the validity of much of the published research (Campbell and Stanley, 1966).

Recently, attempts have been made to correct these shortcomings. Vines (1974) designed a study which ut1lized two different types of assessment procedures. These included the pre- and post-treatment administration of the Sex Knowledge and Attitude Test and a behavioral assessment of interviewer comfort with a "simulated patient."

Voss (1979) measured changes in sex knowledge, attitudes and behaviors of students who registered for a two-day sexual awareness weekend. Random assignment to groups, and the Inclusion of a control group in the research design sets this study apart from others which have been reported.

Hong, et a1. (1979) also emphasized the research aspects of sex education training. Ratings of training seminars, pre- and post- 
administration of paper-and-pencil tests, and a behavioral assessment of physicians conducting an interview before and after the sex education course were incorporated in the design.

The evaluation of sex education programs ia a relatively recent phenomena. Assessment instruments for this purpose have only been developed in the past ten years (Williams and Miller, 1978). Publication of program evaluations are few and are often criticized because of inadequate controls and simplistic designs. The need for a more sophisticated methodology of evaluating sex education programs has been noted (Williams and Miller, 1978).

Dogmatism

As suggested by Kaas (1978), stereotypes and prejudices may have an impact on the attitudes held by nursing home staff regarding sexual expression among the elderly. It is furtehr suggested by Rokeach (1960) that individuals may differ in the degree to which their attitudes are affected by stereotypes and prejudices.

Major research has been undertaken in this area. Rokeach (1954, 1960) formulated a theory directed at differentiating between individuals who are prone toward rigid, prejudiced and stereotypic thinking, whom he labeled as dogmatic, and those who are not. The Dogmatism scale (D scale), was designed as a generalized measure of authoritarianism. Rokeach asserted that an individual's openness or closedness to new information could be predicted with the use of this scale.

As seen by Rokeach, a closed minded or high dogmatic (HD) individual was described as one who believes that the world is a threatening 
place, that authority is absolute, and that others are to be accepted or rejected on the basis of their agreement or disagreement with authority. These beliefs are held in isolation from each other with a relatively narrow, future oriented time perspective.

Rokeach offers a contrasting description of a low dogmatic (LD) Individual. He is one who believes that the world is a friendly place, and does not rely on absolute authority to make his decisions. Authority figures are not absolute, and people are not evaluated according to their agreement or disagreement with authority. A degree of congruence within and between the belief systems exists, and the time perspective is one which incorporates the past and present, as well as the future. Dogmatism has been shown to be related to religious beliefs, racial prejudice and political beliefs (Rokeach, 1960). A relationship has also been drawn between dogmatism and personal sexual attitudes. Kilpatrick, Cauthen, Sandman and Quattlebaum (1968) administered Form E of the Dogmatism scale and a Sexual Attitude Survey to 388 volunteers from an introductory course in psychology. The Sexual Attitude Survey, developed by the authors covered areas such as: under what circunstances kissing, petting and sexual intercourse are permissable; attitude towards marrying a virgin; estimation of the number of male and female virgins among peer groups; personal sexual behavior; and the degree of relationship present between partners having sexual intercourse.

Results indicated that high-dogmatic males were more sexually conservative than low-dogmatic males. While no difference in conservatism of sexual attitudes was demonstrated between high-dogmatic and low-dogmatic 
females, females were found to be more conservative in their sexual attitudes than male subjects.

Other evidence suggestive of a relationship between dogmatism and sexual attitudes was reported by Hood (1973). It was demonstrated that HD's hold more stereotypic attitudes of homosexuals than LD's. It was also found that these attitudes generalized to other specific groups including suicidal persons and the mentally ill.

While studies suggest that individuals who rank high in dogmatism are conservative in their sexual attitudes and generally intolerant of deviant groups, other research indicates that these attitudes can be changed. In fact, research seems to suggest that HD's are more likely to change their attitudes in reponse to social. Influence than $L D^{\prime} s$. Gold, Richmann, and Rodda (1973) found that HD's exposed to counterattitudinal information in a group discussion changed their attitudes toward the group position. Norris (1965) and Chronkhite and Goetz (1971) have suggested that the HD is more persuasible. The Janis Field Test of General Persuasibility was used in the latter study. Chronkhite and Goetz (1971) concluded that "dogmatism and general attitude instability are two symptoms which tend to accompany the syndrome of 'general persuasibility'" (p. 348).

It is the intent of this study to investigate the relationship that dogmatism has to an individual's propensity to change his sexual attitudes. The Dogmatism scale (Rokeach, 1960) will be administered prior to treatment for the purpose of establishing the degree to which dogmatism interacts with participation in the Sexual Attitude 
Reassessment workshop.

Summary. A review of the research on dogmatism indicates that dogmatism has been shown to have a relationship to religious beliefs, racial prejudice and political beliefs (Rokeach, 1960). Correlational studies by Kilpatrick (1968) and Hood (1973) suggest that dogmatism is related to personal sexual attitudes.

While some studies indicate that high dogmatics tends to be conservative in sexual attitudes, other research suggests that these attitudes can be changed (Gold, Rickman, and Rodda, 1973; Norris, 1965; and Chronkhite and Goetz, 1971). The investigator's intent to examine the relationship between dogmatism and an individual's propensity to change his sexual attitudes was stated. 
Chapter III: Procedures

In Chapter III will be discussed the sample, the observation scheme, the independent variables, pre-experimental assessment procedures, the experimental treatment sequence, criterion measures, the research design, the data analysis process, and the hypotheses.

The Sample

Forty-five staff members from the Lafayette Villa Nursing Home, Norfolk, Virginia, were subjects for this study. Included in the sample were registered nurses, licensed practical nurses, nurses' aides, nursing home administrators and nursing home activities directors. Each of the individuals included in this study had applied for the workshop on sexuality and signed a walver consenting to the use of sexually explicit audio-visual materials in the workshop.

Prior to exposure to the experimental workshop, Rokeach's Dogmatisn scale (1960) was adminfstered. The 45 staff members were then assigned to either a high dogmatistn or a low dogmatism group, based on being either above or below the dogmatism scale median respectively. In table 3:01 is presented the means and standard deviations for the high dogmatism and low dogmatism groups on the Dogmatism scale. The analysis of variance statistic indicated the means were significantly different $(p<.01), \underline{F}=45.03, \mathrm{df}=1$.

Staff members in the high dogmatism and the low dogmatism groups were randomly assigned to three groups using the table of random numbers 
In Kerlinger (1973). All participants were told that assignment to groups was according to a lottery system, and that those who did not recelve training in the first two sessions were to be trained at a 1ater date.

Table 3:01

Summary of Means and Standard Deviations

for the High Dogmatism and Low Dogmatism

Groups on the Dogmatism Scale

\begin{tabular}{llll}
\hline Group & $\mathrm{n}$ & $\overline{\mathrm{x}}$ & S.D. \\
\hline High Dogmatism & 16 & 179.19 & 25.69 \\
Low Dogmatism & 16 & 140.00 & 19.43 \\
\hline
\end{tabular}

Of the 45 staff who registered for the SAR, 32 attended the twoday workshops. Reasons given for lack of attendance included: inability to change work assignments, emergencies at work which required their presence, illness of family members, and previous committments. No significant differences in occupational status or level of dogmatism were noted between those who registered for the SAR and did not attend, and those who registered for the SAR and did attend.

Each of the two treatments was conducted by a heterosexual team of counselors who were randomly assigned to groups. One problem inherent in having two different teams of counselors conduct the SAR's was that the counselors would operate differently in one group than in the other. To ensure that the experimental treatments were conducted in the 
same way, except for the presence or absence of the independent variable, one counselor in each team was given instruction in the use of a daily observation scheme developed by the investigator.

Another problem existed. Because of the staffing requirements of the Lafayette Villa Nursing Home, it was not possible for all workshop registrants to be away at a two-day training at the same time. Consequently the two treatments could not be conducted simultaneously. This posed a problem, that is, that subjects in each of the experimentaI groups would discuss the nature of the audio-visual materials with those assigned to other groups. To minimize the possibility of this occurring, experimental treatments one and two were conducted "back' to back." The first experimental group was scheduled for Thursday and Friday, while the second group was scheduled for Monday and Tuesday of the next week. Due to the nature of the audio-visuals planned for the explicit group, the implicit group was conducted first. Subjects were requested to sign a statement promising not to divulge the content of the program to which they had been assigned (see Appendix C). Audio-Visual Materials

The audio-visual materials used for this SAR were obtained from two primary sources: Focus International Inc., and Multi Media Resource Center, Inc. Each of these firms routinely provide films and slides for SAR training. However, many of the films available were of an explicit nature. This posed two problems in the presentation of the audio-visual materials. First, while the film materials presented to the implicit treatment group could not include scenes of explicit sexual activity, 
they had to address the same subject areas covered in the explicit treatment group. Second, the definitions of the terms explicit and implicit, as applied to audio-visual materials, had to be clearly defined. These problems were dealt with in the following way: first, when available, films which were sexually implicit were used in the Implicit treatment group. These films addressed the same subjects as those which were covered in the explicit group. Second, for those sexual topics where implicit materials were not avallable, explicit materials were shown with deletions made of overt sexual activity. This was accomplished by videotaping the films twice. The explicit treatment group was shown the unedited video-tape. The implicit group was shown the edited version. Third, all audio-visual materials were viewed by a panel of five objective observers for the purpose of verifying an implicit or explicit rating.

Ratings were based on the following dimensions: a) presence or absence of verbal descriptions of sexual activity; b) presence or absence of nudity of "live" actors- and c) presence or absence of visual presentations of sexual activity such as masturbation, sexual intercourse, homosexual activity and oral-genital sex.

Those audio-visual materials which included verbal descriptions of sexual activity were classified as implicit. Audio-visual materials which included nudity of "live" actors and visual representations of sexual activity such as masturbation, sexual intercourse, homosexual. activity and oral-genital sex were classified as explicit. Inter-rater reliability ratings were determined after a brief training session 
focusing on the discriminating characteristics of implicit and explicit materials. An inter-rater reliability score of .83 was judged as an acceptable level of reliability. The Independent Variable

The experimental groups of subjects participated in a sex education program, which was summarized above. The groups differed, however, in the explicitness of the audio-visual materials used to implement this process. A description of the materials and the workshop format follows.

The Implicit Group

Introduction (30 minutes). After the factlitators introduced themselves, a brief talk on ths history of Sexual Attitude Reassessment workshops (SAR's) and their purpose was given by a group facilitator. Workshop participants were instructed as to SAR's origins in the Methodist Church and its association with the Glide Foundation of California. Handouts were given to each participant including: myths and messages about sexuality, general information about heterosexuality and homosexuality, the history of masturbation, and information about sexuality and the aged and disabled. An additional handout was provided on which participants listed areas in which they had the most difficulty dealing (see Appendix F')

The introduction also included a discussion of confidentiality, and the importance of trust in a discussion of this nature. Participants were encouraged to talk about their own sexual behavior if they so desired. However, discussions regarding the sexual behavior of others, 
both within and outside the workshop setting, were strongly discouraged. Workshop participants were then assigned to one of two discussion groups. They were then told that they may leave a film if they were particularly offended by $1 t$, but that they should not leave their discussion groups for the entirety of the workshop.

Factors which inhtbit discussions related to sex (10 minutes). A brief talk on some of the factors which inhibit discussions of sexual issues was given by one of the group facilitators. Topics related to secrecy, ignorance and sexual trauma were addressed.

Sma11 groups (20 minutes). Participants spent a short time getting acquainted with each other and the facilitators. Expectations for the workshop were discussed.

Sensuality ( 45 minutes). Workshop participants were shown two brief film segments as an introduction to the topic of sensuality. Orange* is a film showing that eating an orange can be a sensuous experience. Love Toad ${ }^{*}$ is a humorous film depicting the sexual activity of two beanbag frongs.

After the films, group members participated in a number of experiences In which the senses, other than sight, were explored. Participants were blindfolded and offered various things to touch such as a furry cloth, a pine cone, a statue of lovers kissing, and models of male and female genitals. They were then asked to taste a number of different foods, a slice of orange, peanut butter and candy, for example. The

\footnotetext{
*Film and slide materials are marked with an asterisk.
} 
sense of smell was explored by having participants smell and identify such things as peppermint extract, garlic and perfume. Lastly, group. members heard an audio recording. Sounds of a puppy crying, a jungle, a punching bag, and a storm are examples of those which were played and identified. This portion of the workshop was concluded with the playing of the song "Ebb Tide." Participants were asked to relax and to visualize a scene. A discussion of this experience followed. Communication about sexual issues (45 minutes). Three short films were used to discuss some of the issues which confront medical personnel in the course of their work. Nursing and Sexuality ${ }^{*}$ discusses disability, body Image and varlous medical problems which Impact on sexuality. Minnesota Soap Series* demonstrates some good and some bad ways of dealing with questions and concerns about sexuality. Communication Slides/ Genesis* graphically represents the ways in which we talk to each other. Sexual taboos which apply to both males and females are presented in these films in a numorous way.

Understanding the language (15 minutes). A brief didactic presentation was made by one of the facilitators regarding the problem of having an appropriate language for discussing sexual matters.

Language and values associated with sexuality ( 50 minutes). This portion of the program was introduced by a slide serles called World Erotica.* Group members were palred with a partner. The partner viewed a screen on which erotic art from around the world was shown. The partner facing the screen then described the picture to the individual who was facing away from it. This exercise was followed by another exerctse 
which related to talking about sex, the grafitti exercise. After forming into their small groups, the facilitators instructed their members to list all the words they could which were synonyms for penis and vagina. The group members quickly found that most of the synonyms for these terms were slang. The exercise demonstrated the fact that most of us lack a comfortable language in which to communicate about sex.

The facilitators then made a presentation on values associated with sex, and discussed the ways in which language reflected these values. After this discussion, individuals were asked to respond to a number of value statements by moving to one end of the room if they agreed with the statement, to move to the other end of the room if they disagreed with the stagement, and to stay in the center of the room if they were undecided about the statement. The following statements were read:

1. Masturbation is no longer necessary after marriage.

2. An extramarttal affair may sometimes improve a marriage.

3. Sexual activity is reduced after age sixty.

4. Homosexuality is a disease.

Small groups ( 30 minutes). Group members were asked to report on their thoughts and feelings regarding the films and exercises which they had experienced.

Heterosexuality (50 minutes). A didactic presentation was made discussing myths and fallacies associated with sex. The film Sexuality and Communication was shown. This film presents a doctor and his wife discussing lssues related to sexuality as they apply to the doctor/patient relationship, and the husband/wife relationship. 
Small groups ( 30 minutes). Groups were led in a discussion of the film and their reaction to 1 .

Homosexuality (40 minutes). A presentation of homosexuality was made by the faclittators. Some sharing of personal experiences was made to provide a model for self-disclosure. Two films were shown. A Gay View/Male* presented a personal discussion by three gay males. Feelings about men, women and children are explored. Issues related to labeling, intimacy and deflning oneself as gay were also explored. Gay Women Speak $^{*}$ was also shown. In this film, three lesblan women discuss their 11festyles, relationships and problems as they pertain to their sexual preferences.

Small groups (30 minutes). The groups were led in discussion of the homosexual films. Facilitators encouraged participants to share personal feelings and reactions.

Touching (10 minutes). A brief talk about touching behaviors was given. Participants were instructed to form pairs and to touch each other in the following way: right hand to left toe, left hand to right shoulder, right hip to right hip, etc. Participants were encouraged to discuss what it felt like to be touched in a nonsexual way.

Massage ( 40 minutes). The second day of the SAR began with a talk about some of the cultural taboos about touching. A brief talk on massage was given by one of the facilitators. Following the talk, group participants were asked to work with a partner. They were then given an opportunfty to both give and recelve hand, face and foot massages. Masturbation (50 minutes). A brief introduction to the subject of 
masturbation was made. Taboos related to touching one's genitals were discussed. Feeling Good ${ }^{*}$ was shown. This film presents a number of men sharing their boyhood expertences and feellngs today about self-sexuality. No explicit scenes of masturbation were included, as that portion of the film was edited. The facilitators discussed myths and taboos related to female self-sexuality as well.

Smal1 group (30 minutes). Group members were encouraged to discuss their feelings and reactions to the films.

Group and bisexuality ( 45 minutes). A brief didactic presentation was made introducing the topic. Two films were then shown. Kinsey Three* is a film depicting the true story of a bisexual man. He discusses his bisexual philosophy in the film. Explictt sexual activity was omitted. Reflections ${ }^{*}$ is a film about group sex. A group of eight, Including couples and single persons, discuss their sexual expertences with each other. Scenes depicting group sexual activity were edited.

Small group (30 minutes). Group members were encouraged to react to the films and to share their feelings about them.

Spectal populations (45 minutes). A didactic presentation was made concerning sexual expression of the aged and disabled. Myth regarding "gexlessness" were explored. The film, Grow Old Along with Me* was shown with A Rose by Any Other Name.* Grow Old Along with Me* presents two people about 60 years of age who, after thirty years of marriage, adopt an alternate 1ffestyle. A brief explicit scene in this film was edited. A Rose by Any Other Name* demonstrates that closeness and Intimacy are as important to the elderly as they are for the young. Attitudes 
toward the elderly and their sexual needs were explored.

A guided fantasy exercise was also conducted. Workshop participants were asked to visualize a country scene In which they Inadvertently come upon a couple making love. After visualizing the couple, group particlpants were asked if anyone lmagined that either of the sexual partners was a person over 60. They were also asked if the people that they visualized had a physlcal disability.

Groups ( 30 minutes). Groups were led in a discussion of the films and were encouraged to react to them, as well as the fantasy exercise. Body Image (45 minutes). A didactic presentation about the diversity of human appearance was presented. S1ldes of people who are fat, thin, tall, short, old, and young were shown. A discussion of body Image was led by the facilitators.

Panel and group discussion ( 30 minutes). At this time the factiltators formed a panel to discuss any Issues which may have not been touched on during the workshop. Panel members referred to a handout given at the beginning of the SAR. This handout provided space for the participants to list those areas of human sexuality that were most difficult for them to deal with.

Sex therapy ( 45 minutes). A brief didactic presentation was made concerning the sexual response cycle. Identifylng sexual problems was discussed, as well as how to refer to an appropriate sex therapist. Erogeny ( 5 minutes). The sound track from the film Erogeny ${ }^{*}$ was played. In the sound track a poem is read which describes the topography of a female's body. 


\section{Concluston.}

The Explicit Group

Introduction (30 minutes). The introduction for the explictt group was the same as the one given to the implictt group.

Factors which inhlbit discussions related to sex (10 minutes). This section was the same as the one given to the implicit group.

Small groups (20 minutes). The small group discussion was the same as that of the implicit group.

Sensuality (45 minutes). This section was identical to the one glven to the Implicit group.

Understanding the language (15 minutes). This presentation was also the same as the one made to the implicit group.

Language and values associated with sexuality (50 minutes). This portion of the program was introduced by a slide sertes called World Erotica. ${ }^{*}$ Group members were paired with a partner. The partner viewed a screen on which erotic art from around the world was shown. The partner facing the screen then described the picture to the Individual who was facing away from it. This exerclse was followed by another exercise which related to talking about sex, the graffiti exerclse. The exercise required participants to form into thelr small groups. The factlitators then instructed the groups to make a list of all. the words they could which were synonyms for penis and vagina. The exerclse demonstrated the fact that most of us lack a comfortable language in which to communtcate about sex.

Words of Love* was then shown. This is an explicit film which 
shows male and female sexual anatomy and brief scenes of individuals climaxing to orgasm. After this film, individuals responded to a number of value statements by moving to one end of the room if they agreed with the statement, to the other end of the room if they disagreed with the statement, and to stay in the center of the room if they were undecided. The following statements were read:

1. Masturbation is no longer necessary after marriage.

2. An extramarital affair may sometimes improve a marriage.

3. Sexual activity is reduced after age sixty.

4. Homosexuality is a disease.

Small groups ( 30 minutes). Group members were asked to report on their thoughts and feelings regarding the films and exercises which they had experienced thus far.

Heterosexuality (40 minutes). A brief didactic presentation was made discussing myths and fallacies associated with sex. Two films were shown: Rich and Judy ${ }^{*}$ is a film showing a couple who has been married several years enjoying oral sex and intercourse. Going Down to Bimini ${ }^{*}$ represents a young couple's fulfillment of an erotic fantasy. Lovemaking takes place on a deserted island in the Bahamas.

Small group ( 30 minutes). Groups were led in a discussion of the films and their reactions to them.

Homosexuality (40 minutes). A brief presentation of homosexuality was made by the facilitators. Some sharing of personal experiences was made to provide a model for self-disclosure. Two films were shown. Nik and John ${ }^{*}$ presents the experience of two homosexuals meeting at a dinner 
party. They discuss their lifestyles, feelings and experiences. Explicit sexual scenes, including anal and oral expression, were presented. A film depicting a lesbian sexual relationship was shown, called We Are Ourselves. "The film Includes explicit sexual activity, as well as a discussion of their individual evolutions to lesbianism.

Sma11 group (30 minutes). The groups were then led in a discussion of the homosexual films. Facilitators encouraged participants to share personal feelings and reactions.

Touching (10 minutes). A brief talk about touching behaviors was given. Participants were instructed to form pairs and to touch each other in the following way: right hand to left toe, left hand to right shoulder, right hip to right hip, etc. Participants were encouraged to discuss what it felt like to be touched in a non sexual way.

Massage (40 minutes). The second day of the SAR began with a brief talk on massage. The film Massage ${ }^{*}$ was shown which depicts the art of massage and some of the techniques which are important. After exploring cultural taboos concerning touch, several different couples are shown as they engage in complete body massage.

Masturbation (50 minutes). A brief introduction to the subject of masturbation was presented. Taboos related to touching one's genitals were discussed. Feeling Good ${ }^{*}$ and Soma Touch* were shown simultaneously. Feeling Good ${ }^{*}$ presents a number of men sharing their boyhood experiences and feelings today about self-sexuality. Explicit masturbation patterns are included. Soma Touch ${ }^{*}$ if a fi.tm which shows one man's masturbatory experience. Female masturbation is represented with the films, Margo* 
and Handvoice. ${ }^{*}$ The film Margo* depicts a woman engaged in manual stimulation of her breasts and genttals. Handvoice* is a film depicting a woman in her thirties engaging in manual stimulation to orgasm.

Smal1 groups (30 minutes). Group members were encouraged to discuss their feelings and reactions to the films.

Group and bisexuality (45 minutes). A brief didactic presentation was made introducing the topic. Two films were then shown. Kinsey Three* is a film depicting the true story of one bisexual man. He discusses his bisexual philosophy, and engaged in explicit sexual activity with both a man and a woman. Reflections ${ }^{*}$ is a film about group sex. A group of eight, including couples and single persons, discuss their sexual experiences with each other. Explicit scenes of their group sexual activity are included.

Small groups ( 30 minutes). Group members were encouraged to react to the films and share their feelings about them.

Special populations (45 minutes). A brief didactic presentation was made concerning sexual expression of the aged and the disabled. Myths regarding "sexlessness" in these groups were explored. The film A Ripple In Time ${ }^{*}$ was shown with A Rose by Any Other Name.* A Ripple in Time* presents an elderly couple engaging in active sexual expression. A Rose by Any Other Name* demonstrates that closeness and intimacy are as important to the elderly as they are to the young. Attitudes towards the elderly and their sexual needs are explored. The f11m Touching was also shown. This is a film about the sex life of a man suffering from a C-6 spinal cord Injury. He and his partner are shown to have a warm 
and satisfying relationship with oral sex as the primary means of stimulation.

Smal1 group (30 minutes). Groaps were led in a discussion of the films and were encouraged to react to them.

Body image (45 minutes). A didactic presentation about genital size was made. Three films were shown simultaneously. These were Exhibition: the Male Genltals, "Riverbody, * and Female Genitalia.* Each of these films depicts individuals of various shapes and sizes in the nude. The Erogenist* was also shown. This film presents a man giving a woman a full body massage.

Panel and group discussion ( 30 minutes). At this time the facilitators formed a panel to discuss any issues which may not have been specifically addressed. Panel members referred to the handout given at the beginning of the SAR. This handout provided space for the participants to list those areas of human sexuality that were most difficult for them to deal with.

Sex therapy (45 minutes). A brief didactic presentation was...made concerning the sexual reponse cycle. Identifying sexual problems was discussed, as well as how to refer to an appropriate sex therapist.

Erogeny ( 5 minutes). Erogeny ${ }^{*}$ is a short film which shows two bodies meeting and touching. A poem is read by the man which describes the topography of the female's body.

\section{Conclusion.}

The Observation Scheme

Two observation schemes were developed. The explicit treatment 
scheme asked the counselors to indicate on a checklist if the following components were included in the SAR: didactic instruction, experiential exercises, small group discussion, and films and slides which graphically depicted sexual behaviors such as masturbation, intercourse, and homosexual activity. The implicit schene asked the counselors to indicate on a checklist if the following components were included in the SAR: didactic instruction, experiential exercises, small group discussion and films and slides which did not graphically depict sexual behaviors such as masturbation, intercourse and homosexual activity.

It should be emphasized that the purpose of the observation scheme was not to provide data to statistically compare groups, but to guide the facilitators' behavior in conducting the SAR's. It was hoped that the observation schemes would insure that the two treatments would be differentiated in respect to only the independent variable.

Pre-experimental workshop. Prior to the experimental SAR's, a workshop conducted by the investigator was held at Lafayette Villa Nursing Home to familiarize the counselors and the director of staff development with the purpose and procedures of the study. The workshop consisted of a two-hour session. It was attended by the four counselors who conducted the experimental SAR's, the director of staff development for the nursing home, and the investigator.

During the workshop session the format of the experimental SAR's was discussed in detail. Particular attention was paid to differentiating between the explicit and implicit SAR programs. Films and slide materials were evaluated in terms of their explicitness or implicitness. 
The counselors were asked to conduct the explicit and implicit SAR's exactly the same, except for the use of fllm materials. They were also instructed not to divulge the content of the deleted film sequences in the presentation made to the Implicit group. The observation scheme was also discussed.

Following the review of workshop procedures, the investigator initiated a discussion of issues related to confidentiality as they applied to group work. The Ethical Standards of the American Personnel and Guidance Association were read, and were to govern the group processing which was incorporated in the SAR program. They are that:

The member's primary obligation is to respect the integrity and promote the welfare of the counselee(s), whether the counselee(s) is (are) assisted individually or in a group relationship. In a group setting, the member/leader is also responsible for protecting individuals from physlcal and/or psychological trauma resulting from interaction within the group (1974).

Group leaders were encouraged to facilitate the examination of values and attitudes associated with sexuality. However, deep exploration of personal problems was strongly discouraged. Furthermore, workshop participants were to be advised to the purpose of the group processing, and informed that they were not required to do any personal sharing. Workshop participants were to be asked to sign a statement of confidentiality, guaranteeing that information disclosed during the group sharing periods was to remain confidential (see Appendix $C$ ). Dogmatism Measure

Rokeach's (1956) Dogmatism scale, form E, was used to measure this trait. Rokeach's conception of dogmatism refers to "an authoritarian 
outlook on life, an intolerance toward those with opposing beliefs, and a sufference of those with similar bellefs" (p. 4). According to Rokeach, the primary purpose of the $\mathrm{D}$ scale is to measure individual differences in openness or closedness of belief systems.

Rokeach has revised this scale several times in an attempt to improve the reliability, as well as to refine the theoretical formulations on which the scale is based. Test-retest reliability coefficients for the D scale range from .68 to .93 , with a median of .74 , for intervals ranging from one to six months (Rokeach, 1960). The author points out that the relfabilities established are quite satisfactory, especially since the items included on the scale are of such a diverse nature. Despite this diversity, Rokeach contends that item analyses bear out the consistent differences in response styles between high and low dogmatic subjects.

The validity of the $D$ scale has been established largely by comparing $D$ scale scores with cognitive and various other personality criteria, such as the capacity to integrate new belief systems, differential aesthettc preferences, and evaluations of peers (Rokeach, 1960). The reported data appears to indicate that the $D$ scale provides a valid measurement of general authoritarianism. (Robinson and Shaver, 1973). Sex Knowledge and Attitude Test. The Sex Knowledge and Attitude Test (Leif and Reed, 1972) normed on a sample of 850 medical students, was used as a post treatment assessment of group differences in sexual knowledge and attitudes. The Sex knowledge and Attitude Test (SKAT) yields a single knowledge score and attitude scores on four dimensions: 
masturbation, sexual. myths, heterosexual relations, and abortion. All scores are negatively skewed, i.e., there is a greater spread of scores in the lower range, which denote more conservative attitudes and less knowledge. Hoyt reliability estimates fall within the .71 to .80 range. This measure was given one week after treatment. Criterion Instruments

The LTK Attitude Rating Scale was designed by the investigator to answer the question: do subjects exposed to the explicit SAR program perceive slides, representing individuals of various ages engaged in sexual activity differently than those who have not been exposed to explicit sexual material?

The LTK Attitude Rating Scale, normed on a sample of 18 community college students, was also used as a posttreatment assessment of group differences on perceptions of sexual behavior. The LTK Attitude Rating Scale consists of an eight-item questionnaire which asks the subjects to respond by circling $1,2,3,4,5,6,7$. The rating scale is anchored at points 1 (very little), 4 (moderate), and 7 (very much). The scale items were developed by the investigator for inclusion in the questionnaire. They were based upon scale items that were used in a study on attitudes toward sexual behavior in the aged by LaTorre and Kear (1977). The eight scales were credible, moral, erotic, arousing, boring, disgusting, acceptable, and sexually stimulating. Pearson correlation reliability estimates fall within the .62 to .94 range. This measure was given one week after treatment.

Subjects were asked to view slides presenting the sexual behavior 
of individuals of various ages while rating their responses on the scales. The slides included the following:

1. a man and woman over the age of 60 engaged in mutual masturbation;

2. a man and woman in their 20's engaged in mutual masturbation;

3. a heterosexual couple in their $60^{\prime}$ s engaging in sexual intercourse;

4. a heterosexual couple in their $20^{\prime}$ s engaging in sexual intercourse;

5. a heterosexual couple in their 60's engaging In oral-genital sex; and

6. a heterosexual couple in their $20^{\prime}$ s engaging in oral-genital

sex.

Research Design

The research design used for this study is Campbell and Stanley's (1963) "Post-test only Control. Group Design." The design is as follows:

Experimental Group 1: $\quad \mathrm{R} \quad \mathrm{x}_{1} \mathrm{o}_{1}$

Experimental Group 2: $\mathrm{R} \quad \mathrm{x}_{2} \quad \mathrm{O}_{2}$

Control Group: $\quad \mathrm{R} \quad \mathrm{O}_{3}$

Key: An " $R$ " indicates that subjects were randomly assigned to separate treatment groups; " $\mathrm{X}$ " represents the exposure of a group to an experimental variable; "o" refers to the process of observation, or the post-tests; the left to right dimension indicates the sequence of the process as it applied to each specific group.

Experimental group 1. This group was exposed to a sequence of sexually implicit audio-visual presentations. The films and slides shown did not graphically depict sexual activity. 
Experimental group 2. This group was exposed to a sequence of sexually explicit audio-visual presentations. These materials depicted persons, couples and groups involved in sexual activity.

Control group. This group was not exposed to either explicit or or implicit sex education materials. In addition, no attempt was made to meet with this group for the purpose of discussing sexual issues. Hypotheses

Analysis of the research and theory presented in Chapters I, II, and III suggest that it would be meaningful and reasonable to test the following hypotheses:

Ho ${ }^{1}$ : There is no significant difference in general attitudes towards sex, as measured on the Sex Knowledge and Attitude Test (SKAT), between the implicit, explicit, and control groups.

$\mathrm{Ho}^{2}$ : There is no significant difference in general attitudes towards sex, as measured on the SKAT, among groups of nursing home staff differing on levels of do.gmatism.

$\mathrm{Ho}^{3}$ : There is no significant difference in general sex knowledge, as measured on the SKAT, between implicit, explicit, and control groups.

$\mathrm{Ho}^{4}$ : There is no significant difference in general sex knowledge, as measured on the SKAT, among groups of nursing home staff differeing on levels of dogmatism.

Ho ${ }^{5}$ : There is no significant interaction between treatment and dogmatism on nursing home staff attitudes towards sex.

Ho ${ }^{6}$ : There is no significant interaction between treatment and dogmatism on nusring home staff knowledge about sex.

$\mathrm{Ho}^{7}$ : There is no significant difference in the perception of sexual behavior as measured with the LTK Attitude Rating Scale, between implicit, explicit, and control groups. 
Ho ${ }^{8}$ : There is no significant difference in the perception of sexual behavior, as measured with the LTK Attitude Rating Scale, of groups of nursing home staff differing on levels of dogmatism.

Ho ${ }^{9}$ : There is no significant interaction between treatment and dogmatism on nursing home staff perceptions of sexual behavior, as measured on the LTK Attitude Rating Scale.

\section{Statistical Analysis}

All data obtained on the two posttests was analyzed using one-way analysis of variance. Two-way analysis of varfance (treatment $x ! d o g-$ matism) was used to test interaction effects. The Statistica1 Package for the Social Sciences (Nie, et al., 1975) was used. When the F ratio indicated rejection at the .05 level of significance, the null hypothesis of equal means was rejected. An a posteriori comparison of group means was made using the Newnan-Keuls method (Hinkle, et al., 1979). Hinkle states that the Newman-Keuls method is a powerful statistical test that can be used when a significant $\underline{F}$ ratio is anticipated and group sample sizes are equal.

Hinkle lists four assumptions that underly both one-way and twoway analyses of variance. Those assumptions are: 1) the samples are Independent, random samples from defined populations, 2) the dependent variable is measured on at least an interval scale, 3) the scores on the dependent variable are normally distributed in the population, and 4) the population variances for all the cells in the design matrix are equal. In the present study the four assumptions were met as follows: 1) the samples were randomly assinged to treatments and were therefore independent, 2) although interval and ordinal scale measurements were 
used in the present study, Hinkle reports that no serious effects on the probability statement result, 3) scores on the dependent measures were believed to be normally distributed throughout the population, and 4) homogeneity of variance within the cells of the design matrix was believed to exist due to random assignment. 
This chapter presents the statistical analysis of the data and the results of these analyses.

The purpose of this study was to investigate the effects of implicit and explicit sex-related materials on the perceptions, attitudes and knowledge of high and low dogmatic nursing home staff enrolled in Sexual Attitude Reassessment Workshops.

The investigator had formed nine null hypotheses based upon a review of the research and theory on sexuality and aging, sexual attitude reassessment workshops, and dogmatism. Each of these null hypotheses were statistically tested, and the results of the analyses are presented below. Statement of Null Hypotheses and Results of Statistical Testing

The first null hypotheses tested was:

$\mathrm{Ho}^{1}$ : There is no significant difference in general attitudes towards sex, as measured on the SKAT, between the implicit, explicit, and control groups.

Analysis of variance procedures on posttest data indicate significant differences existed between treatment and control subjects on the attitudinal scales of the SKAT. Ho ${ }^{1}$ is therefore rejected. Table $4: 1$ summarizes the means and standard deviations for effects of treatment for experimental and control groups. A review of posttest means indicates that except for the abortion scale, the treatment groups achieved higher scores than the control group on all four attitude scales of the SKAT. 


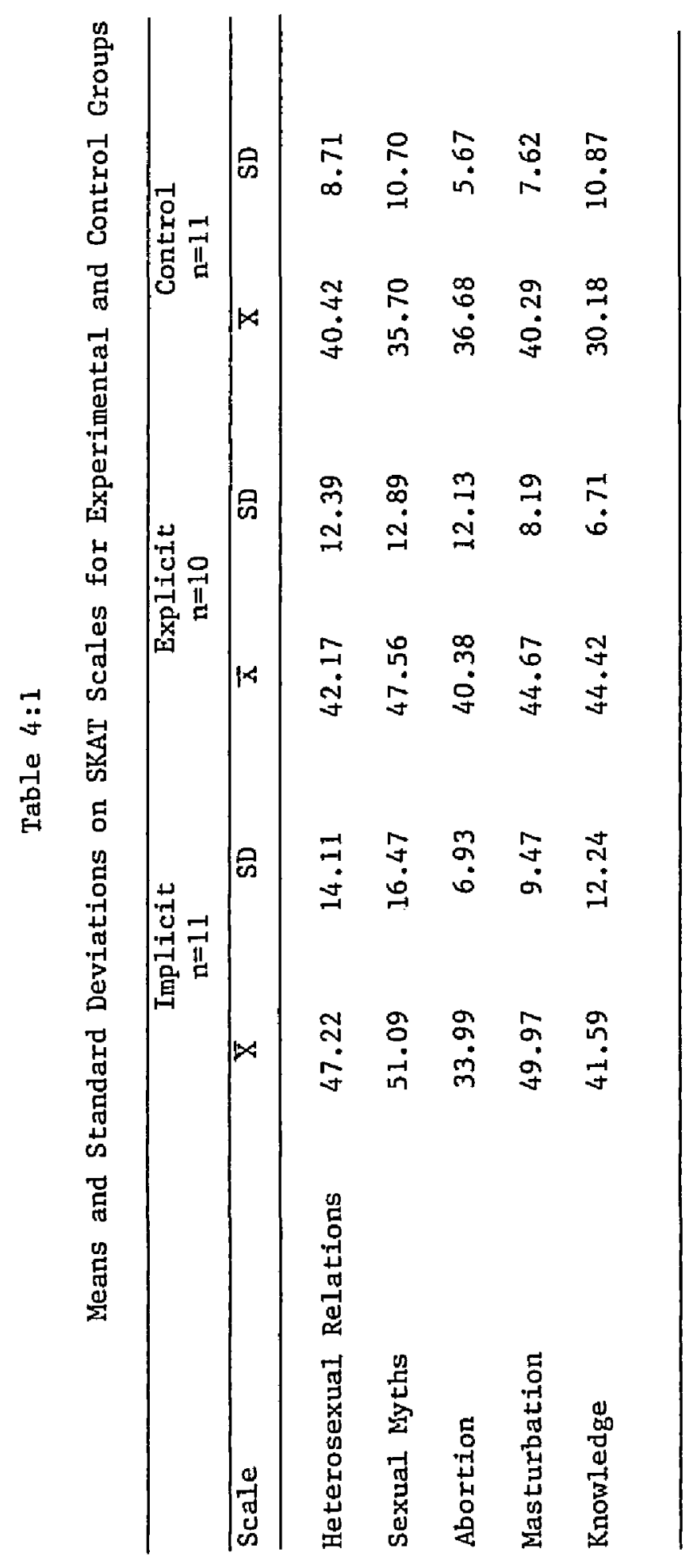


Normative data for the SKAT is reported by Lief and Reed (1973). In general, scores are interpreted as follows: for each of the scales Heterosexual Relations, Sexual Myths, Abortion, and Masturbation, high scores indicate that subjects expressed liberal, accepting attitudes toward these areas. Low scores imply conservative, negative attitudes toward these areas. In the present study, two scales which reflected the greatest between group differences were the sexual myths and the masturbation scales. For the sexual myths scale, the implicit group obtained a mean equal to 51.09 indicating a tendency toward rejecting commonly held misconceptions about sex. These scores contrast with those of the control group whose mean was 35.70. According to Leif and Reed (1973), scores below 40 indicate a tendency toward accepting commonly held misconceptions about sex. The same is true for the masturbation scale. The implicit group obtained a mean equal to 49.97 reflecting a generally permissive attitude toward masturbation. A mean score of 40.29 for the control group implies an orientation which sees masturbation as an unhealthy practice.

Table 4:2 summarizes analysis of varlance for effects of treatment on SKAT scales. As indicated, results which were not significant were found on the Heterosexual Relations and Abortion scales. Differences which were significant at .0329 level of probability were found for the sexual myths scale, however. Significant between group differences were also found on the masturbation scale. A probability level of .0399 on this scale indicates that between group differences were too great to attribute random sampling error. 


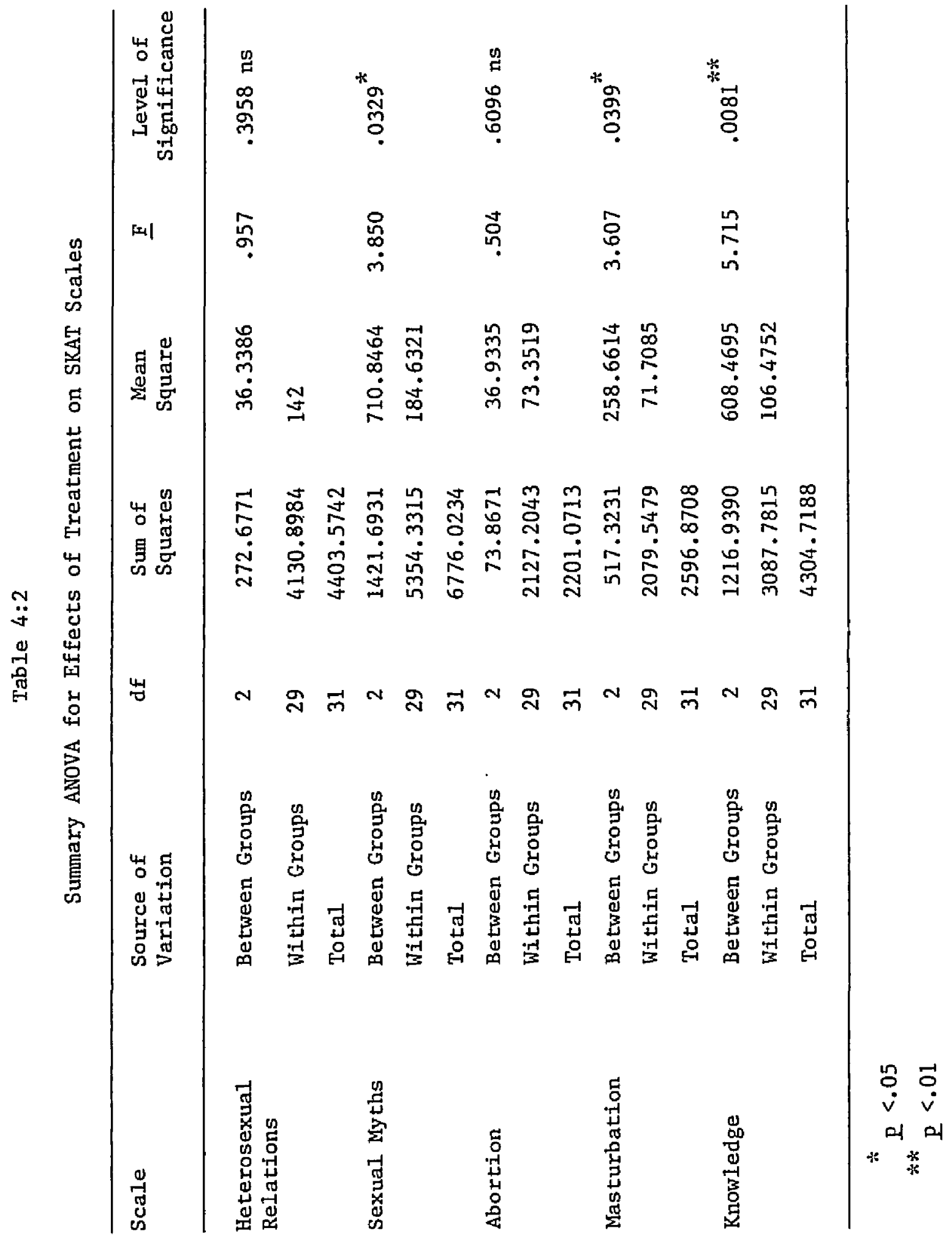


Following the rejection of the null hypothesis, a post hoc test of means, using the Newman-Keuls method, produced further results. It was indicated that significant differences existed between the implicit and control groups on the sexual myths and masturbation scales $(\underline{p}<.05)$. No significant differences were found between the explicit and control groups, however $(\underline{p}>.05)$. Results of this analysis are reported in Table $4: 3$.

The second null hypothesis tested was:

$\mathrm{Ho}^{2}$ : There is no significant difference in general attitudes towards sex, as measured on the SKAT, among groups of nursing home staff differing on levels of dogmatism.

Analysis of varlance procedures were employed to determine if level of dogmatism produced a significant effect on attitudes toward sex. Table 4:4 summarizes means for high and low dogmatism implicit, explicit and control groups. A review of posttest mean scores failed to indicate any specific trends in scoring. For the implicit group, high dogmatism mean scores were greater than low dogmatism mean scores on the abortion and masturbations scales. However, for that same group, Iow dogmatism mean scores were greater than high dogmatism mean scores on the heterosexual relations and sexual myths scale.

For the explicit group, high dogmatism mean scores were slightly greater than low dogmatism mean scores on three out of the four attitude scales. These included the heterosexual relations, sexual myths and masturbation scales. Low dogmatism mean scores were slightly greater than high dogmatism mean scores on the abortion scale, however.

For the control group, high dogmatism mean scores were slightly higher 
Table $4: 3$

Post Hoc Comparison of Means on SKAT Scales

\begin{tabular}{lccc}
\hline Scale & $\begin{array}{c}\text { Implicit } \\
\text { vs. } \\
\text { Control }\end{array}$ & $\begin{array}{c}\text { Explicit } \\
\text { vs. } \\
\text { Control }\end{array}$ & $\begin{array}{c}\text { Implicit } \\
\text { vs. } \\
\text { Explicit }\end{array}$ \\
$\begin{array}{l}\text { Heterosexual } \\
\text { Relations }\end{array}$ & - & - & - \\
Sexual Myths & $*$ & - & - \\
Abortion & - & - & - \\
Masturbation & $*$ & - & - \\
Knowledge & $*$ & $*$ & \\
\hline
\end{tabular}

*Indicates significant differences (p.<.05) 


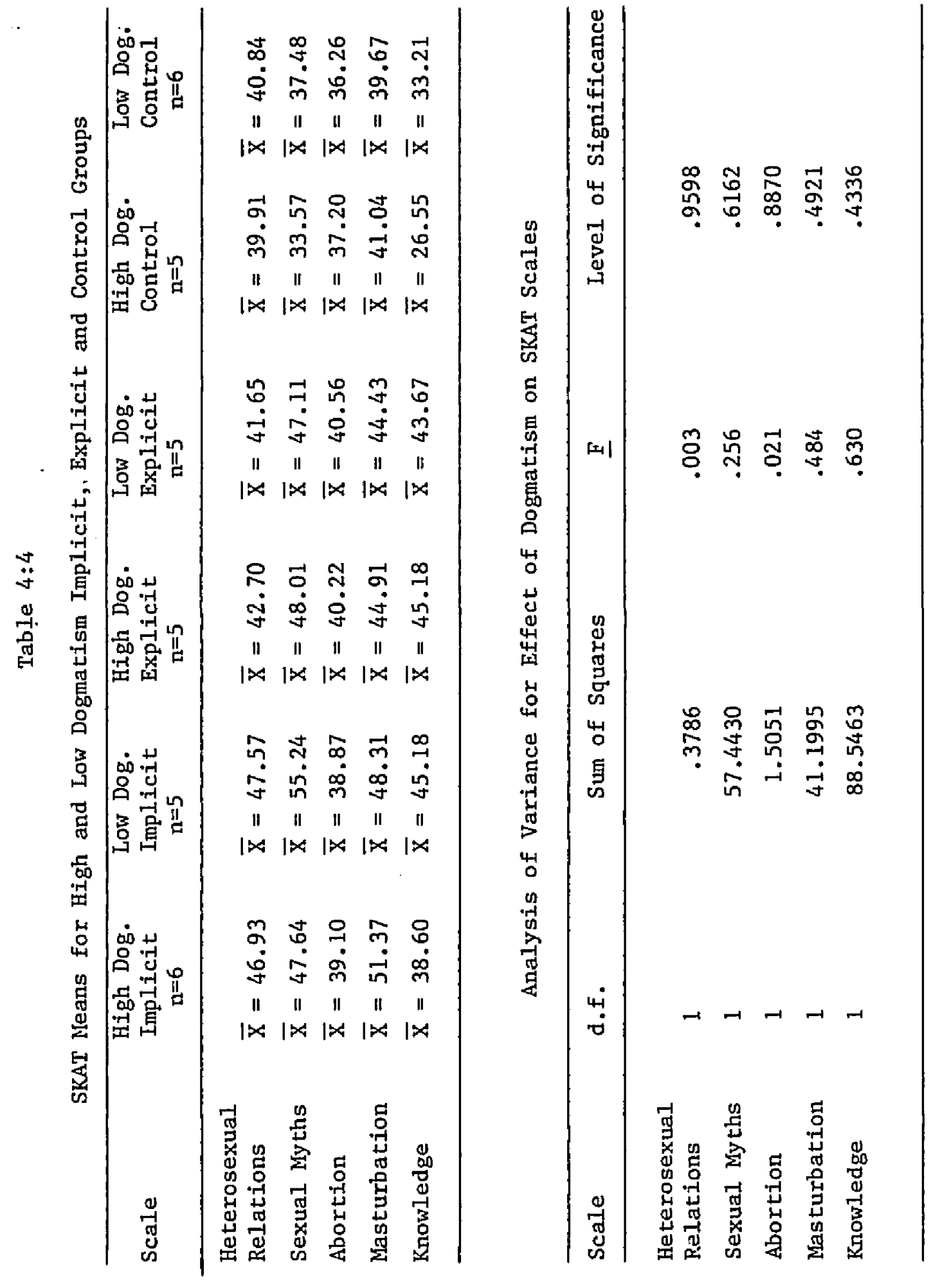


than low dogmatism mean scores on abortion and masturbation scales. Low dogmatism mean scores were slightly greater than high dogmatism mean scores on the heterosexual relations and sexual myths scales. Analysis of variance for effect of dogmatism on SKAT scores is summarized in Table 4:4. Results indicate that level of dogmatism produced no significant differences in any of the four attitude scales of the SKAT. $\mathrm{Ho}^{2}$ is therefore accepted.

The third hypothesis to be tested was:

$\mathrm{Ho}^{3}$ : There is no significant difference in general sex knowledge, as measured on the SKAT, between implicit, explicit, and control groups.

Analysis of varlance results in significant $F$ values for the effects of treatment on SKAT knowledge scores $(\mathrm{p}<.01)$. Therefore, $\mathrm{Ho}^{3}$ is rejected. Newman-Keuls post hoc comparisons of adjusted treatment means show that both the implicit and explicit groups performed significantly better than the control group $(\mathrm{p}<.05)$. No significant difference was found, however, between the implicit and explicit treatment groups. Tables $4: 1$ and 4:2 summarlze the sex knowledge data generated from the two experimental conditions and the control group. A review of posttest means indicates that each of the treatment groups scored higher than the control group on the knowledge scale of the SKAT. Test scores on this scale are interpreted just as the attitude scale. Scores above 50 indicate a high degree of knowledge about sextual behavior. Scores below 50 Indicate a lesser degree of knowledge of sexual behavior (Leif and Reed, 1973). Although none of the experimental groups achieved scores which were comparable to the normative group of nurses, it is clear that the implicit and 
explicit groups performed considerably better than the control group on the knowledge scale of the SKAT. Post hoc comparison of treatment means are presented in Table $4: 3$.

The fourth null hypothesis to be tested was:

Ho ${ }^{4}$ : There is no significant difference in general sex knowledge, as measured on the SKAT, among groups of nursing home staff differing on levels of dogmatism.

Analysis of variance was used to determine if level of dogmatism produced a significant effect on general knowledge of sexual behavior. Table 4:4 summarizes means for high and low dogmatism implicit, explicit, and control groups. A review of posttest means indicates that for two out of three groups, low dogmatism scores were greater on the knowledge scale than high dogmatism scores, although these differences were not statistically significant. These scores indicate that low dogmatics had a greater knowledge of facts about sexual behavior than high dogmatics. For the implicit group, low dogmatism mean scores were approximately seven points greater than high dogmatism mean scores. The same holds true for the control group. Low dogmatism mean scores for the control group were approximately five points greater than high dogmatism mean scores. The smallest spread in scores between high and low dogmatism groups was found for subjects who had participated in the explicit experimental condition. While both high and low dogmatism mean scores for the explicit group were relatively good, the low dogmatism mean score was approximately two points below high dogmatism mean scores.

Analysis of varlance for effect of dogmatism on SKAT scores is summarized in Table 4:4. Results Indicated that level of dogmatism had no 
significant effect $(p>.05)$ on general sex knowledge of groups of nursing home staff. $\mathrm{Ho}^{4}$ is therefore accepted.

The flfth hypothesis to be tested was:

$\mathrm{Ho}^{5}$ : There is no significant interaction between treatment and dogmatism on nursing home staff attitudes towards sex.

A two-way analysis of variance was used to test this hypothesis. The data in table 4:5 indlcate that the tests for interaction of main effects on all four attitude scales of the SKAT were statistically nonsignificant $(\mathrm{p}>.05)$. The null hypothesis is therefore accepted.

Table $4: 5$

Two-way Interaction Analysis of Main Effects

(Treatment by Dogmatism) on Nursting Home

Staff SKAT Scales

\begin{tabular}{lcccc}
\hline Scale & $\begin{array}{l}\text { Sum of } \\
\text { Squares }\end{array}$ & d.F. & $\underline{F}$ & $\begin{array}{c}\text { Level of } \\
\text { Significance }\end{array}$ \\
\hline $\begin{array}{l}\text { Heterosexual } \\
\text { Relations }\end{array}$ & 5.85 & 2 & .018 & .982 \\
Sexual Myths & 94.58 & 2 & .239 & .789 \\
Abortion & 2.111 & 2 & .013 & .987 \\
Masturbation & 9.09 & 2 & .058 & .944 \\
Knowledge & 113.55 & 2 & .519 & .601 \\
\hline
\end{tabular}

The sixth hypothesis to be tested was:

$\mathrm{Ho}^{6}$ : There is no significant interaction between treatment and dogmatism on nursing home staff knowledge about sex. 
This hypothesis was tested using the two-way analysis of vartance procedure. Results presented in Table 4:5 indicated that there were no significant interaction effects between treatment and dogmatism on the knowledge scale of the SKAT $(\mathrm{p}>.05)$. The null hypothesis is therefore accepted.

The seventh hypothesis tested was:

$\mathrm{Ho}^{7}$ : There is no significant difference in the perception of sexual behavior, as measured on the LTK Attitude Rating Scale, between implicit, explicit, and control groups.

Analysis of varlance was used to test this hypothesis. Results indicate that no significant differences occurred between Implicit, explicit, and control group perceptions of the three sexual behaviors presented in the slides $(\mathrm{p}>.05)$. The null hypothesis is therefore accepted. These results are summarlzed in Tables $4: 6,4: 7$, and $4: 8$.

Analysis of variance further revealed that no significant differences occurred between implicit, explicit and control group perceptions of sexual behavior when age of sexual participants presented in the slide was the discriminating variable $(p>05)$. Table 4:9 presents cell means for effects of age on ratings of sexual behavior for experimental and contro? groups.

Although the results were statistically insignificant, a review of posttest mean scores measuring perceptions of young and old sexual participants reveal.s interesting results. For the implicit group, the sexual. behavior of young couples was found to be slightly more credible, moral, erotic, arousing, acceptable and sexually stimulating than the sexual behavior of elderly couples. It was also Indicated that the sexual behavior 
Table $4: 6$

Analysis of Variance for Effects of Treatment on LTK Attitude Rating Scale for Behavior $1^{*}$

\begin{tabular}{llcccc}
\hline Scale & $\mathrm{df}$ & $\begin{array}{c}\text { Sum of } \\
\text { Squares }\end{array}$ & $\begin{array}{c}\text { Mean } \\
\text { Square }\end{array}$ & $\underline{F}$ & $\begin{array}{c}\text { Level of } \\
\text { Significance }\end{array}$ \\
\hline Credible & 2 & 3.3699 & 1.6850 & .644 & .5328 \\
Moral & 2 & 4.6655 & 2.3328 & .923 & .4089 \\
Erotic & 2 & 5.3600 & 2.6800 & 1.029 & .3702 \\
Arousing & 2 & .3302 & .1651 & .049 & .9520 \\
Boring & 2 & 1.4346 & .7173 & .501 & .6114 \\
Disgusting & 2 & .1219 & .0609 & .045 & .9565 \\
Acceptable & 2 & 2.1011 & 1.0505 & .479 & .6244 \\
Sexualiy & & .6255 & .3127 & .098 & .9067 \\
Stimulating & 2 & & & & \\
\hline
\end{tabular}

* Sexual Behavior 1 consists of slides of young and old couples engaged in mutual masturbation 
Table $4: 7$

Analysis of Variance for Effects of Treatment on LTK Attitude Rating Scale for Sexual Behavior $2^{*}$

\begin{tabular}{|c|c|c|c|c|c|}
\hline Scale & $d f$ & $\begin{array}{l}\text { Sum of } \\
\text { Squares }\end{array}$ & $\begin{array}{l}\text { Mean } \\
\text { Square }\end{array}$ & $\underline{F}$ & $\begin{array}{c}\text { Leve1 of } \\
\text { Significance }\end{array}$ \\
\hline Credible & 2 & .0242 & .0121 & .005 & .9945 \\
\hline MoraI & 2 & 1.1000 & .5500 & .182 & .8344 \\
\hline Erotic & 2 & 4.9773 & 2.4886 & .890 & .4215 \\
\hline Arousing & 2 & 4.4703 & 2.2351 & .554 & .5808 \\
\hline Boring & 2 & .5016 & .2508 & .135 & .8744 \\
\hline Disgusting & 2 & 2.6386 & 1.3193 & .682 & .5137 \\
\hline Acceptable & 2 & 4.2919 & 2.1459 & 1.215 & .3113 \\
\hline $\begin{array}{l}\text { Sexually } \\
\text { Stimulating }\end{array}$ & 2 & 1.3263 & .6631 & .174 & .8414 \\
\hline
\end{tabular}

* Sexual Behavior 2 consists of slides of young and old couples engaged in sexual intercourse. 
Table $4: 8$

Analysis of Variance for Effects of Treatment on the Attitude Rating Scale for Behavior $3^{*}$

\begin{tabular}{lccccc}
\hline Scale & $\mathrm{df}$ & $\begin{array}{c}\text { Sum of } \\
\text { Squares }\end{array}$ & $\begin{array}{c}\text { Mean } \\
\text { Squares }\end{array}$ & $\underline{F}$ & $\begin{array}{c}\text { Level of } \\
\text { Significance }\end{array}$ \\
\hline Credible & 2 & 3.5736 & 1.7868 & .983 & .3863 \\
Moral & 2 & 4.9899 & 2.4949 & .583 & .5647 \\
Erotic & 2 & 5.0626 & 2.5313 & .702 & .5038 \\
Arousing & 2 & 12.5454 & 6.2727 & 1.462 & .2484 \\
Boring & 2 & .2228 & .1114 & .029 & .9716 \\
Disgusting & 2 & 1.4659 & .7329 & .170 & .8445 \\
Acceptable & 2 & 14.3778 & 7.1889 & 1.244 & .3032 \\
Sexually & & 18.0255 & 9.0128 & 1.930 & .1634 \\
Stimulating & 2 & & & & \\
\hline
\end{tabular}

* Sexual Behavior 3 consists of slides presenting young and old couples engaging in oral-genital sex. 
Table $4: 9$

Cel1 Means for Effects of Age on Ratings of Sexual

Behavior Experimental and Control Groups

\begin{tabular}{|c|c|c|c|c|c|c|}
\hline \multirow[t]{2}{*}{ Scale } & \multicolumn{2}{|c|}{ Implicit } & \multicolumn{2}{|c|}{ Explicit } & \multicolumn{2}{|c|}{ Contro1 } \\
\hline & young $/$ & old & young & old & young & /old \\
\hline Credible & 5.52 & 4.92 & 5.58 & 5.58 & 6.25 & 5.54 \\
\hline MoraI & 5.07 & 5.02 & 4.64 & 5.22 & 5.54 & 5.31 \\
\hline Erotic & 4.18 & 3.69 & 3.82 & 3.82 & 5.11 & 4.14 \\
\hline Arousing & 4.52 & 3.61 & 3.84 & 3.66 & 4.60 & 3.64 \\
\hline Boring & 2.20 & 2.40 & 2.06 & 2.22 & 2.04 & $2.4 \mathrm{I}$ \\
\hline Disgusting & 1.71 & 1.82 & 2.28 & 2.00 & 2.11 & 1.96 \\
\hline Acceptable & 5.78 & 5.13 & 5.20 & 5.50 & 5.82 & 5.60 \\
\hline $\begin{array}{l}\text { Sexually } \\
\text { Stimulating }\end{array}$ & 4.78 & 3.95 & 5.58 & 4.42 & 4.91 & 4.13 \\
\hline
\end{tabular}


of young couples was considered less boring and disgusting by the implicit group.

Similar responses were made by the control group. Mean scores indicate that the control group perceived the sexual behavior of young couples as slightly more credible, moral, erotic, arousing, disgusting, acceptable and sexually stimulating than the sexual behavior of elderly couples. It was also indicated that the sexual behavior of young couples was considered less boring than the sexual behavior of the elderly by the control group.

The explicit group responded somewhat differently, however. Mean scores for this group indicated that subjects perceived the sexual behavior of young couples much the same as they did the sexual behavior of elderly couples. These findings will be discussed further in Chapter V.

The eighth hypothesis to be tested:

Ho ${ }^{8}$ : There is no significant difference in the perception of sexual behavior as measured on the LTK Attitude Rating Scale, or groups of nursing home staff differing on levels of dogmatism.

The eight scales of the LTK Attitude Rating Scale were analyzed using analysis of variance. These scales were: credible, moral, erotic, arousing, boring, disgusting, acceptable, and sexually stimulating.

As indicated in Table 4:10, no statistically significant differences are noted between high and low dogmatism groups in their response to slides depicting old and young couples engaged in mutual masturbation. Results which approached significance were noted on one of the scales, however. A significance level of .0693 was reported for the "disgusting" scale. That is, subjects in the high dogmatism group were more likely to find slides 
Table $4: 10$

Analysis of Variance for Effects of Dogmatism on the LTK Attitude Rating Scale for Behavior $1^{*}$

\begin{tabular}{lccccc}
\hline Scale & $\mathrm{d} f$ & $\begin{array}{c}\text { Sum of } \\
\text { Squares }\end{array}$ & $\begin{array}{c}\text { Mean } \\
\text { Square }\end{array}$ & $\underline{F}$ & $\begin{array}{c}\text { Leve1 of } \\
\text { Significance }\end{array}$ \\
\hline Credible & 1 & 4.0614 & 4.0614 & 1.619 & .2129 \\
Moral & 1 & 6.8450 & 6.8450 & 2.886 & .0997 \\
Erotic & 1 & .1801 & .1801 & .067 & .7977 \\
Arousing & 1 & .0313 & .0313 & .010 & .9225 \\
Boring & 1 & .0200 & .0200 & .014 & .9066 \\
Disgusting & 1 & 4.2050 & 4.2050 & 3.549 & .0693 \\
Acceptable & 1 & 1.9013 & 1.9013 & .893 & .3521 \\
Sexually & 1 & 2.6450 & 2.6450 & .879 & .3650 \\
Stimulating & 1 & & & & \\
\hline
\end{tabular}

* Sexual Behavior 1 consists of slides of young and old couples engaged in mutual masturbation. 
of couples engaged in mutual masturbation to be disgusting than subjects in the low dogmatism group. Results which were in the expected direction were also found on the "moral" scale. A significance level of .0997 indicates that subjects in the high dogmatism group were less likely to find slides of couples engaged in mutual masturbation to be moral than those in the low dogmatism group.

Table 4:11 presents analysis of variance for effects of dogmatism on the LTK Attitude Rating Scale for behavior 2, sexual intercourse. Inspection of this data reveals that no statistically significant dogmatism effects were found.

Results of the analysis of variance for effects of dogmatism on the LTK Attitude Rating Scale for behavior 3, oral-genital sex, are reported in Table 4:12. Statistically significant differences were found between high and low dogmatism groups in their response to slides of old and young couples engaged in oral-genital sex. A significance level of .0266 on the "boring" scale indicates that subjects in the high dogmatism group found slides of couples engaged in oral-genital sex more boring than subjects in the low dogmatism group.

It was also found that statistically significant differences existed between the high dogmatism and low dogmatism groups on the "disgusting" scale. For sexual behavior 3 , subjects in the high dogmatism group reported that oral-genital sex was more disgusting than subjects in the low dogmatism group with a statistical significance level of .0064 . The null hypothesis is therefore rejected.

A level of probability which approached significance was found on 
TabIe 4:11

Analysis of Variance for Effects of Dogmatism on the LTK Attitude Rating Scale for Behavior $2^{*}$

\begin{tabular}{lccccc}
\hline Scale & $\mathrm{df}$ & $\begin{array}{c}\text { Sum of } \\
\text { Squares }\end{array}$ & $\begin{array}{c}\text { Mean } \\
\text { Square }\end{array}$ & $\underline{F}$ & $\begin{array}{c}\text { Leve1 of } \\
\text { Significance }\end{array}$ \\
\hline Credible & 1 & .1251 & .1251 & .059 & .8105 \\
Moral & 1 & .5001 & .5001 & .170 & .6829 \\
Erotic & 1 & .5868 & .5868 & .206 & .6532 \\
Arousing & 1 & .5869 & .5869 & .146 & .7055 \\
Boring & 1 & .5868 & .5868 & .327 & .5717 \\
Disgusting & 1 & 2.7223 & 2.7223 & 1.457 & .2368 \\
Acceptable & 1 & 8.0000 & 8.0000 & 5.238 & .3408 \\
$\begin{array}{l}\text { Sexually } \\
\text { Stimulating }\end{array}$ & 1 & 8.3369 & 8.3369 & 2.412 & .1309 \\
\hline
\end{tabular}

* Sexual Behavior 2 consists of slides of young and old couples engaging in sexual intercourse. 
Table 4:12

Analysis of Variance for Effect of Dogmatism on the LTK Attitude Rating Scale for Behavior $3^{*}$

\begin{tabular}{lcrrrr}
\hline Scale & df & $\begin{array}{c}\text { Sum of } \\
\text { Squares }\end{array}$ & $\begin{array}{c}\text { Mean } \\
\text { Square }\end{array}$ & $\underline{F}$ & $\begin{array}{c}\text { Level of } \\
\text { Significance }\end{array}$ \\
\hline Credible & $I$ & .0703 & .0703 & .016 & .9010 \\
Moral & 1 & 2.8203 & 2.8203 & .670 & .4195 \\
Erotic & 1 & 4.8828 & 4.8828 & 1.399 & .2462 \\
Arousing & 1 & 1.1250 & 1.1250 & .248 & .6218 \\
Boring & 1 & 17.2578 & 17.2578 & 5.440 & $.0266^{* * *}$ \\
Disgusting & 1 & 28.1250 & 28.1250 & 8.577 & $.0064^{* * * *}$ \\
Acceptable & 1 & 21.1250 & 21.1250 & 3.940 & .0564 \\
Sexually & & & & & .5339 \\
Stimulating & 1 & 2.0000 & 2.0000 & .396 & \\
\hline
\end{tabular}

* Sexual Behavior 3 consists of slides of young and old couples engaged in oral-genital sex.

$$
\begin{aligned}
* * & <.05 \\
\text { e } & <* \pi * 1 \\
\mathrm{p} & <.01
\end{aligned}
$$


the "acceptable" scale. A significance level of .0564 was reported indicating that subjects in the high dogmatism group were more likely to find slides of couples engaged in oral-genital sex to be less acceptable than subjects in the low dogmatism group.

Analysis of variance further revealed that no significant differences occurred between high and low dogmatism groups in their perception of sexual behavior when age of sexual participants presented in the slide was the discriminating variable $(\mathrm{p}>.05)$.

The ninth hypothesis to be tested was:

$\mathrm{Ho}^{9}$ : There is no significant interaction between treatment and dogmatism on nursing home staff perceptions of sexual behavior as measured with the LTK Attitude Rating Scale.

Two-way analysis of variance (treatment by dogmatism) was used to test this hypothesis. Tests for interaction of main effects for sexual behaviors 1 (mutual masturbation), 2 (sexual intercourse), and 3 (oralgenital sex) were found to be statistically non significant on all eight scales of the LTK Attitude Rating Scale $(p>.05)$. Results of this analysis are presented in Tables $4: 13,4: 14$, and 4:15. The null. hypothests is therefore accepted.

Using the two-way analysis of variance, further results indicate that no significant interaction effects occurred when age of sexual participant in the slide was the discriminating variable $(\mathrm{p}>.05)$. Summary

Significant differences in general attitudes toward sex were found between the treatment and control groups. Scores on the Sex Knowledge and Attitude Test were analyzed using the analysis of variance procedure with 
Table 4:13

Interaction Effects for LTK Attitude Rating Scale for Behavior $1^{\text {* }}$

\begin{tabular}{lccccc}
\hline Scale & df & $\begin{array}{c}\text { Sum of } \\
\text { Squares }\end{array}$ & $\begin{array}{c}\text { Mean } \\
\text { Square }\end{array}$ & $\underline{F}$ & $\begin{array}{c}\text { Level of } \\
\text { Significance }\end{array}$ \\
\hline Credible & 2 & 4.535 & 2.267 & .869 & .431 \\
Moral & 2 & 4.644 & 2.322 & .967 & .394 \\
Erotic & 2 & .646 & .323 & .112 & .894 \\
Arousing & 2 & 2.773 & 1.387 & .382 & .686 \\
Boring & 2 & 6.774 & 3.387 & 2.534 & .099 \\
Disgusting & 2 & .937 & .469 & .355 & .705 \\
Acceptable & 2 & 10.772 & 5.385 & 2.734 & .084 \\
Sexully & & & & & .598 \\
Stimulating & 2 & 3.942 & 1.971 & .598 & .557 \\
\hline
\end{tabular}

* Sexual Behavior 1 consists of slides of young and old couples engaging in mutual masturbation. 
Table 4:14

Interaction Effects for LTK Attitude Rating Scale for Behavior $2^{*}$

\begin{tabular}{lccccc}
\hline Scale & $\mathrm{df}$ & $\begin{array}{c}\text { Sum of } \\
\text { Squares }\end{array}$ & $\begin{array}{c}\text { Mean } \\
\text { Square }\end{array}$ & $\underline{F}$ & $\begin{array}{c}\text { Level of } \\
\text { Significance }\end{array}$ \\
\hline Credible & 2 & 3.206 & 1.603 & .685 & .513 \\
Moral & 2 & 2.051 & 1.025 & .314 & .733 \\
Erotic & 2 & 1.564 & .782 & .257 & .775 \\
Arousing & 2 & 6.419 & 3.210 & .757 & .479 \\
Boring & 2 & .348 & .174 & .085 & .919 \\
Disgusting & 2 & 3.673 & .177 & .102 & .903 \\
Acceptable & 2 & 4.688 & 2.344 & 1.350 & .277 \\
Sexualiy & & & & & .760 \\
Stimulating & 2 & 2.151 & 1.075 & .278 & \\
\hline
\end{tabular}

* Sexual Behavior 2 consists of slides of young and old couples engaged in sexual intercourse. 
Table 4:15

Interaction Effects for LTK Attitude Rating Scale for Behavior $3^{*}$

\begin{tabular}{lccccc}
\hline Scale & df & $\begin{array}{c}\text { Sum of } \\
\text { Squares }\end{array}$ & $\begin{array}{c}\text { Mean } \\
\text { Square }\end{array}$ & $\underline{F}$ & $\begin{array}{c}\text { Level of } \\
\text { Significance }\end{array}$ \\
\hline Credible & 2 & 8.015 & 4.007 & .895 & .421 \\
Moral & 2 & 4.591 & 2.296 & .510 & .506 \\
Erotic & 2 & 11.865 & 5.223 & 1.241 & .319 \\
Arousing & 2 & 19.764 & 9.882 & 2.469 & .104 \\
Boring & 2 & 1.272 & .636 & .177 & .839 \\
Disgusting & 2 & 2.612 & 1.306 & .363 & .699 \\
Acceptable & 2 & 21.340 & 10.670 & 2.191 & .132 \\
Sexually & & & & & .055 \\
Stimulating & 2 & 26.819 & 13.409 & 3.248 & \\
\hline
\end{tabular}

*Sexual Behavior 3 consists of slides of young and old couples engaged in oral-genital sex. 
a 95 percent level of confidence. Significant differences were found between groups on two of the four attitude scales. These included the sexual myths and the masturbation scales. An a posteriort comparison of means indicated that these differences were significant for the implicit and control groups $(\mathrm{p}<.05)$. Statistically non significant differences were found between the implicit and explicit groups ( $p>0.05)$.

Groups of nursing home staff which differed on levels of dogmatism, did not significantly differ in general attitudes toward sex $(p>.05)$. It was also found that groups of nursing home staff which differed on levels of dogmatism, were not significantly different in terms of scores on the knowledge section of the SKAT $(\mathrm{p}>.05)$.

Both treatment groups' sex knowledge scores were found to differ significantly from those of the control group (p<.05). Significance was established at the .01 level of probability. However, no significant interaction" was observed between treatment and dogmatism on either general attitudes toward sex, or knowledge of sexual behavior $(\mathrm{P}>.05)$.

The treatment groups and the control group did not significantly differ in their perceptions of sexual behavior as measured with the LTK Attitude Rating Scale $(\mathrm{p}>.05)$. However, statistically significant differences were demonstrated in perception of sexual behavior, as measured on the LTK Attitude Rating Scale, between groups of nursing home staff differing on levels of dogmatism $(p<.05)$. However, no statistically significant interaction effects were found between treatment and dogmatism on nursing home staff perceptions of sexual behavior as measured on the LTK Attitude Rating Scale ( $p>.05)$. 


\section{Chapter V: Summary, Conclusions, Imp1ications and Recommendations}

This chapter presents a summary of the study, states the conclusions and implications drawn from the results of the study, and makes recommendations for further research.

Summary

The purpose of this study was to determine the effects of sexually implicit and sexually explicit film materials on the perceptions, attitudes, and knowledge of high and low dogmatism nursing home staff engaged in a sex education program.

Recently, a variety of programs have developed to help professionals deal with issues related to human sexuality. Many of these programs incorporate sexually explicit films, small group discussion and values clarification exercises directed at facilitating the development of positive sexual attitudes. While sex educators generally contend that each of these elements is critical to producing changes in attitudes, the results of experimentally controlled studies are mixed in terms of demonstrated sexual attitude change. At the same time, psychologists have suggested that the personality set of closed-minded or dogmatic adults could have an impact on their ability to receive new information. That is, an individual's level of dogmatism may predispose that person to maintain stereotypes and keep certain aspects of experience out of awareness, characteristics which are not conducive to attitude change and 
acquisition of knowledge (Rokeach, 1960). This study was designed to determine whether or not it was the explicit nature of the typical sex education program rather than the sex education program per se which negatively affects the dogmatic adult's attitudes and knowledge.

Prior to exposure to the experimental treatment, Rokeach's (1960) Dogmatism scale was administered to 45 employees of a nursing home in downtown Norfolk, Virginia. These staff were assigned to either a high dogmatism or a low dogmatism group, based upon being either above or below the Dogmatism scale mean respectively. Staff in the high dogmatism and low dogmatism groups were then randomly assigned to three treatments: implicit, explictt, and control. Experimental instruction lasted for two days. Each SAR was 14 hours in duration. In an attempt to control the counselor personality variable, the two heterosexual teams of counselors involved in the study were randomly assigned to groups. One team taught the implicit SAR for the first two-day workshop, while the other team taught the explicit SAR for the second two-day workshop. These workshops were conducted "back to back" to avoid contamination of subjects. Subjects in the experimental and control groups were tested once on two measures. The two measures were the Sex Knowledge and Attitude Test (SKAT) and the LTK Attitude Rating Scale designed to measure if subjects perceived the two treatments differentiy than thecontrol group. Each of these measures was administered to the control group prior to exposure of the implicit and explicit groups to treatment. One week following treatment, the SKAT and the LTK Attitude Rating Scale were administered to the experimental groups. 
Both the implicit and explicit groups were exposed to similar content (films and small group discussions related to a variety of sexual behaviors). Also, both groups were engaged in the same values clarification exercises, which consisted of being confronted with an issue, examining one's personal reactions and sharing these reactions with the group. The organizational pattern for each of the experimental groups was the same. However, since implicit film materials were not available for each of the content areas covered in the explicit group (i,e., female masturbation), the implicit group was exposed to more lecture and values clarification exercises than the explicit group.

The 106-item Sex Knowledge and Attitude Test developed by Lief and Reed (1972) consisted of two parts. The first part was composed of 35 attitude statements to which subjects responded by marking on an answer sheet A, B, C, D, or E (strongly agree, agree, uncertain disagree, strongly disagree). The second part was composed of a 71-item test of knowledge. Responses to this test were made on the answer sheet by marking $(T)$ if the statement was true, and $(F)$ if thestatement was false. The 80-item LTK Attitude Rating Scale, developed by the investigator, was based on the work of LaTorre and Kear (1978). This test was designed to measure differences in perception of sexual behavior as these perceptions related to the age (young or old) of participants engaged in sexual activity. Three behaviors were presented of young sexual participants: mutual masturbation, sexual intercourse, and oral-genital sex. The same three behaviors were presented for the old sexual participants. Subjects were asked to respond to slides of young and old couples engaged in sexual 
behavior by circling $1,2,3,4,5,6$, or 7 . Responses were anchored at 1 (very 1ittle), 4 (moderate), and 7 (very much). Eight scales were presented for each slide. They were: credible, moral, erotic, arousing, boring, disgusting, acceptable, sexually stimulating.

Hoyt reliability estimates for the SKAT fall within the .7I to .80 range. The 80-item LTK Attitude Rating Scale, developed by the Investigator, was estimated to have test-retest reliability of .62 to .94 using the Pearson product moment correlation method.

Analysis of variance of the 32 subjects' scores were run for the SKAT. Signiftcant differences were found between the Implicit, explicit and control groups on the Sexual Myths and the Masturbation scales $(p<.05)$. No significant differences existed between groups on the Heterosexual Relations and the Abortion scales. A two-way analysis of variance (treatment by dogmatism) produced no significant interaction effects $(\underline{p}>.05)$. It was also found that level of dogmatism had no significant effect on sex attitudes or knowledge of sexual behavior ( $\mathrm{p}>05)$. Significant $F$ values for the effects of treatment on the knowledge section of the SKAT were found, however $(p<.01)$.

The data generated from the LTK Attitude Rating Scale was analyzed using analysis of variance. All three treatments were included in this analysis. Results indicate that no signiflcant differences occurred between implicit, explicit, and control group perceptions of the three sexual behaviors presented in the slides $(p>.05)$. Further results indicated that the age (young / old) or sexual participants presented in 
the slides produced no significant between group differences $(p>.05)$. Analysis of variance results.indicate that level of dogmatism produced a significant effect, however $(p<.05)$. While a number of scales approached significance, statistically significant differences were found between high and low dogmatism groups in thetr response to slides of young and old couples engaged in oral-genital sex. A significance level of .0266 was found on the "boring" scale, and .0064 was found on the "disgusting" scale for this behavior. These scores indicate that subjects in the high dogmatism group found slides of couples engaged in oral-genttal sex to be more boring and more disgusting than subjects in the low dogmatism group. Analysis of variance Eurther revealed that no significant differences occurred between high and low dogmatism groups in their perception of sexual behavior when age of sexual participants presented in the slide was the discriminating variable $(\underline{p}>.05)$.

The assumptions underlying one-way and two-way analysis of variance were discussed, and it was determined that these assumptions were met in this study. When significant differences between means were found, post hoc Newman-Keuls comparisons were made in order to determine which adjusted means were significant.

\section{Conclusions}

Conclusions regarding the effects of implicit and explicit sexrelated materials on the perceptions, attitudes and knowledge of high and low dogmatism nursing home staff will be presented below.

Hypothesis 1. The null hypothesis that there would be no difference 
in attitudes towards sex between Implicit, explicit and control groups was rejected for two of the four SKAT scales. This hypothesis was rejected at the .0329 level of confidence for the Sexual Myths scale, and at the .0081 level of confidence for the Masturbation scale, Post hoc comparison of adjusted means indicated that significant differences $(p<.05)$ existed between the implicit and control groups. The fact that the implicit group scored significantly better on the posttest than the control groups is not surprising considering that the control group was not exposed to any sex education training.

More interesting from the standpoint of this study was the fact that there was no significant difference found between the explicit and control groups on the attitude scales of theSKAT. The review of research on attitude change resulting from participation in SAR's presented in Chapter II reports mixed results on the question of whether SAR's have a positive impact on the sexual attitudes of participants.

Studies coneucted by Gordon (1973), Phillips et al. (1975), Hinkley (1976), Monea (1978), Madison and Meadow (1979), and Meston (1980) are in general agreement that SAR participants report increased knowledge about sexual matters and more tolerant sexual attitudes. Garrard et a1. (1972) compared pre- and posttest SKAT scores and found that SAR participants showed a significant change in sexual attitudes tending toward increased Iiberalization. Voss' (1979) research showed significant increase in attitude change regarding tolerance of one's own and other people's sexuality after participation in a SAR program.

While the above studies suggest that SAR's have a positive Impact 
on sexual attitudes, there are many studies reporting no difference between SAR participants and nonparticlpants on tests which measure sexual attitudes.

Golden and Liston (1972) found no changes on the SKAT following a course on human sexuality for second year medical students. Vine's (1974) research found no significant difference on the attitude section of the SKAT between SAR participants and nonparticipants. However, Vines reported that students who had attended the workshop were less anxious than controls when interviewing a "simulated patient" with a sexual complaint.

The findings reported above do not shed much light on the differential effect implicit and explicit film materials have on subjects' scores on a test of sexual attitudes. It is therefore necessary to interpret these findings in light of other reviewed literature.

One cluster of interpretations has to do with anxiety and group process. First, the explicit film materials can be described as much more anxiety provoking than the materials used in the implicit group. While research indicates that a degree of anxiety can facilitate learning and attitude change (Rosenzweig and Pearsall, 1978), the nature of the explicit materials used in this workshop may have produced an overwhelming degree of anxiety which was not facllitative. It is postulated that subjects in the explicit group attained a degree of anxiety so great that it interfered with their ability to examine and reassess their sexual attitudes. The converse of this may have been operating in the implicit group. Here, the anxiety level was facilitative, and subjects were able 
to examine and reassess thelr attitudes thereby leading to changes in sexual attitudes.

A second, related interpretations is that the use of explicit materfals with this particular population does not lead to destred attitude change. Much of the research which reports positive attitude changes in SAR participants is conducted on populations which are dissimilar to the one used in the present study. These results are based on populations which are composed of young, white, middle-class professionals, graduate students, or medical students (Meston, 1979; Voss, 1979; and Garrard et al., 1972). In this study, approximately 50 percent of the participants were black and few had achieved an educational level beyond the one-year requirement for licensed practical nursing.

While race alone has not been found to be a significant factor in determining an individual's degree of conservatism or liberalism in rem gard to sexual attitudes (Reiss, 1974; Delcampo, et a1., 1976), an Individual's age and level. of education have been found to be significant (Katchadourian and Lunde, 1972). The explicit film materials may cause a "backlash" effect with older, less educated and more conservative groups. That is, instead of stimulating attitude change, the film materials may have provoked subjects to retain their attachment to sexually conservative attitudes with an increased intensity.

A third interpretations of the differences found in attitudes between the Implicit and explicit groups has to do with group process. In the expliclt SAR, two factors may have had a negative Impact on the group processing which occurred. The presence of the nursing home administrator 
seemed to inhibit discussions of sexual behavior and expressions of feelIngs evoked by the films and exercises. The administrator stated definttively that he was not going to discuss personal feelings or experiences with the people who worked for him. Staff members reclprocated by stating that there would be a limlt to the degree of sharing they were willing to do as well.

A second Inctdent occurred which also had an Impact on group processing. One member of the group became quite distressed when explicit films of homosexual behavior were shown. Expressing strong feelings that this behavior was imoral and sinful, she proceeded to quote the Bible and read from the one she carried in her purse. Although the SAR trainers were quite capable of diffusing the emotlonal reactivity of this individual, there seemed to be a wartness in group members toward expressing attitudes which were too liberal.

A fourth interpretation has to do with differences in group leadership. While the four counselors who participated in this study frequently work together, each SAR was conducted by a different team of leaders. This fact is important in interpreting statistical differences between the implictt and explicit groups. Different leadership was a practical necessity, but it is not without its theoretical implications. Ideally, the same leaders should have conducted both groups. However, because of the time involved, this was not feastble.

Hypothesis 2. The null hypothesis that 1evel of dogmatiom produced no signiflcant difference in general attltudes towards sex falled to be rejected $(p>.05)$. These findings run counter to the theory discussed in 
Chapter II. Rokeach (1960) and Kilpatrick, et al. (1968) found significant correlations between rlgid, closed-minded Individuals--characteristics obviously not conductve to attitude change and the acquisition of new knowledge--and highly dogmatic individuals. In another study, it was found that a correlation existed between level of dogmatism and tolerance of what may be termed "deviant groups." Hood (1973) found that high dogmatic individuals held more stereotypic attitudes of homosexuals, mentally $i 11$ and suicidal persons than did the low dogmatic group. The results of all these studies suggest that ligh dogmatic individuals would not express as many positive attitudes about sex on the SKAT as would low dogmatic individuals.

The results of the present study did not confirm this hypothesis. Perhaps the investigator may have misinterpreted the results of these correlational studies. The fact that high dogmatism and closed-mindedness correlate highly together does not necessarily imply that highly dogmatic individuals will be closed-minded or display other characteristics which might inhibit attitude change. Indeed, some research shows that high dogmatic Individuals may be more susceptable to changing their attitudes than low dogmatic individuals. Norris (1965) and Chronkhite and Goetz (1971) have suggested that high dogmatic individuals are more persuastble than low dogmatic individuals. In an experimental study, Gold et al. (1973) found that high dogmatic individuals exposed to counter-attitudinal. Information in a group discussion, changed their attitude toward the group position.

Another explanation may be that the present study's high dogmatism 
group mean of 179.19 , while signiflcantly different from the low dogmatism group mean of 140.00 , does not indicate that high dogmatism group subjects were truly highly dogmatic. Rokeach (1960) in his studies, does not clearly define ranges of scores for the Dogmatism scale. Dogmatism scale scores appear to be a relative measure which differ from group to group. Consequently, it is difficult to examine high and low dogmatism responses in terms of a score that is generally believed to be reflective of high dogmatic or low dogmatic brilef systems.

Hypothesis 3 . The null hypothes is that there were no differences between groups on the knowledge section of the SKAT was rejected at the .01 level of significance. Newman-Keuls post hoc comparisons of adjusted treatment means indicated that both experimental groups performed significantly better than the control group $(p<.05)$. No significant difference was found, however, between the implicit and explicit treatments. These findings are consistent with those discussed in Chapter II where the research on evaluation of SAR's was reviewed. This research suggested strongly that group undergoing SAR training performed significantly better than control groups on tests of sexual knowledge (Vines, 1974; Garrard, et al., 1972; and Hong, et al., 1979). Inspection of mean scores in Table 4:1 reveals that the implicit group's mean score on knowledge was approximately 42, the explicit group's mean score was approximately 44, and the control group's mean score was approximately 30 . A score of 39 to 50 indicates that subjects performed similarly to RN's who had graduated from a two-year program. A score of 34 and below indicates that subjects performed similarly to nurses who had completed less than one 
year of training (SKAT Technical Manual, 1973).

Hypothesis 4 . The null hypothesis that there would be no difference in general sex knowledge between groups differing on levels of dogmatism failed to be rejected. These findings are inconsistent with the theory discussed in Chapter II. Studies by Rokeach (1960) and Kilpatrick, et a1. (1968) suggest that rigid, closed-minded individuals (high dogmatics) would be less receptive to new learning than flexible, open-minded individuals (low dogmatics).

There are two interpretations of the results cited above. The first is as in the discussion of $\mathrm{Ho}^{2}$, that although a high degree of dogmatism is correlated with closed-mindedness, it does not necessarily imply that highly dogmatic individuals will be closed-minded or display other characteristics which might inhibit acquisition of knowledge. In fact, Rokeach's (1960) research indicates that high dogmatics are very susceptible to learning when an individual who is in a position of authority is instructing the group.

A second explanation is that although the resalts were nonsignificant, the low dogmatism group in effect performed better than the high dogmatism group. For the implicit group, low dogmatism subjects received a mean score of 45.18 compared to 38.60 for high dogmatism subjects. The control group performed similarly. Low dogmatism subjects in the control group received a mean score of 33.21 compared to 26.55 for high dogmatism subjects. For the explicit group the reverse was true; however, the spread of scores was very small. Low dogmatism subjects received a mean score of 43.67 compared to 45.18 for the high dogmatism group. Nevertheless, with 
an $\underline{F}$ value equal to .630 , it is concluded that the effect of dogmatism on knowledge of sexual behavior was insignificant.

Hypothesis 5. The null hypothesis that there were interaction effects between treatment and dogmatism on the attitude scales of the SKAT failed to be rejected. Two-way analysis of variange resulted in $F$ values for all four attitude scales which were statistically nonsignificant. These results are reported in Table 4:5.

Hypothesis 6. The null hypothesis that there were interaction effects between treatment and dogmatism on the knowledge section of the SKAT failed to be rejected. With an $\underline{F}$ value of .601 it can be concluded that the interaction of treatment and dogmatism on SKAT knowledge scores was insignificant.

Hypothesis 7 . The null hypothesis that there were between group differences in perception of sexual behavior as related to age failed to be rejected. Analysis of variance of implicit, explicit, and control group perceptions of sexual behaviors resulted in $\underline{F}$ values which were nonsignificant. These results are summarized in Tables $4: 6,4: 7$, and 4:8.

The findings cited above were unanticipated considering the theory discussed in Chapters I and II. Studies conducted by Gold and Kagan (1959) and Butler and Lewis (1976) suggest that attitudes and perceptions regarding sexual expression among the elderly are generally negative. In another study, LaTorre and Kear (1977) found that nursing home staff not only have negative feelings about sexual expression in the elderly, but were in general more negative about sex than a control group composed of community college students. One would expect, therefore, that the 
control group would perceive sexual behavior in the elderly more negatively than the treatment group.

One explanation for the absence of these results lies with the criterion instrument used to measure perceptions of sexual behavior. The LTK Attitude Rating Scale is a Lykert-type scale. Couch and Keniston (1960) state that one of the problems associated with this kind of scale is that there is ". . a general tendency to agree or disagree with questionnaire items, regardless of their content" (p.163).

A second related explanation has to do with the transparency of the instrument. Since subjects were aware of the nature of the research, and asked to respond to slides of young and old couples engaged in sexual activity, it may have appeared obvious that a comparison was to be made. Subjects, therefore, may have reported what they felt were "desired effects" by the investigator.

A third explanation for the lack of differences in perception of sexual behavior by treatment and control groups may be due to a tendency to report attitudes which are more liberal than would be demonstrated behaviorally. Wasow and Loeb (1977) report that while the nursing home staff they studied verbally approved of freedom of sexual expression in the elderly, Iittle support for such activities was found in their faci1ity.

Hypothesis 8. The null hypothesis that there would be no difference in perception of sexual behavior between groups of nursing home staff differing on levels of dogmatism was rejected. While insiginificant differences were found between high and low dogmatism groups in response to 
Behavior 2 (sexual intercourse), results which approached significance were noted in response to Behavior 1 (mutual masturbation). A significance leve1 of .0693 was reported for the "disgusting" scale. These findings indicate that subjects in the high dogmatism group were more likely to find slides of old and young couples engaged in mutual masturbation to be disgusting than subjects in the low dogmatism group (see Tables $4: 10$ and $4: 11$ ).

Significant results were found when high and low dogmatism groups were asked to respond to slides of young and old couples engaging in oral-genital sex. On the "boring" scale a .0266 level of probability was attained. These results indicate that subjects in the high dogmatism group found slides of old and young couples engaged in oral-genital sex more boring than subjects in the low dogmatism group.

Similar results were found on the "disgusting" scale. A significance level of .0064 indicates that high dogmatism subjects were much more likely to respond negatively to slides of couples engaged in oralgenital sex than were subjects in the low dogmatism group (see Table 4:12).

These findings are in agreement with the theory discussed in Chapter II. Kilpatrick, et al. (1968) found that high dogmatism subjects were more conservative in their sexual attitudes than were low dogmatism subjects. Other research by Hood (1973) suggests that high dogmatism subjects hold attitudes which are more negative and stereotypic than low dogmatic subjects.

An interesting aspect of the findings reported above is that while no significant differences in attitudes were found between high and low 
dogmatism groups on the SKAT, significant between group differences in perception of sexual behavior were found on the LTK Attitude Rating Scale. Two possible explanations are offered to account for this discrepancy. One is that the LTK Attitude Rating Scale was a more "sensitive" instrument than the SKAT in terms of differentiating groups on level of dogmatism. Another explanation is that the slides used for the LTK Attitude Rating Scale were more provocative than the written statements to which subjects responded on the SKAT. Consequently, responses on the LTK Attitude Rating Scale reflected a greater level of emotional intensity than responses made on the SKAT.

Hypothesis 9. The nul1 hypothesis that there would be no interaction between treatment and dogmatism on staff perceptions of sexual behavior failed to be rejected. Using two-way analysis of variance (treatment by dogmatism), tests for interaction of main effects were found to be statistically nonsignificant for all eight of the LTK Attitude Rating Sacles. Interaction effects were found to be insignificant for sexual behaviors I (mutual masturbation), 2 (sexual intercourse), and 3 (oral-genital sex). Age of sexual participants presented in the slides also produced insignificant effects (please refer to Tables 4:13, $4: 14$, and $4: 15$ ).

In this study the following null hypotheses were tested:

$\mathrm{Ho}^{1}$ : There is no significant difference in general attitudes towards sex, as measured on the Sex knowledge and Attitude Test (SKAT), between implicit, explicit, and control groups (rejected).

$\mathrm{Ho}^{2}$ : There is not significant difference in general attitudes towards sex, as measured on the SKAT, among groups 
of nursing home staff differing on levels of dogmatism (not rejected).

$\mathrm{Ho}^{3}$ : There is no significant difference in general sex knowledge, as measured on the SKAT, between implicit, explicit and control groups (rejected).

$\mathrm{Ho}^{4}$ : There is no significant difference in general sex knowledge, as measured on the SKAT, among groups of nursing home staff differing on levels of dogmatism (not rejected).

$H^{5}$ : There is no significant interaction between treatment and dogmatism on nursing home staff attitudes toward sex (not rejected).

Ho ${ }^{6}$ : There is no significant interaction between treatment and dogmatism on nursing home staff attitudes towards sex (not rejected).

$\mathrm{Ho}^{7}$ : There is no significant difference in the perception of sexual behavior as measured with the LTK Attitude Rating Scale, between implicit, explicit and control groups (not rejected).

$\mathrm{Ho}^{8}$ : There is no significant difference in the perception of sexual behavior as measured with the LTK Attitude Rating Scale, of groups of nursing home staff differing on levels of dogmatism (rejected).

$H^{9}$ : There is no significant interaction between treatment and dogmatism on nursing home staff perceptions of sexual behavior, as measured on the LTK Attitude Rating Scale (not rejected).

The major findings of the study are:

1. Nursing home staff can change sexual attitudes as a result of participation in a SAR workshop.

2. Implicit and explicit film materials differentially affected staff attitudes towards sexual behavior.

3. High dogmatism staff score as well as low dogmatism staff within treatments on the postexperimental test of sexual attitudes and knowledge. 
4. Sexual Attitude Reassessment workshops can improve nursing home staff knowledge of sexual behavior.

5. There was no significant interaction between treatment and dogmatism on staff postexperimental test scores measuring sexual attitudes and knowledge.

6. No differences were found in perception of sexual behavior between staff exposed to implicit, explicit, and control group conditions.

7. Staff in the high dogmatism group perceived sexual behavior more negatively than staff in the low dogmatism group.

8. There was no significant interaction between treatment and dogmatism on staff perceptions of sexual behavior. Implications

One major implication suggested by the results of the study is that film materials used for SAR workshops should be selected carefully. That is, care should be taken to assess the group for whom the materials are intended, and to monitor the effect of these film materials on that given group. Specifically, this study demonstrates that changes in attitudes and knowledge can be produced with the use of sexually implicit film materials. These results are contrary to what many sex educators contend is essential to the sexual attitude reassessment process. It has been found that the sexually explicit film materials are not necessary to produce changes in attitudes and knowledge of sexual behavior. In fact, the group to whom sexually explicit film materials were shown performed no better than the control group on measures of attitudes toward sex. 
Another Implication related to the one stated above is that the findings of psychologists and counselors in the area of sex education research are extremely relevant to educators interested in effective ways of increasing tolerance and knowledge of sexual behavior. In the present study, for example, staff who were exposed to the sexually implicit film materials tended to have more positive attitudes toward sexual behavior than staff who were exposed to sexually explicit film materials. The application of research methods to Sexual Attitude Reassessment programs has only just begun.

\section{Recommendations}

Recommendations for further research are as follows:

1. This study obviously needs to be replicated in setting where both higher and lower levels of education are represented. In addition, the number of experimental treatments needs to be increased in order that the research can be cross-validated.

2. Since no dogmatism or interaction effects were found in the study, it would be interesting to block staff on other salient variables like I.Q., internalizers-externalizers, and anxiety levels, in order to determine if implicit and explicit treatments differentially affect certain "types" of staff.

3. As brought out in the discussion of postexperimental tests of perceptions of sexual behavior, other kinds of attitude measures need to be developed that are not susceptable to "response sets" and tendencies to report the "desired" response.

4. There is also a need for research in this area that utilizes 
observation schemes designed to get at the behavior and attitudes of staff before, during and after participation in the SAR experimental program. 5. A1so, there is a need for developing more and different types of implicit (and explicit) SAR programs which staff can engage in under experimental conditions. For example, can a variety of film materials of differing Ievels of explicitness be developed that would allow an individual to challenge his sexual attitudes, while not provoking undue anxiety, and encourage him to translate expressed attitudes Into observable behavior? 
Appendix A

Film Materials

Checklist for Film Materials 
AIl but three of the films listed below appear on the 1981 catalog of the Multi Media Resource Center, 1525 Franklin Street, San Francisco, California 94109. The Multi Media Resource Center is the sole distributor of matertals developed by the National Sex and Drug Forum, 330 Ellis Street, San Francisco, California 94102. Films are 1isted in alphabetical order with brief descriptions included.

A Gay View/Male Filmmaker: Laird Sutton/National Sex Forum. Presents a personal discussion of three gay males. Feelings about men, women and children are explored. Issues related to labeling, intimacy and defining onself as gay are also explored.

A Ripple in Time Filmmaker: Laird Sutton/National Sex Forum. Presents an elderly couple engaging in active sexual expression.

A Rose by Any Other Name Filmmaker: Judith Keller. Demonstrates that closeness and intimacy are important to the elderly as they are to the young.

Communication Slides/Genesis Cartoonist: Dan O'Neill. Graphically represents the ways in which we talk to each other. Sexual taboos which apply to both males and females are presented in a humorous way.

Erogeny Filmmaker: Laird Sutton/National Sex Forum. This is a short film which shows two bodies meeting a touching. A poem is read by the man which describes the topography of the female's body.

Erogenist Filmmaker: Laird Sutton/National Sex Forum. This film presents a man giving a woman a full body massage.

Exhibition: Male Genitals Filmmaker: National Sex Forum. A slide presentation which represents a variety of genitalia in different modes: flaccid, urinating, erect, ejaculating, and multiracial.

Feeling Good Filmmaker: Laird Sutton/National Sex Forum. Presents a number of men sharing their boyhood experiences and feelings today about self-sexuality. Explicit masturbation patterns are included.

Female Genitalia/Grand Opening Filmmaker: Tee Corinne. Presents slides of the genitalia of 25 different women. These slides 
Gay Women Speak- Filmmaker: Laird Sutton/National Sex Forum. An intimate discussion among three professional women active in the gay community. They share anecdotes of childhood, careers and of their lesbian experiences.

Going Down to Bimini-Filmmaker: Laird Sutton/National Sex Forum. Represents a young couple's fulfillment of an erotic fantasy. Lovemaking takes place on a deserted island in the Bahamas.

Handvoice- Filmmaker: Laird Sutton/National Sex Forum. Is a film depicting a woman in her $30^{\prime} s$ engaging in manual stimulation to orgasm.

Just be Patient- Filmmaker: Korzeniowsky Films/Focus International, 1776 Broadway, New York, NY 10019. Discusses disability, body image and various medical problems which impact upon sexuality.

Kinsey Three-

Filmmaker: National Sex Forum. A film depicting the true story of one bisexual. man. He discusses his bisexual philosophy, and engages in explicit sexual. activity with both a man and a woman.

Love Toad-

Filmmaker: Greg von Buchau. A humorous film depicting the sexual activity of two beanbag frogs.

Nik and Jon-

Filmmaker: Ed Dundas. Presents the experiences of two homosexuals meeting at a dinner party. They discuss their lifestyles, feelings and experiences. Explicit sexual scenes including oral and anal expression are presented.

Orange- Filmmaker: Karen Johnston. A film showing that eating an orange can be a sensuous experience.

Margo- Filmmaker: Laird Sutton/National Sex Forum. The film depicts a woman engaged in manual stimulation of her breasts and genitals.

Massage- Filmmaker: Gordon Inkeles. Depicts the art of massage, and some of the techniques which are important.

Minnesota Soap Series- Filmmaker: Laird Sutton/National Sex Forum. Demonstrates some good and bad ways of dealing with questions and concerns about sexuality. 
Reflections-

Rich and Judy-

Riverbody-
Filmmaker: Laird Sutton/National Sex Forum. A film about group sex. A group of eight, including couples and single persons, discuss their sexual experiences with each other. Explicit scenes of their group sexual activities are included.

Filmmaker: Laird Sutton/National Sex Forum. A film shwoing a couple who has been married several years enjoying oral sex and intercourse.

Filmnaker: Anne Severson and Shelby Kennedy. Eighty-seven male and female bodies of different heights and shapes, ages and races, are shown in continuous dissolve.

Sexuality and Communication- Filmmaker: Ortho Pharmaceutical Co., Canada Ltd., 1971. A doctor and his wife use role playing to explore sexuality and communication as they relate to the doctor/patient relationship and the husband/wife relationship.

Soma Touch-

Touching-

We Are Ourselves-

World Erotica-
Filmmaker: Laird Sutton/National Sex Forum. Shows one man's masturbatory experience.

Filmmaker: Laird Sutton/National Sex Forum. This is a film about the sex life of a man suffering from a C-6 spinal cord injury. He and his partner are shown to have a warm and satisfying relationship with oral sex as the primary means of stimulation.

Filmmaker: Ann Hershey. A film depicting a lesbian sexual relationship. The film includes explicit sexual activity, as well as a discussion of their individual evolutions to lesbianism.

F1lmmaker: National Sex Forum. A collection of erotic art drawn from around the world is presented. A variety of media are included. 


\section{Checklist for Film Materials}

Please rate this film on the following dimensions:

1. Does this film include verbal descriptions of sexual activity?

$$
\text { Yes__ No }
$$

2. Does this film include nudity of "live" actors?

$$
\text { Yes _______ No }
$$

3. Does this film include visual representations of sexual activity such as masturbation, sexual intercourse, homosexual activity or oral-genital sex?

Yes___ No 
Appendix B

Observation Schemes 


\section{Observation Scheme}

Please indicate by marking yes or no if the following are included in the Explicit SAR Workshop.

1. Didactic instruction:
Yes
No

2. Experiential exercises:

Yes

No

3. Small group discussion:

Yes

No

4. Sexually explicit film material:

Yes

No 


\section{Observation Scheme}

Please indicate by marking yes or no if the following are included in Implicit SAR Workshop.

1. Didactic instruction:

Yes: No

2. Experiential exercises:

Yes__ No

3. Small group discussion:

Yes

No

4. Sexually explicit film materials:

Yes___ No ______ 
Appendix C

Registration Form

and

Forms of Agreement 
Sexual Attitude Reassessment Workshop

\section{Purpose:}

This!workshop is designed to help health professionals to explore and reassess their personal attitudes towards human sexuality. The experiential nature of the program will evoke feelings similar to those evoked in the work setting when caring for patients with sexual problems or questions. Didactic sessions and small group discussions will also be utilized.

Objectives:

After the Sexual Attitude Reassessment Workshop (SAR), the participant should be able to:

1. Give accurate information about a whole range of sexual activity including heterosexuality, homosexuality, masturbation, sexuality of disabled persons, exuality and aging, etc. activity.

2. Explore and state their own attitudes regarding human sexual

3. Work more effectively with the feelings and attitudes of others regarding sexual activity.

4. Clarify and state their own personal values and attitudes regarding human sexual activity.

What to Bring:

We ask that you bring a large floor pillow or anything you might be comfortable sitting on during the program. Since participants will be sitting: on the floor, comfortable and casual clothing is advised, i.e., slacks, jeans, etc. You will be expected to provide your own lunch during the workshop. A sack lunch may be advisable since the lunch break will be rather short.

Workshop Leaders:

The SAR workshop will be facilitated by Allen B. Craven, D. Min., Coordinator of the Marriage, Family and Sexual Unit at Ghent Psychological Services; Stephanie Lloyd, R. N., B. S. N., Coordinator of Community Relations, Alcoholism Recovery Center of Virginia; Llew Roberts, R. N., B. S. N., Nurse Educator for the Norfolk Family Planning Project for the Norfolk Health Department; and Don Self, Ph. D., Director of Human Values in Medicine Program and Associate Professor in the Department of Family Medicine at Eastern Virginia Medical School. 
These four have worked together frequently in the past to present this program to various groups of health professionals in Tidewater.

\section{Cost:}

There will be no charge for the workshop. However, participants will be asked to complete several. forms:designed to evaluate the effectiveness of the program. The evaluation process will require approximately one and one-half to two hours of your time. Your cooperation in this project is very much appreciated.

Anne Aja, M. S., ABD

Program Evaluator

\section{Registration:}

Registration is linited to 60 participants. After all have been registered, participants will be assigned to training groups according to a lottery system. The first SAR workshop is scheduled for Apri1 22 and 23 . The second SAR workshop is scheduled for April. 26 and 27. Those who do not receive training in either one of these sessions, will be trained at a later date.

\section{Contact Person:}

Elizabeth Chamberlain, R. N.

Ms. Chamberlain has also offered her assistance in arranging work scheduled around the workshop dates.

Workshop will. be held at the Crittenden Home, 52nd Street and Colley Avenue, Norfolk, Virginia, from approximately 9:00 a.m. to 4:30 p.m.

NAME

STREET ADDRESS

CITY STATE

TELEPHONE 


\section{Consent Form}

Research Topic: Sexuality and the Aged

Researcher: Anne $\Lambda \mathrm{ja}$

College of William and Mary

Willilamsburg, Virtinta

I hereby agree to participate in research almed at evaluating the effectiveness of a Human Sexuality Workshop. I understand that this workshop is designed to assist health professionals in thetr dealings with patients who express sexual problems or concerns. I further understand that the purpose of this workshop is to help health professionals explore and reassess their personal attitudes toward human sexuality.

I agree to participate in the full two-day training program and realize that some of the materials used may be sexually explictt in nature. While I may refuse to particlpate in viewing certain sexually explicit materials, I agree to take part in the small group discussions which follow. I understand that all information acquired in this research will remain anonymous, and that I have the right to refuse participation in this research without penalty.

Signed

Date 


\section{Statement of Confidentiality}

I am aware that this workshop is designed to encourage exploration and reassessment of personal attitudes toward sexuality. I acknowledge the right to discuss my own feelings and concerns about various forms of sexual behavior. However, I agree to keep those feelings and concerns expressed by others in the workshop in complete confidence.

Signed

Date 


\section{Statement of Non-Disclosure}

I agree not to disclose the content of this workshop to anyone at the Lafayette Villa Health Care Facility.

Signed

Date 
Appendix D

Demographic Data 


\section{Demographic Data}

I. We strive to maintain complete confidentiality. Some identifying number is necessary for the processing of this material. If there is some concern about using your Social Security number, make up your own unique number and retain the key.

1. Identification number

II. Background information. Please complete the following by circling the appropriate response. This information will be treated as strictly confidential. It will be used for research purposes only.

2. Age:
A. 17 or under
F. 26 to 30
B. 18 to 19
G. 31 to 35
C. 20 to 21
H. 36 to 40
D. 22 to 23
I. 41 to 45
E. 24 to 25
J. 46 or more

3. Sex:
A. male
B. female

4. Race:
A. white
B. non-white

5. Marital Status:
A. single
B. married
c. divorced

6. If you have been or are married, age at first marriage:
A. 17 or under
D. 27 to 35
B. 18 to 22
E. 36 or more
C. 23 to 26

7. If you have been or are married, how long?
A. under 1 year
D. 11 to 15 years
B. 1 to 5 years
E. 16 to 20 years
C. 6 to 10 years
F. 21 or more years

8. Which of the following alternatives best describes your present education?

A. Non-high school graduate

B. High school graduate 
8. (continued)

C. High school graduate plus technical school

D. Nursing degree, \# of years in training

E. Some college

F. College graduate

G. Graduate training

9. Which of the following alternatives best describes your present occupation?
A. Nurse's aide
D. Activities director
B. Licensed practical nurse
E. Administrator
C. Registered nurse
F. Other

10. Religion:
A. Catholic
C. Jewish
B. Protestant
D. Other 
Appendix $E$

Measurement Instruments 


\section{The Dogmatism Scale}

Social Security or other Identification Number

The following is a study of what the general public thinks and feels about a number of important social and personal questions. The best answer to each statement below is your personal opinion. We have tried to cover many different and opposing points of view; you may find yourself agreeing strongly with some of the statements, disagreeing just as strongly with others, and perhaps uncertain about others; whether you agree or disagree with any statement, you can be sure that many people feel the same as you do.

Mark each statement in the left margin according to how much you agree or disagree with it. Please mark every one. Write $+1,+2,+3,-1,-2$, -3 , depending on how you feel in each case.

+1 : I AGREE A LITTLE

+2: I AGREE ON THE WHOLE

+3: I AGREE VERY MUCH

\section{-1: I DISAGREE A LITTLE}

-2: I DISAGREE ON THE WHOLE

-3: I DISAGREE VERY MUCH

1. The United States and Russia have just about nothing in common.

2. The highest form of fovernment is a democracy and the highest form of democracy is a government run by those who are most intelligent.

3. Even though freedom of speech for all groups is a worthwhile goal, it is unfortunately necessary to restrict the freedom of certain political groups.

4. It is only natural that a person would have a much better acquaintance with ideas he believes in than with ideas he opposes.

5. Man on his own is a helpless and miserable creature.

6. Fundamentally, the world we live in is a pretty lonesome place.

7. Most people just don't give a "damn" for others.

8. I'd like it if I could find someone who would tell me how to solve my personal problems.

9. It is only natural for a person to be rather fearful of the future.

10. There is so much to be done and so little time to do it in. 
11. Once I get wound up in a heated discussion I just can't stop.

12. In a discussion $I$ often find it necessary to repeat myself several times to make sure I an being understood.

13. In a heated discussion I generally become so oabsorbed in what I am going to say that I forget to listen to what the others are saying.

14. It is better to be a dead hero than to be a live coward.

15. While I don't like to admit this even to myself, my secret ambition is to become a great man, like Eistein, or Beethoven or Shakespeare.

16. The main thing in life is for a person to want to do something important.

17. If given the chance I would do something of great benefit to the world.

18. In the history of mankind there have probably been just a handful of really great thinkers.

19. There are a number of people I have come to hate because of the things they stand for.

20. A man who does not believe in some great cause has not really lived.

21. It is only when a person devotes himself to an ideal or cause that life becomes meaningful.

22. Of all the different philosophies which exist in this world there is probably only one which is correct.

23. A person who gets enthusiastic about too many causes is likely to be a pretty "wishy-washy" sort of person.

24. To compromise with our political opponents is dangerous because it usually leads to the betrayal of our own side.

25. When it comes to differences of opinion in religion we must be careful not to compromise with those who believe differentialy from the way we do.

26. In times like these, a person must be pretty selfish if he considers primarily his own happiness.

27. The worst crime a person could commit is to attack publicly the people who believe in the same thing he does. 
28. In times Iike these it is often necessary to be more on guard against ideas put out by people or groups in one's own camp than by those in the opposing camp.

29. A group which tolerates too muchidifferences of opinion among its own members cannot exist for long.

30. There are two kinds of people in this world: those who are for the truth and those who are against the truth.

31. My blood boils whenever a person stubbornly refuses to admit he's wrong.

32. A person who thinks primarily of his own happiness if beneath contempt.

33. Most of the ideas which get printed nowadays aren't worth the paper they are printed on.

34. In this c-mplicated world of ours the only way we can know what's going on is to rely on leaders or experts who can be trusted.

35. It is often desirable to reserve judgment about what's going on until one has had a chance to hear the opinions of those one respects.

36. In the long run the best way to live is to pick friends and associates whose tastes and beliefs are the same as one's own.

37. The present is all too often full of unhappiness. It is only the future that counts.

38. If a man is to accomplish his mission in life it is sometimes necessary to gamble "all or nothing at all."

39. Unfortunately, a good many people with whom I have discussed important social and moral problems don't really understand what's going on.

40. Most people just don't know what's good for them. 
LTK Attitude Rating Scale

Directions: The folloiwng rating scale is to be completed while viewing slides of individuals and couples engaging in sexual activity. Please circle the numbers which most accurately describe your responses to each of the slides.

a. Credible:

(very Iittle)

2

3

4
(moderate)

5

$6 \quad \begin{aligned} & 7 \\ & \text { (very much) }\end{aligned}$

b. Moral:

(very little)

2

$3 \quad \begin{gathered}4 \\ \text { (moderate) }\end{gathered}$

5

6

7

(very much)

c. Erotic:

(very little)

2

3. $\begin{gathered}4 \\ \text { (moderate) }\end{gathered}$

5

$6 \quad \begin{gathered}7 \\ \text { (very much) }\end{gathered}$

d. Arousing:

1
(very little)

2

34

(moderate)

5

6

7

(very much)

e. Boring:

(very little)

2

4
(moderate)

5

$6 \quad 7$

Disgusting:

(very little)

2

3

4
(moderate)

5

6

(very much)

g. Acceptable:

(very 1ittle)

2

(moderate)

5

6 (very much)

h. Sexually stimulating:

(very little)

2

3

4
(moderate)

5

$6 \quad \begin{aligned} & 7 \\ & \text { (very much) }\end{aligned}$ 
PLEASE NOTE:

Copyrighted materials in this document have not been filmed at the request of the author. They are available for consultation, however, in the author's university library.

These consist of pages:

147 Sex Knowledge and Attitude Test

\section{University} Microfilms International

300 N Zeeb Rd., Ann Arbor, MI 48106 (313) 761.4700 
Appendix F

Workshop Handouts 
Don't let anyone tell you that when you grow older you lose all interest in sexual activity. Sexual drive may decrease but it does not go away unless you want it to. Even then it can be recaptured.

Sexuality is a concern of all ages, but the many myths about sex can be confusing. The elderly often find themselves in settings that offer little or no encouragement to express their sexuality. Sometimes they are embarrassed to admit to their children or friends that they have sexual interests "at their age." One of the problems in the area of sexuality and aging is that older individuals themselves accept the myths of a "sexless old age." They were raised in a Puritan era that sald sex was for making bables. People, of course, often discovered for themselves that sex was a1so pleasurable! But there was a lot of stress and fear attached to sex: fear of pregnancy, V.D., shame, guilt, and sin. For women, especially, the anxiety about sex was often very high.

Intercourse is not the only form of sexual activity. Touching, holding, genital play, oral sex, as well as intercourse, are all healthy and enjoyable kinds of sex, for those that like them. The need for close, warm bodily and emotional contact is a part of every human being, and does not have to diminish with age.

Sex After Sixty: R. N. Butler and M. D. Lewis. Harper and Row, 1976. The First of Autumn: P. A. Dickensen. Sterling Publishing, 1977. 


\section{DISABLED}

The disabled are people, and people are sexual. Much of our sense of personhood comes from our ability to play a sexual role. The disabled share with the rest of us the misfortune of living in a society that has traditionally avoided and censured sex, but this hits the disabled harder than others. They have been subjected, like the old, to castrating black magic: "Of course they wouldn't want to talk about $1 t$; they'd be embarrassed." "It's rather unsuitable; doesn't do to ralse false hopes." Generations of disabled have been hocussed out of sexual personhood by this sort of hogwash, other'people's embarrassment, the patterns of institutions, and society's tendency to suppress any sex that is suppressible.

Virtually nobody is too disabled to derive some satisfaction and personal reinforcement from sex--with a partner if possible, alone if necessary. When a disabled person is unable to enjoy sex, the greatest obstacle to enjoyment usually isn't the difficulty or Impossibility of making particular movements, but the social convention that sex consists of putting the penis in the vagina and that all the rest of the rich range of human and mammalian sexual responses-oral, manual, and skin stimulation-are abnormal. Human sex is widely versatile and not linited to the genitalia.

The Sensuous Wheeler: Barry J. Rabin, Multi Media Resource Center, 1980.

Sexual Dptions for Paraplegics and Quadriplegics: T. D. Mooney, T. M. Cole. R. A. Chilgren. Iittle Brown, 1915 . 
MALE SEXUALITY: MYTHS \& SOCIETAL MESSAGES

DO: Perform/get it up/achieve/keep it up/initiate/work/always be turned on/be young/be a sex machine/protect/measure up/control/be responsible/ fuck only young attractive women/know what to do/give women orgams/ have a big cock/succeedscore/rationalize/hide your feelings of fear, inadequacy, rejection or helplessness/keep a stiff upper lip.

DON'T:quit/fall/enjoy yourself/play/feel/be vulnerable, weak, receptive, or gay/take strokes/be honest about your real sexual needs, especially with women/be passlve/let go/take responsibility for birth control.

\section{FEMALE SEXUALITY: EARLY MESSAGES}

DON'T: touch "down there"/talk about sex/learn about sex/read about sex/ think about or experiment with sex/get turned on/get out of control/ let your partner get out of control/give in to sexual desires/be available/look at your genitals/let anyone else look at your genitals/ kiss on the first date/feel sexual/get a "bad" reputation/be too forward/play doctor.

DO: Be attracttive, obedient, passive/maintain a "good reputation"/wajt for the male to initiate/use sex for non-sexual reasons/expect the man to know all about sex/refuse a man when he asks you to be sexual.

BECOME A POSITIVE SEXUAL PERSON, WE NEED SELF-KNOWLEDGE, FACTS, OPTIONS, TECHNIQUES, HONESTY.

\section{EXAMPLE: SELF-KNOWLEDGE}

1. Learn as much about your own body as you can. Learn how to keep it healthy.

2. Read, explore, examine your feelings.

3. Begin talking with other people about what being sexual is to them. Find out how they feel.

4. Examine your genitals with a mirror. Get to know them, they are yours and they are BEAUTIFUL!

5. Learn about your own sexual responses, fantasies, turn ons, preferences.

6. Have a frank discussion with a partner about who initiates sex.

7. State your pleasures positively.

8. Devote time alone to taking care of yourself.

9. Try new things.

10. Remember, you can control your sexual definition about yourself. You can change your opinion, change your mind, change your feelings, do whatever you like. 
11. Determine your sexual needs and how you can best meet them. 12. Read about sex; finds the words to express yourself. 


\section{HOMOSEXUALITY}

It may be said that the human sexual response can be stimulated by the most superficial opportunities, or it may await the most profound and personally meaningful associations of which the individual is capable. In terms of anything basic in the organism, the physical and psychological differences in kinds of sexual behavior seem strictly trivial. People simply respond sexually in ways in which they have learned to respond and toward objects which, for the moment, for a longer time, or for a lifetime, have taken on sexual meaning for them. Conversely, people fail to respond sexually when, and only when, they have arrived at an aversion. Every sexually responsibe person could respond to every other sexually responsive individual if it weren't for aversion reactions. Sometimes an individual will arive at a particular aversion through powerful direct conditioning, such as a bitter experience with a kind of person, or a kind of situation. But otherwise, aversions seem to arise quite automatically toward sexual conditioning characteristics that stand in contrast to ones that are highly valued. In most cases, sexual conditioning remains stable for life, although in some cases conditioned preferences and aversions are subject to change. We know that by sixteen years of age, some 90 percent of males have attained the preferences which will dominate their sexual patterns for the rest of their lives. Shifts in sexual preferences, when they do occur, result from reconditioning that stems either from sexual or nonsexual sources or from changes in a person's particular values and needs.

Homosexual Behavior: A Modern Reappraisal. Judd Marmor, Ed, ,

Basic Books, 1980.

Exploring Intimate Lifestyles. B. J. Murstein, Ed., Springer Publications, 1978 . 


\section{HISTORY OF MASTURBATION}

1. Masturbation has been documented for many acient cultures, including Babylonian, Egyptian, Hebrew, Indian and Greco-Roman.

2. The Medieval Church regarded masturbation as a more serious sin than fornication, adultery, or rape.

3. As late as 1940, a candidate for admission to the Naval Academy was rejected if the examing surgeon found "evidence of masturbation" (whatever that was).

4. The cause of "self-pollution" resulted from bad habits such as reading dime novels, associating with bad playmates and sleeping on feather beds and pillows. If parents were lustful and licentious during the child's prenatal life, masturbation could be inherited.

5. In 1758, the Swiss physician Tissot listed disorders caused by masturbation which included insanity, epilepsy, "eyes directed upward and sideways," "morbid changes in the nose," "masturbator's heart," acne, deafness and afflictions of ovaries, uterus and vagina.

6. Females who practices "self-pollution" failed to develop as women, remaining flat chested and sterile.

7. People were reported to have "just died from its effects" (masturbation).

8. Parents were admonished to carefully observe daughters who crossed their thighs and preferred darkness and solitude.

9. The practice of masturbation could be detected in boys who had poor posture, pimples, sunken eyes or poor eye contact.

10. Treatment for masturbation included cold showers, leeches applied to the base of the penis, "opening the bowels with castor oil," "blistering the male member," beatings and warnings about going to hell, electrical devices to detect erections, aluminum mitts, chastity belts for boys. (The U. S. Government Patent Office awarded 33 patents to inventors of sexual restraint devices.)

\section{FACTS REGARDING MASTURBATION}

1. Most people masturbate at some time in their lives.

2. It is not harmful to masturbate.

3. It is $O K$ if you DO and $O K$ if you DON'T masturbate.

4. Masturbation provides release, relaxation and pleasure for many males and females.

5. Masturbation can relieve painfuI menstrual cramps.

6. Masturbation provides an opportunity for a person to explore their own sexuality.

7. Masturbation is a healthy sexual outlet. It is not 1imited to practice when one does not have a partner.

\section{BIBLIOGRAPHY}

1. Male Self-Pleasuring for Men. Richard Timmers, Madison, Wisconsin: Midwest Sexual Counseling Center, 1975. 
(Bibliography--continued)

2. Female For Yourself: The Fulfillment of Female Sexuality, Lonnie Barbach, Doubleday and Company, Inc., Garden City, New York, 1975.

3. SIECUS Study Guide \#3 Masturbation 4274, Warren Johnson.

4. Common Sense Sex. Ronald Mazur, Beacon Press, Boston, Massachusetts, 1968 .

5. Katchadurian, H. and Lurd, D. T. Fundamentals of Human Sexuality. McGraw-Hil1, New York, New York, 1979.

6. Hyde, Janet S. Understanding Human Sexuality. McGraw-Hil1, New York, New York, 1979.

7. McCarey, James L. Human Sexuality, Third Edition. Van Nostrand Company, New York, 1979.

8. Loving, C. V., M.D. Myths About Masturbation Throughout the Ages, Vol. 1, Number 5, Summer, 1979. 


\section{HETEROSEXUALITY}

A. Myths Held by Both Males and Females.

1. One's worth as a human being is directly proportional to how good one performs sexually. If you fail sexually, you are a no good person.

2. Simultaneous orgasms are necessary or very important.

3. Good sex before marriage equals marital compatibility.

4. Males and females should stay in their culturally defined roles.

5. Sex equals intercourse.

6. Adultery equals lack of love for your spouse.

7. Good sex should be spontaneous and natural without working at it.

B. Myths Held Mainly by Males.

1. The penis needs to be large or at least bigger is better.

2. Fast ejaculation is terrible.

3. Sex is all important for a good marriage.

4. Sex arousal and satisfaction has to be spontaneous.

5. A good man doesn't slow down sexually.

6. All women are very sexy creatures and you just have to handle them properly to get from them and give them sexual satisfaction.

C. Myths Held Mainly by Females.

1. Sex must go with love.

2. Being sexually assertive is shameful.

3. Women who screw a lot don't get married.

4. Women must get quick orgasms (and multiple orgasms) to be good lovers.

5. Women must be beautiful and young looking to be sexually attractive or feminine. 
The area of human sexuality that I have the most difficulty in dealing with, as it relates to my profession, is: 
After seeing this film, I feel ...

I was surprised to find out . .

I am still not clear about...

The thing I'll remember most about this film is... 
References

Aja, A. M. LTK Attitude Rating Scale, 1982.

American Personnel and Guidance Association. Ethical Standards, 1974.

Berezin, M. S. Sex and old age: a review of the 1iterature. Journal of Geriatric Psychiatry, 1969, 2, 131-149.

Brownmiller, Susan. Against our wi1l: men, women and rape. New York: Bantam, 1976.

Burnside, Irene. Sexuality in aging. In I. Burnside (Ed.), Sexuality and aging. California: University of Southern California Press, 1975 .

Butler, R. N. Why survive: being old In America. New York: Haper and Row, 1975.

Butler, R. N., and Lewis, M. I. Sex after sixty: a guide for men and women for their later years. New York: Harper and Row, 1976 .

Butler, R. N., and Lewis, M. I. Aging and mental health (2nd ed.). St. Louis: C. V. Mosby, 1977.

Calderone, M. Human sexuality and the Quaker conscience. Philadelphia: Friends General Conference, 1973.

Campbell, D. T., and Stanley, J. C. Experimental and quast-experimental designs for research. Chicago: Rand McNally, 1966 .

Cavan, R. S. Speculations on Innovations to conventional marriage in old age. Gerontologist, $1973, \underline{13}, 409-411$.

Comfort, A. Sexuality in later 1ife. In J. Birren and R. B. Sloane (Eds.), Handbook of mental health and aging. Englewood Cliffs: Prentice Hall, Inc., 1980 .

Commission on Obscenity and Pornography. The report of the commission on obscenity and pornography. New York: Bantam, $1 \overline{970}$.

Corby, N. and Solnick, R. Psychosocial and physiological Influences on sexuality in the older adult. In J. Birren, R. B. Sloane (Eds.), Handbook of mental health and aging. Englewood Cliffs: Prentice Ha11, Inc., 1980 .

Corinne, Tee. Female genitalia (fllm). San Francisco: Multi Media Resource Center, 1981 catalog. 
Couch, A. and Kenniston, K. Yeasayers and naysayers: agreeing response set as a personality variable. Journal of Abnormal and Soctal Psychology, LX (1960), 151-174..

Crawley, L., Malfetti, J. and Bartholomew, F. E. Sex education for school physicians: follow up of an inservice training course. Family Coordinator, $1974,24,359-369$.

Cronkhite, G. and Goetz, E. Dogmatism, persuasibility, and attitude instability. Journal of Communication, 1971, 21, 342-352.

Crooks, R. and Baur, K. Our sexuality. Menlo Park, Calif,: Benjamin/ Cummings Publishing Co., 1980.

Davis, K. and Braucht, G. Reactions to viewing films of erotically realistic heterosexual behavior. Technical Reports of the Commission on Obscenity and Pornography. Washington, D.C.: U. S. Government Printing Office, $1971,8,68-96$.

Davies, L. J. Attitudes toward old age and aging as shown by humor. Gerontologist, 1977,17 (3), 220-226.

Dean, S. R. Discusstons of "sexual behavior in middle life" by E. Pfetffer, A Verwoerdt and G. David. In A. M. Tuhasz (Ed.), Sexual development and behavior: selected readings. Homewood, IIl.: Dorsey Press, 1973 .

Delcampo, R., Sporakowski, M. and Delcampo, D. Premarital sexual permissiveness and contraceptive knowledge: a biracial comparison of college students. Journal of Sexual Response (1.2), 1976: 180-192.

Dennerstein, L., Wood, C., and Burrows, G. D. Sexual response following hysterectomy and oophorectomy. Obstetrics and Gynecology, 1977, 49, 92-96.

Dundas, Ed. Nik and Jon (film). San Francisco: Multi Media Resource Center, 1981 catalog.

Falk, G., and Falk, U. Sexuality and the aged. Nursing Outlook, 1980, Vo1. 28, (1).

Felstein, Ivor. Sex in 1ater 11fe. Middlesex, England: Penguin, 1970.

Fletcher, Joseph. Situation ethics, in J. L. Malfetti and E. Eidlitz (Eds.), Perspectives on sexuality. New York: Holt, Rinehart and Winston, 1972 .

Ford, A. and Orfirer, A. Sexual behavior and the chronically 111 patient. Medical Aspects of Human Sexuality, 1967, 1, 51 . 
Frledman, J. M. Sexual adjustment of the postcoronary male. In J. LoPlccolo and L. LoPiccolo (Eds,), Handbook of sex therapy. New York: Plenum, 1978.

Garrard, J., Vaitkis, A., and Chilgren, R, Evaluation of a course in human sexuality: Journal of Medical Education, 1972, 47: 77\%-778.

Gold, J. A., Ryckman, R. M. and Rodda, W. C. Differential responsiveness of dissonance manfpulations by open- and closed-minded subjects in a forced compliance situation. Journal of Soctal Psychology, 1973. $\underline{90}, 72-83$.

Golde, P., and Kogan, N. A sentence completion procedure for assessing attitudes toward old people. Journal of Gerontology, 1959, 14, 355-360.

Goldern, J. S. and Liston, E. H. Medical sex education: the world of 1llusion and the practical realities. Journal of Medical Education, 1972, 47: 761-771.

Gordon, S. Sex education for youths who know it all. Journal of Family Counseling, 1973, 47-55.

Hershey, Anne. We are ourselves (film). San Francisco: Multi Media Resource Center, 1981 catalog.

Hinkle, D., Wlersma, W., and Jurs, S. Applied statistics for the behavioral sctences. Chicago: Rand MeNally, 1979.

Hinkley, N. Sexuality and agIng. ERIC, 1976.

Hong, K., Maddock, J., Greenberg, L. Developmental sexuality: the introduction of a new curriculum in child psychlatry trafning. Journal of Sex and Marttal Therapy, Vol. 5, No. 4, Winter, 1979.

Hood, R. W. Dogmatism and oplnions of mental 11lness. Psychological Reports, 1973, 32, 1283-1290.

Horn, P. and the editors of Dehavior Today. Rx: sex for sentor citizens. Psychology Today, June, 1974, 18-20.

Howard, J. Relfler, C., and Liptzin, M. Effects of exposure to pornography. Technical report of the commission on obscentty and pornography. Washington, D. C.: U. S. Government Printing Office, 1971, $\underline{B}, 97-132$.

Inkeles, Gordon. Massage (f1lm). San Francisco: Multi. Media Resource Center, 1981 catalog.

Johnston, Karen. Orange (ftlm). San Franctsco: Multi Media Resource Center, 1981 catalog. 
Kaas, M. J. Sexual expresaion of the elderly In nursing homes. The Gerontologist, $1978,18,372-378$.

Kahana, B. Soctal and psychologtcal aspects of sexual behavior among the aged. In E. S. E. Hafez (Ed.), Aging and reproductive phystology, pp. 89-95. Ann Arbor Sctence, 1976.

Kaplan, H. S. The new gex therapy. New York: Bruner/Mazel, 1974.

Kart, C., Metress, and Metress, J. Aglng and health. Menlo Park, Calif.: Addison-Wesley Publishing Co., 1978.

Kassel, V. You never outgrow your need for gex. Presented at the 53rd Annual Meeting of the New England Hosp1tal Assembly, Boston, March 27,1974 .

Katchadourtan, H. and Lunde, D. Blological aspects of human sexuality. New York: Holt, Rinehart and WInston, 1975.

Keller, Judith. A roge by any other name (F1lm). New York: Focus International, 1981 catalog.

Kent, R. Should you sleep with your boss? Harper's Bazaar, 1975, p. 147.

Kerlinger, F. Foundatlons of behavioral research. New York: Holt, Rinehart and WInston, Inc, 1973 .

K1lpatrick, D. G., Cauthen, N. R., Sandman, C. A. and Quattlebaum, L. F. Dognatism and personal sexual attitudes. Psychological Reports, 1968, 23, $1105-1106$.

Kinsey, A. C., Pomeroy, W. B., and Martin, C. E. Sexual behavtor in the human male. Ph1ladelphia: W. B. Saunders, 1948.

K1nsey, A. C., Pomeroy, W. B., Mart1n, C. E., and Gebbard, P. Il. Sexua1 behavior in the human female. Philadelphia: W. B. Saunders, 1953.

Kirkenda11, L. A. Sex education. Sex Information and Education Counc11 of the Unt ted States, New York, 1965.

Korzenlowsky Films. Just be patient (f1.m). New York: Focus Internattonal, 1981 catalog.

LaTorre, R. A. and Kear, K. Attitudes toward sex in the aged. Archives of Sexual Behavior, 1977, 20, 145-153.

Ledger, N. J. Infections in elderly women. Clinical obstetrics and Gynecology, 1977, 20, 203-213. 
Llef, H. I., and Reed, D. M. Sex knowledge and Attitude Test (SKAT) (2nd ed.). Center for the Study of sex Education in Medicine, 1972.

Lobsenz, N. Sex and the senior citizen. The New York Tlmes Magazine, January 20,1974 , pp. 87-91.

Madison, J. and Meadow, R. A one-day workshop for women. Journal of Sex Education and Therapy, 1980, vo1. 2 .

Masters, W. H., and Johnson, V. E. Human sexual response. Boston: Little, Brown, 1966.

Masters, W. H., and Johnson, V. E. Human sexual Inadequacy. Boston: Little, Brown, 1970.

McCarthy, Patricta. Geriatric sexuality: capacity, interest, and opportunity. Journal of Gerontological Nursing, Jan.-Feb., 1979, 5: 20.

Meston, J. T. The use of a sexual enrichment program to enhance selfconcept and interpersonal relationshtps of homosexuals. Journal of Sex Education and Therapy, 1979, vol. 1, no. 6 .

Miller, D. Sexual practices and administrative policies in long term care institutions. In R. L. Solnick (Ed.), Sexuality and aging, pp. 163-175. Los Angeles: University of Southern California Press, 1978.

Monea, H. Experiential teaching on the subject of sexuality. In I. Burnside (Ed.), Sexuality and aging. Los Angeles: University of Southern California Press, 1975.

Nass, G. D., Libby, R. W., and Fisher, M. P. Sexual choices. Belmont, California: Wadsworth Inc., 1981.

National Sex Forum. World Erotica (ftlm). San Francisco: Multi Media Resource Center, $\overline{1981}$ catalog.

National Sex Forum. Kinsey Three (f1lm). San Francisco: Multi Media Resource Center, 1981 catalog.

National Sex Forum. Exhibltion: male genitals (film). San Francisco: Multi Media Resource Center, 1981 catalog.

Nie, N., Hu11, C., Jenkins, J., Steinbrenner, K., and Bent, K. Statistical package for the social sciences. New York:

Norris, E. L. Attitude change as a function of open- or closed-mindnedness. Journalism Quarterly, 1965, 42, 571-575. 
Novak, E., Jones, G., and Jones, H. Novak's textbook of gynecology (8th ed.). Baltimore: Williams and Wilkins, 1970 .

0'Neill, Dan. Communication slides/Genesis (film). San Francisco: Multi Media Resource Center, 1981 catalog.

Ortho Pharmacuetical Co. Sexuality and communication (film). Canada Limited, 1971.

Page, J. The other awkward age. Berkeley: Ten Speed Press, 1977.

Pfeiffer, E., and Davis, G. Determinants of sexual behavior in middle and old age. Journal of the American Geriatric Society, 1972, 10, 753-758.

Pfeiffer, E., Verwoerdt, A., and Wong, H. Sexual behavior in aged men and women. Observations on 254 community volunteers. Archives of General Psychiatry, 1968, 19, 753-758.

Phillips, E., Celio, D., and Sowards, S. Outreach programming on human sexuality: a first effort. Counseling Psychologist, 1975, $\underline{5}$ : 98-100.

Polivy, J. Psychological effects of mastectomy on a woman's feminine self-concept. The Journal of Nervous and Mental Diseases, 1977, 164, 77-87.

Reiss, I. L. Hetersexual relationships, In R. Green (Ed.), Human sexuality: a health practitioner's text. Baltimore: Williams and Wilkins, $197 \overline{4}$.

Richman, J. The foolishness and wisdom of age: attitudes toward the e.lderly as reflected in jokes. Gerontologist, 1977, 3, 210-219.

Robinson, J. P., and Shaver, P. Measures of social psychological attitudes. Ann Arbor: University of Michigan Press, 1973.

Rodin, J. and Langer, E. Aging labels: the decline of control and the fall of self-esteem. Journal of Social Issues, $1980, \underline{36}, 12-28$.

Rokeach, M. The nature and meaning of dogmatism. Psychological Review, 1954,6 , 194-204.

Rokeach, M. Political and religious dogmatism: an alternative to the authoritarian personality. Psychological Monographs, 1956, 70 (18, Whole No. 425).

Rokeach, M. The open and closed mind. New York: Basic Books, 1960. 
Rosencrane, H. A factor analysis of attitudes toward the elderly. Gerontologist, 1969 , 9 : 55-59.

Rosenzweig, F., and Pearsal1, F. P. Sex education for the health professional. New York: Grune and Stratton, 1978 .

Rubin, I. Sexual life after sixty. New York: Basic Books, 1961.

Severson, Anne and Kennedy, Shelby. Riverbody (film). San Francisco: Multi Media Resource Center, 198 I catalog.

Silny, A. Sexuality and aging. In J. Money (Ed.), Handbook of sexuality. Englewood Cliffs: Prentice Hall, Inc., 1980.

Silverstone, B., and Wynter, L. The effects of introducing a heterosexual living space. Gerontologist, 1975.

Stryker, J. Use of hormones in women over forty. Clinical Obstetrics and Gynecology, 1977, 20, 155-164.

Sutterly, D., and Donnelly, G. Perspectives in human development, Philadelphia: Lippincott, 1973.

Sutton, Laird/National Sex Forum. Touching (film). San Francisco: Multi Media Resource Center, 1981 catalog.

Sutton, Laird/National Sex Forum. Soma touch (film). San Francisco: Multi Media Resource Center, $1 \overline{981}$ catalog.

Sutton, Lair/National Sex Forum. Rich and Judy (film). San Francisco: Multi Media Resource Center, 1981 catalog.

Sutton, Laird/National Sex Forum. Reflections (film). San Francisco: Multi Media Resource Center, 1981 catalog.

Sutton, Laird/National Sex Forum. Minnesata soap series (film). San Francisco: Multi Media Resource Center, 1981 catalog.

Sutton, Lair/National Sex Forum. Margo (film). San Francisco: Multi Media Resource Center, 1981 catalog.

Sutton, Laird/National Sex Forum. Handvoice (film). San Francisco:

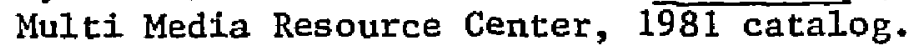

Sutton, Laird/National Sex Forum. Going down to Bimini (film). San Francisco: Multi Media Resource Center, 1981 catalog.

Sutton, Laird/National Sex Forum. Gay women speak (film). San Francisco: Multi Media Resource Center, 1981 catalog. 
Sutton, Laird,/National Sex Forum. Feeling good (film). San Francisco: Multi Media Resource Center, 1981 catalog.

Sutton, Laird/National Sex Forum. Erogenist (film). San Francisco: Multi Media Resource Center, 1981 catalog.

Sutton, Laird/National Sex Forum. Erogeny (film). San Francisco: Multi Media Resource Center, 1981 catalog.

Sutton, Laird/National Sex Forum. A ripple in time (film). San Francisco: Multi Media Resource Center, 1981 catalog.

Sutton, Laird/National Sex Forum. A gay view/male (film). San Francisco: Multi Media Resource Center, $19 \overline{81}$ catalog.

Sviland, M. Helping elderly couples become sexually liberated: psychosocial issues. The Counscling Psychologist, 1975, 1 (5), 67-72.

Sviland, M. A program of sexual liberation and growth in the elderly. In R. L. Solnick (Ed.), Sexuality and aging, pp. 96-114. Los Angeles: University of Southern California Press, 1978.

Ullerstrom, L. The erotic minorities. New York: Grove Press, 1974.

Umland, M., Jelinek, R., and Santos, P. Psychophysiological aspects of aging. In M. O'Hara 'Devereaix and Andrus C. Scott (Eds.), Eldercare: a practical guide to clinical geriatrics. New York: Grune and Stratton, 1981 .

U. S. Department of Commerce. Statistical portrait of women. Special studies series, p. 23, no. 58. Washington, D.C.: U.S. Government Printing Office, 1975.

Verwoerdt, A., Pfeiffer, E., and Wang, H.S. Sexual behavior in senescence: changes in sexual activity and interest of aging men and women. Journal of Geriatric Psychiatry, 2; pp. 163-180, 1969.

Vines, N. R. Responses to sexual problems in medical counseling as a function of counselor exposure to sex education procedures incorporating erotic film (Ph.D. dissertation, University of Pennsylvania, 1974).

von Buchau, Greg. Love toad (film). San Francisco: Multi Media Resource Center, 1981 catalog.

Voss, J. R., and Mckillip, J. Program evaluation in sex eudcation: outcome assessment of sexual awareness weekend workshops. Archives of Sexual Behavior, $1979, \underline{6}, 20-27$. 
Wasow, H. Sexuality in homes for the aged. Concern in the Care of the Aging, $1979, \underline{6}, 32-41$.

Webster, D. Webster's new world dictionary. Cleveland: World Publishing Company, 1977.

Weg, R. Physiology and sexuality in aging. In I. Burnside (Ed.), Sexuality and aging. Los Angeles: University of Southern California Press, 1975.

Wellisch, D. K., Jamison, K. R., and Pasnau, R. O. Psychosocial aspects of mastectomy: the man's perspective. American Journal of Psychiatry, $1978,135,543-546$.

Winer, B. Statistical principles in experimental design (2nd ed.). New York: McGraw-Hil1, 1971.

Williams, A. M. and Miller, W. R. The design and use of assessment instruments and procedures for sexuality curricula. In N. Rosenzweig and F. P. Pearsall (Eds.), Sex education for the health professional. New York: Grune and Stratton, 1978 .

Zarit, S. H. Aging and mental disorders. New York: The Free Press, 1980. 
Vita

Anne M. Aja was born in Cinnaminson, New Jersey on June 25, 1947. She was graduated with a Bachelor of Science in education from Temple University, Philadelphia, Pennsylvania, in May, 1969. She received her Master of Science degree in Counselor Education with an emphasis in rehabilitation counseling at Syracuse University, Syracuse, New York, in August, 1975.

From August, 1977 to August, 1979 she was employed as a family therapist with the Ninth District Court Service Unit, Yorktown, Virginia. In September, 1979 she entered the College of William and Mary to begin her studies for the Doctor of Education degree in Counseling. 
Abstract

ALTERNATE METHODS OF CHANGING NURSING HOME STAFF ATTITUDES TOWARDS SEXUAL BEHAVIOR IN THE AGED

Anne Marie Aja, Ed.D.

The College of William and Mary in Virginia, August 1982

Chairman: Fred L. Adair, Ph.D.

In recent years workshops have been developed to assist professionals in dealing with issues related to human sexuality. Called Sexual Attitude Reassessment workshops (SAR's), they are designed to impart relevant information concerning sex functioning and to provide an opportunity for personal exploration of attitudes and values. While much attention has been directed at providing sex education to a variety of groups across the country, few programs have focused on improving attitudes toward sexual expression in the aged, and increasing understanding of their sexual needs.

The purpose of this study was to determine whether or not nursing home staff differed in their perceptions, attitudes and knowledge as a result of exposure to either implicit or explicit sex related materials. Participation in the two experimental SAR's (implicit or explicit) was voluntary and open to all nursing home staff at a downtown Norfolk nursing home. Of the 45 staff who applied for the workshop, 32 attended the two-day training. Workshop participants ranged in age from 18 to 62 , and represented a variety of educational backgrounds.

The research design used was the posttest only control group design. The study design first divided nursing home staff into two groups. Group assignment was based upon scores obtained on Rokeach's (1960) Dogmatism scale. Subjects who scored above or below the dogmatism scale mean were assigned to either a high dogmatism or low dogmatism group, respectively. Staff in the high dogmatism and low dogmatism groups were then randonly assigned to three treatments: implicit, explicit, and control.

The format used for both the implicit and explicit workshops was similar to that of the Sexual Attitude Reassessment (SAR) process developed by the National Sex Forum. For the implicit group participants were exposed to sexually implicit materials (usually films) and encouraged to react to these materials in small groups. Implicit materials were defined as those films and slides which did not graphically depict sexual behavior of "live" actors. Except for the film materials, the explicit group was conducted in exactly the same way. Participants were exposed to sexually explicit materials (usually films) and encouraged to react to these materials in small groups. Explicit materials were defined as those films and slides which graphically depict the sexual behavior of "1ive" actors. 
It was hypothesized that: (1) there would be no significant difference in general attitudes towards sex between implicit, explicit and control groups (rejected); (2) there is no significant difference in general attitudes towards sex among groups of nursing home staff differing on levels of dogmatism (not rejected); (3) there is no significant difference in general sex knowledge between implicit, explicit and control groups (rejected); (4) there is no significant difference in general sex knowledge among groups of nursing home staff differing on levels of dogmatism (not rejected); (5) there is no significant interaction between treatment and dogmatism on nursing home staff attitudes toward sex (not rejected); (6) there is no signifjcant interaction between treatment and dogmatism on nursing home staff knowledge about sex (not rejected): (7) there is no significant difference in the perception of sexual behavior between implicit, explicit and control groups (not rejected); (8) there is no significant difference in the perception of sexual behavior between groups of nursing home staff differing on levels of dogmatism (rejected); and (9) there is no significant interaction between treatment and dogmatism on nursing home staff perceptions of sexual behavior (not rejected).

Two instruments were used to measure between group differences in attitudes, knowledge and perceptions of sexual behavior in general, and sexual behavior in the aged. These included the Sex Knowledge and Attitude Scale (Leif and Reed, 1973) and the LTK Attitude Rating Scale (Aja, 1982). Results indicate that both the implicit and explicit treatment groups achieved significantly higher scores on the knowledge scale of the SKAT when compared to the control group $(\underline{p}<.05)$. However, post hoc comparison of group means indicate that changes in sexual attitudes, in the direction of Increased tolerance, were more clearly made in the implicit treatment group than they were in either the explicit treatment group or the control group $(\underline{p}<.05)$. Level of dogmatism produced statistically insignificant results $(\underline{p}>.05)$ on all scales except for those which measured perceptions of young and old couples engaged in oral-genital sex. For this behavior, high dogmatism groups reported significantly greater negative perceptions than the low dogmatism groups $(\mathrm{p}<.05)$.

It was concluded that there is a need for sexual awareness prograns for individuals of varying educational levels. Further investigation of Sexual Attitude Reassessment workshops including methods, materials, and evaluation procedures are necessary to find effective ways to facilitate exploration of sexual attitudes and values, increase knowledge of sexual behavior, and to encourage the development of more tolerant sexual attitudes. 